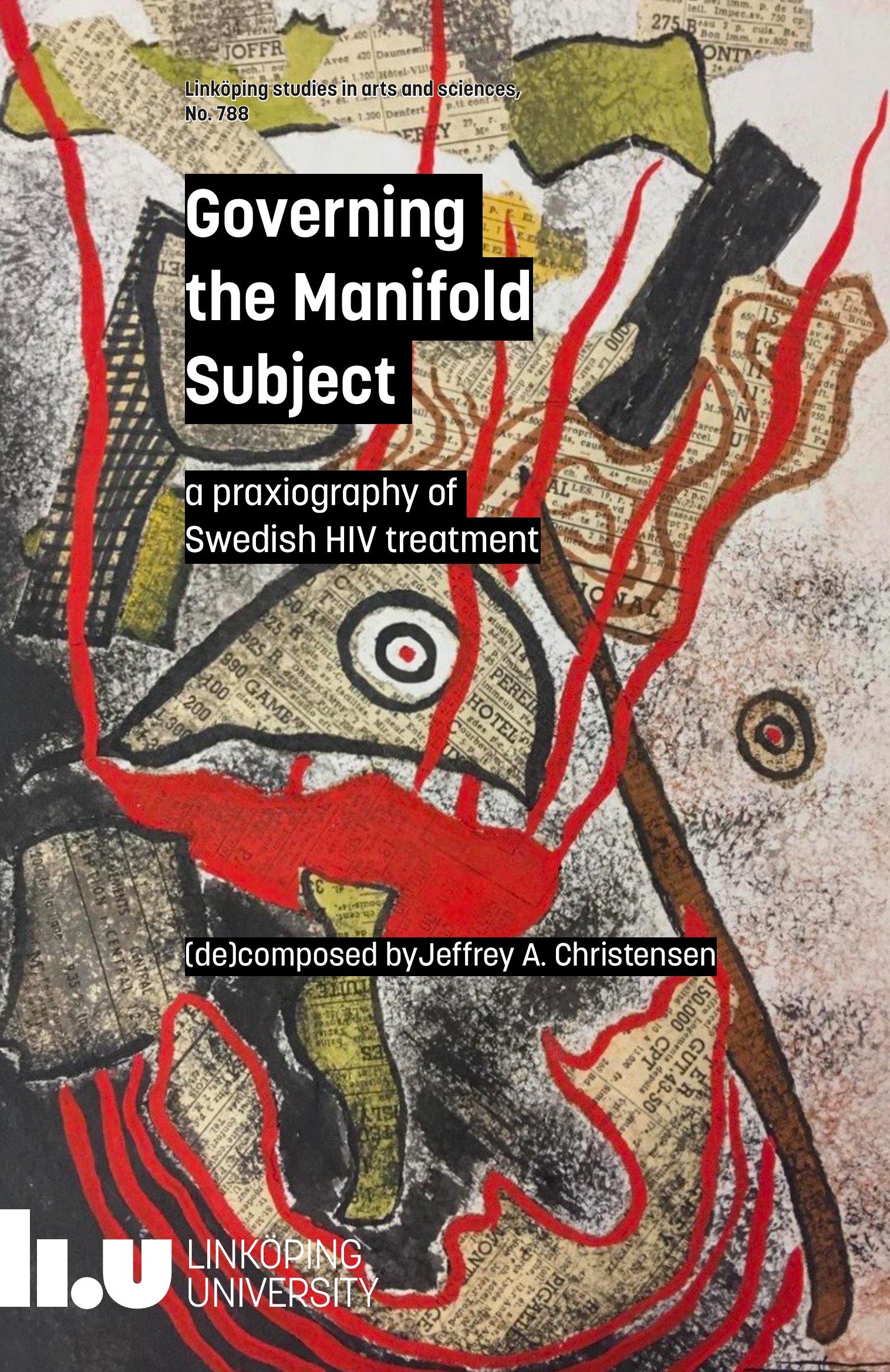


Linköping studies in arts and sciences, No. 788

ISSN 0282-9800

\title{
Governing the manifold subject \\ a praxiography of Swedish HIV treatment
}

\author{
Jeffrey A. Christensen
}

Academic dissertation

Academic dissertation for the Degree of Doctor of Philosophy (PhD, Ph.D., DPhil, Dr. or doctor philosophiae) in Science and Technology Studies, Medical Anthropology, and

Queer Theory at the Faculty of Arts and Sciences. To be publicly defended on Wednesday the 20th of May 2020 at 13:15 - 17:00 TEMCAS, Tema by Jeffrey A. Christensen.

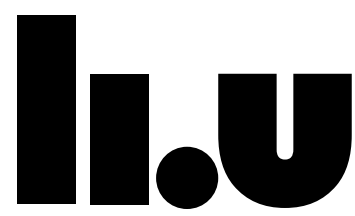

LINKÖPINGS UNIVERSITET

Linköping Studies in Arts and Sciences

Faculty of Arts and Sciences

Linköping 2020 
Linköping Studies in Arts and Sciences · No. 788

At the faculty of Arts and Sciences at Linköping University, research and doctoral studies are carried out within broad problem areas. Research is organised in interdisciplinary research environments and doctoral studies mainly in graduate schools. Jointly, they publish the series Linköping Studies in Arts and Sciences. This thesis comes from the Department of Thematic Studies - Technology and Social Change.

Distributed by:

Department of Thematic Studies - Technology and Social Change Linköping University

58183 Linköping

Jeffrey A. Christensen

Governing the manifold subject

a praxiography of Swedish HIV treatment

Edition 1:0

ISBN: 978-91-7929-845-6

ISSN 0282-9800

(C) JAC // Jeffrey A. Christensen

Department of Thematic Studies - Technology and Social Change 2020

Cover design by Jeffrey A. Christensen

Cover image: Après Guerre, 1954 Paris, Cossette ZENO

Printed by: LiU-Tryck, Linköping 2020

Disputationsdatum: 2020-05-20

Institution: Tema T

All photographs that are not indexed with a source or reference are self-authored. 
To my sisters, in every sense;

to those who gave me the

skill \& fortitude to

work on and to

werk this

project

out. 


\section{Table of Contents}

i // Slowing down the fast-track 1

1.0 Introduction 1

1.1 The fast-track strategy to end HIV \& AIDS; reading the subject at war

Figure 1: the message on the wall and booklet cover 2

Figure 2: the fast-track targets 3

1.2 Investigating normative uncertainty in practice 8

Figure 3: HIV treatment/therapy as normalization 8

1.3 Research questions 10

ii // From biopolitical control to the ontological politics of care 12

2.0 Introduction 12

2.1 What is a governing assemblage? 12

2.2 'Treatment' is governing done otherwise 18

2.3 Decentering the subject with praxiography 23

2.4 Assembling a manifold of materials 29

2.5 Conclusion $\quad 32$

\section{iii // Policing the unwell 33}

3.0 Introduction 33

3.1 Swedish HIV 'treatment' as protection or prosecution? 33

3.2 The historicity of Swedish disease-control 35

3.3.0 The policing script; becoming-obligated to pass as 'well-treated'

Figure 4: the patient-information document as a policing script 39

Figure 5: the plague masked figure of Swedish disease-control 40

3.3.1 The obligation of status disclosure 41

Figure 6: well-treated-patient (left) and doctor (right) information documents 43

3.3.2 The obligation of adherence to anti-retroviral therapy 47

Figure 7: the 'magic bullet' image of anti-retroviral adherence 47

3.3.3 The obligation of compliance with treatment protocol 50

3.4 Conclusion 54

iv // Detecting the undetectables 57

4.0 Introduction 57

4.1 The self-testing device as a matter for concern for disease control 58

4.2 Governing HIV through 'knowing your status'? 60

Figure 8: \#KnowYourStatus 61

4.3 The multiplicity of inscription devices; multiple 'undetectables'

Figure 9: a visualisation of the HIV viron 67

Figure 10: a visualisation of an antibody 68

4.3.1 Knowing HIV in ELISA; enacting the subject with antibodies/antigen 70 
Figure 11: Måns \& Anders (the ELISA machines) 73

Figure 12: analogue \& digital ELISA inscription 74

4.3.2 Knowing HIV in PCR; enacting the subject with RNA 76

Figure 13: setting up the PCR machine 78

Figure 14: the PCR inscription 79

4.3.3 Knowing HIV in flow cytometry; enacting the subject with cd480

Figure 15: drawing the immune system 81

Figure 16: Adam \& Elof (the flow cytometers) \& blood samples rotating 83

4.4 Conclusion 84

v // Folding patients into populations $\quad 86$

5.0 Introduction 86

5.1 Making absent 'individuals' to present 'key populations' 86

Figure 17: the person living with HIV as an accountable population

5.1.1 Folding subjects with antibodies into incidence of infection 93

Figure 18: diagram of a recent infection testing algorithm (RITA) 94

5.1.2 Folding subjects with RNA into transmissions of infection 99

5.1.3 Folding subjects with cd4 into undiagnosed infections 103

Figure 19: the emergence of the 'migrant' (left) 106

and 'gay men \& other MSM' (right) as accountable populations 106

5.2 Conclusion 109

\section{vi // Valuing with dependencies $\mathbf{1 1 2}$}

6.0 Introduction 112

6.1 The mundane subject 113

6.2 Against stigma: 'quality of life' as the fourth 90

114

6.3 The manifold dependencies of Swedish HIV treatment

Figure 20: circulating dependencies

121

Figure 21: examining dependencies 125

Figure 22: evaluating dependencies 130

6.4 Conclusion 132

vii // Taming and attuning to the manifold subject

134

7.0 Slowing down Swedish HIV treatment 134

7.1 Governing the manifold subject with sensitivity and specificity

Acknowledgements

141

Bibliography

142

Appendix 148 


\section{i // Slowing down the fast-track}

\subsection{Introduction}

Many stories have been told about HIV and its unidentical twin - AIDS. Since the very emergence of this phenomenon, an enormous scientific effort has been directed to the discovery of its transmission mechanisms, its etiological origins and causes, and its effects on the human immune system. In addition, technology is said to have played a significant role in the taming of HIV. The development of instruments and processes to handle diagnosis and treatment trajectories has not only provided a range of valuable tools that find an application in medicine, but has also spurred the development of research in such fields as virology, epidemiology, immunology, and pharmacology - each one attending to a particular facet of the phenomenon. The birth of HIV ${ }^{1}$ presented a significant crisis to individual and collective health on a number of fronts. The shockwave struck an emerging community of artists, craftspeople, knowledge producers, political activists, lovers, and many others. The newfound pleasures of the gay liberation movement that were becoming celebrated as part of a valued ethnicity 2 were immediately tested. The widespread panic and hopelessness that ensued marked a challenge that was taken up by actors implicated in starkly different ways. This thesis is an empirical account of the practical differences that take shape in relations of accountability to HIV. My aim will be to describe and analyse a variety of modes through which the subject of Swedish HIV treatment is and ought to be governed, as well as how we might think otherwise about relations of governance and responsibility through this material account. Through descriptive storytelling, I situate and analyse the shifting normativity of what I call the manifold subject.

\subsection{The fast-track strategy to end HIV \& AIDS; reading the subject at war}

July $23^{\text {rd }}$, 2018. The air is warm and crisp this morning as I walk across the large empty square toward the venue that will host the International AIDS conference. In preparation for our participation as volunteers, we will receive a welcome presentation, a tour of the facilities, and training for our roles. The morning light casts a golden hue on a large sign that I notice on the wall. After registering and receiving an orange t-shirt, identification badge, and a pocket-size conference guide, I come to notice the same message from the wall on the back of the booklet cover. The sender of this message is marked by a logo of ViiV Healthcare, the multinational pharmaceutical agency that I recognise as the manufacturer of my own HIV regimen. It reads:

\section{"Dear HIV \& AIDS}

Fair warning. We're not going anywhere. Whatever you throw at us, we'll come back stronger.

\footnotetext{
${ }^{1}$ In accounting for the birth of HIV as a situated object, I also find the occasion to introduce myself as an author and subject in this research. Born in what was then called 'Bombay' and is now called 'Mumbai' in the year 1986, my birth intersects with that of HIV as a classified entity.

2 See Epstein 1998.
} 
More determined to advance the science and the partnerships that fight you and what you do, and will one day eradicate you altogether. So, fair warning. Your days are numbered. We're here until you aren't."
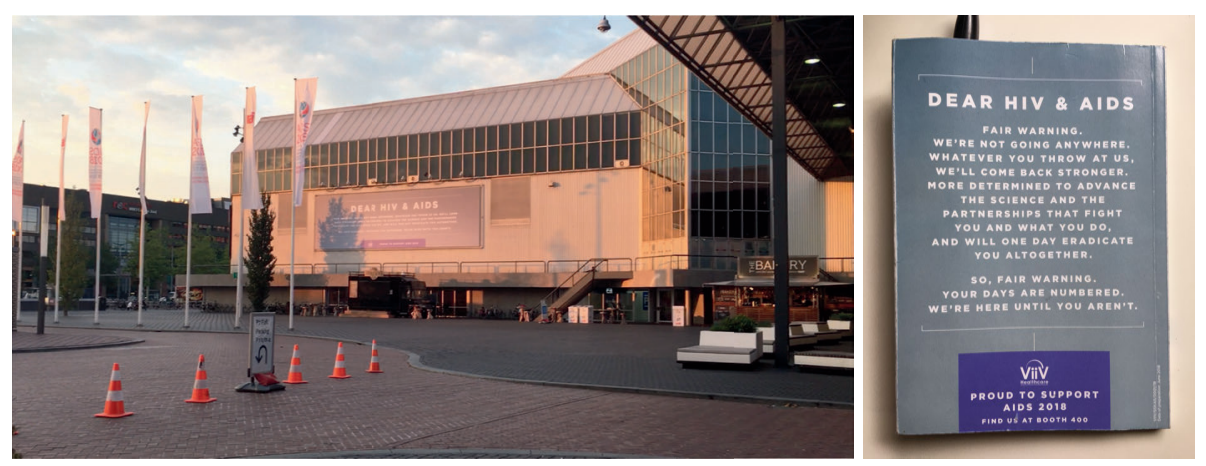

Figure 1: the message on the wall and booklet cover

Reading this message is an odd moment for me. It seems I am the subject to whom it speaks. No, that is not quite it. HIV and AIDS are the subjects to whom it is addressed. I instead am interpellated (Law 2000) as the supposed author of the text. Although as a person living with HIV, I do locate 'it' within me as well, here it is positioned fiercely in opposition to 'me'. The message warns of eradication, but the 'you' that 'we' are supposedly addressing is different - an 'other'. The message further highlights how hopelessness and devastating losses of the past seem to have made way for hope and determination. It draws a clear line between 'science and partnerships' and the enemy against which they/we form a united front. I am reminded of Sontag's words: "where once it was the physician who waged bellum contra morbum, the war against disease, now it's the whole society” (Sontag 2001:10).

Later that day, I will find myself listening to a presentation by one of eight people sitting behind a panel on stage. The black curtains that cover the walls of the room are tinged with a glow of red and blue lighting. On the presentation screen, some figures are given a blue heading that reads: "Fast-track strategy aims to end the AIDS epidemic by 2030". In $2014,{ }^{3}$ the United Nations joint programme on HIV/AIDS released a statement that articulated this new strategy in the following way:

"The world is embarking on a Fast-Track strategy to end the AIDS epidemic by 2030. To reach this visionary goal after three decades of the most serious epidemic in living memory, countries will need to use the powerful tools available, hold one another accountable for results and make sure that no one is left behind." 4

Who it is that might be left behind as the military lingo puts it, the populations affect-

3 http://i-base.info/qa/factsheets/the-swiss-statement, accessed 2020.04.07

${ }^{4}$ https://www.unaids.org/sites/default/files/media_asset/UNAIDS_Gap_report_en.pdf, accessed 2020.04.07 
ed by HIV, parts of 'the' world that may not immediately be embarking on this strategy, these subjects are not defined by this statement. But they will soon come to be. The goals and targets, however, are very clear and plain to see. This is, of course, the purpose of the statement. It out-lines direction and orientation.

\section{Fast-Track Targets}

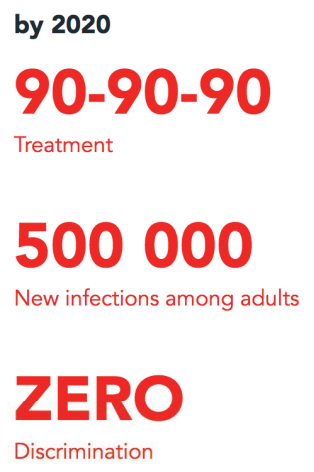

by 2020 by 2030

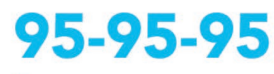

Treatment

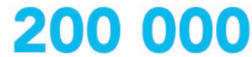

New infections among adults

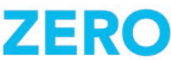

Discrimination

Figure 2: the fast-track targets ${ }^{5}$

Figure 2 shows how the fast-track targets make a stated differentiation between treatment targets, infection targets, and discrimination targets. In each of these three cases, a various kind of value is vertically assigned as goals that have been strategically chosen to achieve the strategy of ending HIV and AIDS. Horizontally speaking, this 'fast-track' strategy first set targets to meet by the year 2020 (shown through red on the left in figure 2), and was then recalibrated to target goals for 2030 (shown through blue on the right in figure 2). This thesis will argue that the 'fast-track' is a complex assemblage of material-semiotic actors that differentially folds the subject of Swedish HIV. By providing the reader with an account that attends to these governing values in practice, I will show how this 'fast-track' can be conceptualised moreover as a governing assemblage that enacts a manifold subject. Of course, it will take the rest of this monograph to understand what I mean by this, but let me try to break it down a little further. While a number of new targets have now been added to the fast-track assemblage, the first treatment target contains three separate aims that are often simply referred to as the '90-90-90 goals'.

"By 2020, 90\% of all people living with HIV will know their HIV status. By 2020, 90\% of all people with diagnosed HIV infection will receive sustained antiretroviral therapy. By 2020, 90\% of

\footnotetext{
5 https://www.unaids.org/sites/default/files/media_asset/201506_JC2743_Understanding_FastTrack_en.pdf, accessed 2020.04 .07
} 
So the first '90' of the 'treatment' target is said to account for the number of people living with HIV who will know their status by 2020, the second stands for those of the previous group who will receive anti-retroviral treatment or therapy, and the last '90' indicates those of the previous group of people who achieve what is called 'viral suppression' or 'viral control'. The 'infection' target that was set for 2020 aims to lower global incidence rates down to 500,000 new infections among adults, and by 2030 to lower this number to 200,000 . Lastly, the target of reaching 'ZERO discrimination' is set for both 2020 and 2030. This aims to enforce the idea that people living with HIV are to be treated no differently, especially by healthcare practices, on the basis of their condition. National agencies and public health professionals often refer to these targets in HIV policy to indicate a sense of accomplishment and progress, but also to induce the aforementioned sense of directionality and orientation. The following statement issued by Michel Sidibé, the 2017 Executive Director of UNAIDS, captures this sense:

"The AIDS response has epitomized the principle of global solidarity and shared responsibility. We have put people at the centre and valued inclusiveness. These are the elements that will lead us to end epidemics and to achieve Sustainable Development Goal 3 (...) Never before have we been closer to our goal of controlling this epidemic. Never before has our progress been so precarious. And never again will we have this window of opportunity." (Michel Sidibé in UNAIDS newsletter, 18 August 2017)

Here, the values of 'inclusiveness' and 'solidarity' are assumed as characteristic of HIV and AIDS governance and deemed essential to the goal of eradicating epidemics. Through these targets, a principle of 'responsibility' becomes associated with a strategy of 'control'. The politics of the fast-track assemblage are said to be putting 'people at the centre'7. In 2016, Sweden claimed to be the first ${ }^{8}$ to reach these ambitious targets. The assessment and proclamation of this 'success' came along with some uncertainty, for example as to the number of people who remain unaware of their status ${ }^{9}$. Even so, the evaluation of

\footnotetext{
6 https://www.unaids.org/sites/default/files/media_asset/201506_JC2743_Understanding_FastTrack_en.pdf, accessed 2020.04.07
7 While I have had to limit my thesis to address the 'fast-track' discourse, there is a considerable discourse on 'patient centred care' that indirectly informs my arguments as well. For an analysis that interferes with this ver- sion of care, see Pols 2005.

8 In 1944, Sweden decriminalised homosexuality and in 1979 it became the first country to declassify homosexuality as a mental illness. In 2018 , it became the first country to provide financial compensation to trans people who became subject to sterilisation in order to attain a legal recognition of their gender. Such accomplishments make for an impressive resume and give Sweden the public image of an LGBTQIA* sanctuary. As it turns out, that depends entirely on the 'kind' you are.
}

${ }_{9}^{9}$ See chapter 5 for a more recent evaluation of this problem. 
this achievement was issued as follows:

"The 2014 UNAIDS/WHO 90-90-90 goals for HIV care means that $>73 \%$ of all patients living with HIV should be virologically suppressed by 2020. Sweden has already achieved this target, with 78\% suppression, and is the first country reported to meet all the UNAIDS/WHO 90-90-90 goals." 10 (Gisslén et al 2017)

The words are tactfully chosen, as the first specification of '90-90-90 goals for HIV care' indicate that the evaluation concerns the fast-track treatment goals particularly. However, the final statement that locates the success within the Sweden treatment regime then renders the accomplishment again as 'all the 90-90-90 goals', a label that could easily be mistaken with the fast-track assemblage more generally as often happens when such scientific accomplishments travel into popular news spaces. In this study, the 'Swedish HIV continuum of care' (Gisslén et al 2017:307) is illustrated as a graph with six stages starting from 'Estimated HIV-infected', proceeding to 'HIV-diagnosed', 'linked to HIV care', 'retained in HIV care', 'on ART', and finally ending with 'HIV RNA $<50$ copies/mL'. This final criteria indicates the local laboratory definition of what is also called 'viral suppression' in care practices. The Swedish approach was found to have reached all of the desired goals. While this sounds great, I hesitate at the proclamation of this success. I think of Paparini and Rhodes (2016, Rhodes et al 2018) who put such notions of "biological efficacy" into question. They warn me that indicators and evaluation devices can oversimplify and hide the inequalities, obscure the local context, and ignore other links to practices that may offer more meaning for people living with HIV. In their efficacy, these devices of evaluation are also said to perform silences and blind spots along with their utility. If this is indeed the case, then it must be important to investigate these local accomplishments of global agendas in more detail.

A first detail that strikes the eye is that interestingly enough, no mention was given as to the evaluation of the final fast-track target of 'ZERO discrimination'. While the fast-track targets for diagnosis, treatment, and surveillance are easily measurable, the amount of discrimination going around would be much harder to qualify. Moreover, through the chosen value of 'ZERO', discrimination becomes intolerable as an absolute principle rather than one that might be measured and evaluated to begin with. Which in one sense is of course just fine; in another sense it is actually quite a problem, because it excludes the value of 'discrimination' from further scrutiny and representation. I think it might be about time to take a closer look at the divergences between the relative value of making difference and discrimination in practice.

As the 'treatment' and 'prevention' goals become well articulated through indication criteria, 'discrimination' risks becoming merely an unaccountable desire of the fast-track assemblage. This is all the more worrying because while many nations have specific laws that criminalise HIV transmission in various ways, Sweden offers a unique case in which the very 'risk' of HIV transmission is itself criminalised, and even quite frequently until recent

10 https://www.ncbi.nlm.nih.gov/pubmed/27535540, accessed 2020.04.07 
events. ${ }^{11}$ In effect, the fast-track assemblage produces a differentiation between its measures that involve a silence to some issues that matter a lot to people living with HIV. It is my intention to follow this silence through this thesis and attempt to articulate it. This does not mean however, that 'discrimination' or 'stigma' are the expressed object of this thesis. Situating this account in my own experiences of living and working with HIV, I intend to follow the fast-track assemblage into the practices of science and technology that locally account for the accomplishment of this 'Swedish success'. Instead of speeding up or getting on the fasttrack, this thesis is one that aims to slow things down.

Here I am inspired by philosopher of science Isabelle Stengers's interventions in political ecology. For Stengers, 'slowing down' (Stengers 2018) means learning how to maintain our balance while shifting into a slower and more careful way of attending to 'pragma' or 'issues' - a pragmatism that attends to objects of political concern and ecological care. The relevant question for this pragmatism is thus how we might allow ourselves to become, "affected by the beings with whom [we are] dealing, looking for suitable relationships with them, putting the adventure of shared relevance above the authority of judgement." (Stengers 2018:42) Teasing apart what she calls the 'harmonic mode' and the 'mechanical mode' of political composition, she puts into question their performing logics and in doing so, she makes room for another way of approaching political issues. This she refers to as the "chemists art'12, a way of organising around an issue together with those who would otherwise be unqualified to participate. The underground arts of association, oriented toward the temperance and catalysis of actants that may become active or passive depending on their mixtures, give Stengers a better way of decomposing and staging issues - of governing (Stengers 2018:61). I thus intend to question accounts of responsibility and control, as well as the values they enact normatively, practically, politically \& socially.

Rather than join along with the crowd for a final sprint, I take it to be a critical moment to ask what these 'powerful tools' (UNAIDS 2014) ${ }^{13}$ are doing, what they might not do, and what they might do otherwise. In other words, this work will take a close and detailed look at the way these aims are carried out in practice. However, my interest in doing so is not just to produce complexity. I rather find it important to rethink, for instance, what it might mean to 'know your status' or to 'control' an epidemic. I want to look at the ways that these efforts come to affect Swedish HIV healthcare - and through it, people's lives. And I want to do it in as simple and comprehensible a way as possible. My intention in adopting this approach of 'slowing down' is, like Stengers, "to remove the anaesthesia produced by the reference to progress or the general interest, to give a voice to those who define themselves as threatened, in a way likely to cause the experts to have second thoughts, and to force them to think about the possibility that their favourite course of action may be an act of war.” (Stengers 2005:14) Instead of turning to the ready-made strategy of knowing your ene-

\footnotetext{
11 See chapters 3 and 6 for more about these events.

12 Not to be thought of as the Science of Chemistry, but as a far older and uncertain craft.

13 https:/www.unaids.org/sites/default/files/media_asset/UNAIDS_Gap_report_en.pdf, accessed 2020.04.07
} 
my (Tzu 2008), I want to experiment with better ways of becoming-with HIV (Haraway 2016). I want to ask how HIV, as a wicked and problematic monster even by the best of standards, might be tamed as a companion species and rendered capable of responding to the worlds it has been knotted and knitted together with since its troubling emergence. This thesis is an effort to find ways of articulating the nature-culture of 'Swedish HIV' as it becomes 'treated' in a practical array of situated knowledges.

Note that 'slowing down' does not mean abandoning the sciences; it does not mean waging a war on knowledge or trying to debunk scientific facts. Here I draw on the Swedish language itself to understand 'Science' more specifically as vetenskap. Since 'veten' means 'knowledge' and 'skap' means 'to craft, make, or produce', science here becomes an art of crafting knowledges. 'Slowing down' is thus a tactic or technique in this very same knowledge-craft commonly known as 'Science', but what I and others (see Mol 2002) call a methodology or strategy of 'praxiography'. The tactic of slowing down does not mean lessening activist efforts, research funding, or public health initiatives. I take care here, as I do not want to be mistaken as posing an obstruction for the control of HIV or the care of people affected by its presence in their lives. In other words, slowing down does not mean coming to a halt, but rather it raises attention to the activities we are engaged in and the objects we depend upon. Slowing down is a cry for us to recognise that the things we do will do us in return. Stengers asks the question: What are we so busy doing? - a question that seems critical to ask of the fast-track assemblage at this moment. My intention is to show how, even in the most accomplished biomedical regimes, a vastly overlooked terrain remains to be traversed before the 'end of HIV and AIDS' can even be given credit as an accountable statement of possibility. Or better still, as an accountable proposition. Slowing down is a tactic that allows me to articulate my concern through an empirical inquiry as to the specificities governing HIV in the situated practices I observe and report from and together with.

As both a patient and an ethnographer, I also want to situate my analysis as an experiment in practicing a 'reflexive symmetry'. That is, while aiming to reflexively account for my own experiences in studying the fast-track assemblage, I want to test the principle of symmetry that guides my understanding of the relation between subject and object ${ }^{14}$. While reflexivity is no doubt essential in ethnographic work, I want to find a way to put 'reflexivity' into question as both resource and topic for my research. Praxiography equips me with a method for doing exactly this. This thesis is thus a praxiography that follows the subject of the fast-track assemblage into the practices that make it accountable as an entity emerging in political ecology. The fast-track assemblage makes of HIV a biopolitical subject and makes HIV governance a technoscientific affair. Following the differentiated goals of the fast-track assemblage will therefore lead me into participant observation with practices of Swedish HIV diagnostics, treatment, surveillance, and regulation. Describing the ways in which I am enacted as a manifold subject throughout these practices allows me to demonstrate the value of praxiography as an alternative and radically situated method assemblage.

14 I will provide the reader with a thicker account of this topic in the following chapter. 


\subsection{Investigating normative uncertainty in practice}

One of they key technologies of the fast-track assemblage are the HIV treatments and anti-retroviral therapies that have altered the effects of HIV so drastically for those who have access to them, that they are often even used to draw a line between post-treatment and pretreatment eras. Today, it is often said, HIV is no longer a death sentence but has instead become a chronic condition ${ }^{15}$. Figure 3 shows how UNAIDS - a United Nations joint response and programmatic organisation towards HIV and AIDS - renders this optimism as normalisation.

\section{HIV treatment can normalize survival}

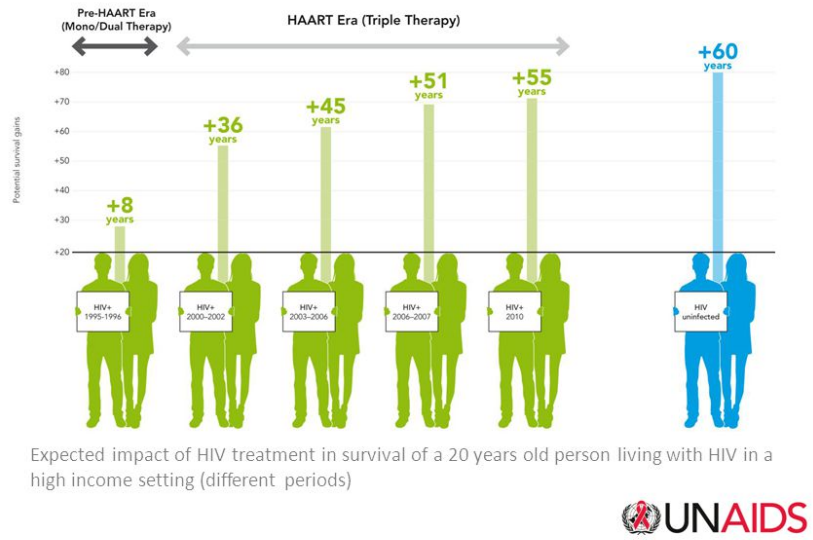

Figure 3: HIV treatment/therapy as normalization ${ }^{16}$

This illustration shows the survival age of different people in what are called different 'eras'. Alongside those marked as 'living with HIV' in green on the left are those 'not living with HIV' marked in blue on the right; these people are shown to be the standard upon which the normalisation is derived. The anthropology of HIV and AIDS repaints the optimism of this picture to highlight persisting concerns. Reflecting on the themes that emerged in five special issues on HIV/AIDS in the journal of Medical Anthropology, Hardon and Moyer (2014) walk us through the early work that treated the phenomenon as a global emergency. Their exploration of this literature cultivates a critical sensitivity toward the economic and gendered asymmetries that mark those affected, as well as the governance mechanisms and biopolitical projects that aim to end AIDS. Teasing out the complexities that have been con-

\footnotetext{
15 https://smw.ch/journalfile/view/article/ezm_smw/en/smw.2016.14246/6b733cad5240879543cbca8a3809b0c3b8a76087/smw_2016_14246.pdf/rsrc/jf, accessed 2020.04.07

16 https://slideplayer.com/slide/4765186/, accessed 2020.04.07
} 
tinuously tackled since its birth lead them to conclude that HIV remains, "a unique lens for examining the imbrication of the global and the local" (Hardon \& Moyer 2014:259). In this anthropological view, HIV is characterised by what they call a "continuous uncertainty” (Moyer \& Hardon 2014:267) that keeps it from becoming a normalized disease.

In this dissertation, I will contribute to this anthropological project by investigating this normative uncertainty, drawing on ethnographic and STS research of biomedical and technoscientific practices, and on my own ethnographic experiences of living with an 'HIV positive' diagnosis in Sweden since 2016. However, I will take a somewhat different approach in doing so than Hardon \& Moyer. Maintaining a symmetry between whether Swedish HIV treatment 'is normalising' and/or 'isn't normalising' enables my analysis to describe normativity as enacted in local practice. In other words, this is a symmetrical anthropology (Latour 2012) of the normativities enacted in the governing of 'Swedish HIV'. I use a 'cautioning' signifier here to mark my choice of words carefully. While of course not wanting to nationalise disease, I do want to understand the particularities of the disease that I live with in Sweden in comparison to the version that is sustained in 'global' discourse. So while explaining my motives, I also want to mess with the assumption that HIV is either a 'local' or a 'global' disease. That is, I want to interfere with the topology of this disease by juxtaposing its regional boundary with the multiplicity of Swedish HIV as I have lived and studied it in practice. Perhaps this even makes the object of this account more 'glocal' (Johnson, Sjögren \& Åsberg 2016) than either global or local.

While the ethnographic fieldwork that I conducted was mostly carried out in Sweden, there is always a variety of elements you encounter in any given setting that can be traced elsewhere. In effect, I believe that this makes my work relevant to many practices 'outside' of Sweden as well. Through my descriptions of participant observation with practices of Swedish HIV regulation, diagnosis, surveillance, and treatment, this thesis will describe the ways in which biopolitical, medical, and technoscientific practices come to fold a multiplicity of heterogeneous materials and concerns in their efforts to govern 'Swedish HIV'. Following 'the subject' of Swedish HIV technoscience through physical examinations, blood tests, algorithmic calculations, and status disclosure practices, I show the variety of stakes involved in producing matters of accountability, matters of concern (Latour 2004), and matters of care (de La Bellacasa 2011) for this disease.

Drawing on my own experiences of living with HIV in Sweden, this thesis thus carries with it a concern with the reflexive and normative dimensions of research practices. Investigating the various 'goods' and 'bads' that are entangled with different methods and their varying subjects, my work aims to interfere with the idea of a single patient perspective that might be articulated by a singular 'self'. I will instead highlight the multiple ways in which subjects are enacted in practices of knowing, treating and living with HIV. Contrary to discourses that attribute a shared responsibility for HIV and AIDS in the past and those that call for individual accountability in the future - such as those sustained through the fast-track assemblage - I wish to cultivate more personal, practical, and political ways of participating in the manifold of accountability and subjectivity through the present case of Swedish HIV. I 
care to practice a slower science.

\subsection{Research questions}

This research will thus address and answer the following question: how is the subject of governing Swedish HIV enacted in practice? To answer this research question, I will focus my work on the investigation of three following sub-questions:

1) what bodies, understood in the broadest sense, are given responsibility for HIV in Sweden; to what obligations are subjects living with Swedish HIV held to account?

2) how do diagnostic and surveillance practices know, make visible, speak about, classify, and manage people living with HIV?

3) how does Swedish HIV treatment take shape in the lives of the subjects it affects?

In answering these questions, this thesis will show how the fast-track strategy to end HIV and AIDS can be handled as a governing assemblage. By describing and situating my encounters with different governing practices, I will describe how the manifold subject of Swedish HIV treatment is a contingent effect of the material-semiotic differences in practices of governing infectious disease. My experiences in studying this situated array of practices enabled me to unpack the techniques through which the subject of Swedish HIV is variously criminalised, regulated, enumerated, normalised, folded, envisioned, treated, prevented, cared for, and moralised.

The thesis is organised in seven parts or seven chapters. This page concludes chapter $1 / /$ Slowing down the fast-track, in which I have argued for the rationale of slowing down the fast-track assemblage. I have empirically demonstrated how Swedish HIV treatment, as a governing assemblage, has been said to accomplish the ambitious 90-90-90 goals which are critical to fast-track as a governing assemblage. Chapter 2 // From biopolitical control to the ontological politics of care will now discuss how I went about answering these questions in theory and practice. By unpacking the body of work that allows me to formulate these questions, I will show the reader how I went about taming the subject of this thesis and how I generated materials through my method of praxiography. Chapter 3 // Policing the unwell next describe the particularly Swedish legal context in which my stories take and took place. Chapter 4 // Detecting the undetectables thereafter accounts for the diagnostic devices upon which these legal structures depend. Chapter 5 // Folding patients into populations moves into other practices yet again by describing the differences between diagnostic and surveillance devices in their scope of vision. Chapter 6 // Valuing with dependencies then folds my experiences inside out and right side up by showing how things might be done otherwise in this case. Chapter 7 // Taming and attuning to the manifold subject will then conclude this thesis by summarising my findings and relating them to my research questions once again.

All throughout, I will argue that the subject, in this case of Swedish HIV treatment, is 
inescapably mediated by material-semiotic principles and practicalities. The settings I write about and the stories I tell capture only a fragment of the possible experiences that would no doubt be relevant to explore further. But these I have tried to tame and account for in-depth. The following chapter will surface the manifold logic through which I have done so. 


\section{ii // From biopolitical control to the ontological politics of care}

\subsection{Introduction}

In the previous chapter, I discussed how fast-track targets - the UNAIDS strategy for achieving the goal of ending AIDS by 2030 - are said to have been achieved by Swedish Public Health. I then proposed the strategy of slowing down the fast-track assemblage as a way of better understanding the material-semiotic composition and performativity of this achievement. Slowing down, I argued, is a valuable way to sensitise the reader to the specificities of what the fast-track is and what it does. I then stated the proposition made by this thesis - that the 'fast-track' might be conceptualised and handled as a governing assemblage. By doing so, I will empirically investigate how these targets are accomplished in practice and what they do to the subject living with Swedish HIV. This chapter will now situate my work within the broader landscape of post-structuralist theory and explain the conceptual sensitivities I have attuned my analysis to throughout this study. I demonstrate how actor-network theory and material-semiotic methods take on some of the same concerns as post-structural theory, but instead offer a way to experiment with the 'slowing down' of HIV governance through empirical study. I thus show how praxiography becomes my method of choice for doing fieldwork and how I mobilised a strategy of following the subject through the analytical and ethnographic description of practical settings. The chapter therefore describes how I undertook this praxiography of Swedish HIV.

\subsection{What is a governing assemblage?}

Accountability is often presented as matter of great importance for good governance. As I have shown in the previous chapter, organisations such as UNAIDS speak of previous efforts to cope with HIV in terms of shared responsibilities, and when speaking of the future work to be done, they talk of holding each other accountable for results. But what is accountability? Which relations of accountability are established and how? And how does accountability relate to the fast-track? In this chapter, I will describe the approach that has led me to treat the fast-track targets as a biopolitical and technoscientific assemblage. I start with a scholar who became foundational for the study of the governing features of medicine and medical knowledge. As a philosopher, Michel Foucault not only conducted analyses that became critical to the practices of psychology, anthropology, activism, and art, but through his scholarship he engaged deeply with the materiality of political and societal institutions. Through archival and ethnographic methods, he studied hospitals, psychiatric wards, prisons, schools, and sexualities as they changed in and through history. In relating to his work, I become able to see how discourses of governance differentially constitute the governing subject: "To govern, in this sense, is to structure the possible field of action" (Foucault 1982:790).

Throughout his body of work, but especially in his later studies, Foucault constructed a genealogy that mapped the emergence of a new form of power. This power he described, "exerts a positive influence on life that endeavours to administer, optimise, and multiply it, 
subjecting it to precise controls and comprehensive regulations.” (Foucault 1998:42) Foucault suggested that this 'biopower' displaced an earlier form of 'sovereign power' that, as he showed through his earlier work, had seen predominance throughout the sixteenth to eighteenth centuries. In contrast to the power of sovereignty wherein the ordained royal or emperor exerts an absolute power over their people, vividly depicted by Foucault through the torture and execution of a condemned man in 1757, the new form of power accords a central place to the sciences. Foucault's aim was to demonstrate how the coming together of what he called an 'episteme' or 'regime of truth' and a historically specific and contingent array of practices produce a matrix of 'knowledge-power' - a construction he refers to as a 'dispositif' or what is variously translated into an 'apparatus' or 'assemblage' in English. An epistemic and practical assemblage not only organises and is productive of knowledge, but it "effectively marks out in reality that which does not exist" (Foucault 2008:19).

This means that a knowledge-power assemblage does not just discover reality, but that reality is an effect of what can be known within the limits of the assemblage. In other words, reality is not a pre-given realm that produces different 'discourses' - ways of thinking, understanding, or talking about the world - rather, different discourses, different ways of talking and acting in the world - of ordering the world - are productive of reality. According to Foucault, an assemblage of knowledge-power submits reality to a test of truth. It produces a way of knowing what is real through its bearing on the conditions of what is possible. Foucault used 'sexuality' as an object with which to study the subject, accountability, and truth as a product of 'discourse'. For example, he showed that although sexual conduct between men thrived in different ways long before 'modern' times, 'the homosexual' as a subject identified and marked as sexually divergent only began to emerge in the Victorian era through practices of seeing, talking about, examining, and articulating 'the homosexual'. Foucault showed how this subject-making power not only works through specific professions, such as psychiatry and law for example, but moreover that it operates in everyday life through mundane category work. It marks individuals and generates their identities in a myriad of ways; it produces what the self and the other will recognise as 'true' about them. Foucault thereby came to offer an account of how governing relations, come to produce the subject of governance. The subject here is grasped in two senses at once: "subject to someone else by control and dependence; and tied to his own identity by a conscience or self-knowledge. Both meanings suggest a form of power which subjugates and makes subject to." (Foucault 1982:781)

Over an archive of work ranging from the historical-empirical to the more abstractphilosophical, Foucault thus provided an account of how knowledge-power came to be configured in the modern-western world. On his account, biopower is constituted along two poles. The first, which he exemplifies with case studies of the socio-material organization of prisons, schools, hospitals, asylums etc., he describes as an "anatomo-politics of the human body" (Foucault 1998:139). Here power is directed toward the discipline of the individual's bodily conduct. The second, exerted through knowledges and measures such as birth registers, mortality rates, fertility rates, measures to encourage family planning etc., he refers to as a "bio-politics of the population" (Foucault 1998:139). While anatomo-politics came first to 
light between the seventeen and eighteen hundreds with the rise of the disciplines - the professional techniques and methods which made possible the meticulous training of bodies biopolitics is depicted in his work as the regulatory mechanisms of control that later come to compliment the disciplines at their operation on the level of the social and collective body.

The anatomo-politics of discipline operates on the human body, ordering its movements through strict sequences and enclosed spaces. In the segmented production line of the factory, the classrooms and auditoriums of the school, and the consultation rooms and corridors of the hospital, disciplinary power works upon the body to make it 'practiced' (Foucault 1977:138). What makes Foucault's account of disciplinary power so intriguing, is that he locates this power within technologies, broadly speaking. Not only are medical professionals or judges performing disciplinary power, but so too are bells, schedules, halls, forms, and examination rooms. As the body is decoded by the disciplines, its movements are rearranged, realigned, and recoded. The factory arranges its bodies not for pleasure, but for precise and mechanical assembly. The school aims not to entertain its students, but to institute a particular knowledge and ways of knowing in every student. Along with the disciplines of pathology and surgery comes a new way of consigning the body to examination. Procedures are contrived to strip the body of its secrets and to cut, sew, and stitch bodies together anew.

Among other key sites, Foucault located medicine as a field that becomes specifically saturated with disciplinary and regulatory powers by the late modern era. Through discourses on madness, illness, and sexuality, medicine became accountable for human bodies and populations. At the bio-political level, new methods come to work in and upon the human species, not so much aiming to discipline and control the actors themselves, but rather seeking to work upon the principles and activity of life (bios) as the object of knowledge-power. As births and deaths of populations are recorded and statistical measures and instruments are put to use, the fluctuations of nations and peoples become the direct domain of intervention. In contrast to the negative power of the sovereign era that was often exercised through the right to kill, the undertaking of medical practice became that of modifying, controlling, and enhancing life through a positive force. The medical apparatus in particular - understood as the collective knowledges, techniques, and practices of medicine - posed a rich case to unpack the intricacies of a knowledge-power assemblage.

One of Foucault's contemporaries, the philosopher Gilles Deleuze, took to refine and extend Foucault's work quite substantially by diagnosing a transformation from 'societies of discipline' to 'societies of control' (Deleuze 1992). Where the former exercised power through spaces of enclosure - such as the clinic, the hospital, the prison, and the factory - the latter have come to infuse more open spaces. Together with Félix Guattari, Deleuze works with Foucault's notion of the dispositif or assemblage. ${ }^{17}$ They define an assemblage as a kind of 'abstract machine' that operates by means of a series of interruptions or cuts through a material-semiotic continuity or flow (Deleuze \& Guattari 1977:36). The primary concern of all

\footnotetext{
${ }^{17}$ Foucault uses the terms 'assemblage' interchangeably with 'discourse' and 'practice'. However, in AngloAmerican language, the latter two terms stage/denote a stronger split between world and word. The term 'assemblage' seems to me a better way to hold things together for now.
} 
three of these authors was to find creative ways of enacting new modes of subjectivity through philosophical praxis. They took as problematic the established ways of treating 'the subject' as a rigid continuity or a determined sense of being. For them, it was more important to highlight the inconsistencies and fluidity of becoming the multiple subject. What I find particularly valuable in the work of these philosophers however, is the stunning and highly specific texture and relationality with which they describe various styles or regimes of governance - of governing assemblages. In line, but also in contrast ${ }^{18}$ with Foucault, Deleuze \& Guattari provide many smaller examples of what they generally refer to as machinic assemblages. Mouths become sucking and speaking machines, cutting off milk, air, sperm, and sound - each materially different. Books become material-semiotic machines that make and break associations to other authors and books with their differing words and concepts. Each of these associations form, inform, and reform the bodies they organise through their associations - their material-semiotic attachments or relations - and they do so with different degrees of intensity. The 'intensity' of associations are what these authors mean by 'power'. This way of handling power does not imagine a substance given to an exclusive class of objects or subjects to the exclusion of others. Power becomes a contingent effect of material-semiotic relations. Governance, in turn, becomes a process of intensive assembling. For Deleuze and Guattari, every machinic assemblage operates according to a material-semiotic code that it transmits to other regions and bodies, and that it receives from other machines (Deleuze \& Guattari 1977:38). The way a code 19 is translated and recorded from one region to another is part of what makes it that very kind of machine and not another. From this perspective we can say, for instance, that the anatomo-political code of discipline ${ }^{20}$ that Foucault described works differently from the bio-political code of control.21 They both, however, stand in stark contrast to the sovereign-judicial code of earlier times. What these post-structuralist theories offer is a radical rethinking of governing regimes; they recast governing as as a practical activity of coding, decoding, and recoding bodies. This body of work sensitises my analysis to

\footnotetext{
18 While differences exist between the work of these philosophers, specifically in relation to the subject of pleasure and desire, this is not my primary concern here. To recap the point shortly though, Deleuze found more interesting the critical investigation of 'desiring-machines', assemblages that operate in powerful ways to construct and deconstruct reality. Foucault, on the other hand, found more capacity for resistance in the subject of pleasure - specifically in and of sexuality as a technology and form of care for selves. In spite of the differences in their conceptual commitments, they both share a concern with power as intensive difference, and this is what I will call on in their work to explore. Chapters $4 \& 5$ will look closer at diagnostic and surveillance 'machines' and chapter 6 will additionally look more into the 'pleasure' becomes handle in the practice of Swedish HIV treatment.
}

${ }^{19}$ Another way to understand this 'code' is with the notion of a 'script'. I will return to this concept in chapter 3.

${ }^{20}$ See Deleuze (1992) for a rather simplified yet comprehensive articulation of differences in his rather monolithic modes of ordering society.

${ }^{21}$ Foucault himself seems to move back and forth between the ideas that these modalities of power reinforce each other and displace each other. For the most part, he seems to be more interested in understanding power as a multiplicity of strategies rather than in ultimately defining a diagram of power in the abstract. 
the varying characteristics, strategies, histories, and aesthetics of governing assemblages and their productive effects.

In the reading Deleuze (2007) makes of Foucault, an assemblage consists of various lines that make reality see-able and speak-able. This enables me to think about biomedical realities as the account-able effects of governing assemblages ${ }^{22}$. In a clinical assemblage, the doctor comes to see the surface of the body as a space where disease becomes articulated.23 With a physical examination at the clinic, symptoms can be read and decoded anatomically. In this Deleuzian reading of Foucault, 'curves of visibility' are juxtaposed with 'curves of utterance': with questions such as, "where does it hurt", the doctor locates the signs that will inform him of his object; "when did this start" provides him with another clue that may identify the symptoms of disease. Deleuze then articulates two more dimensions of a governing assemblage: the 'lines of force' and 'lines of subjectivation'.

The lines of force can be understood as the dimension of power or intensity. As I previously mentioned, this is for Deleuze just what power is - intensive difference: "each intensity is itself a difference, it divides according to an order in which each term of the division differs in nature from the others." (Deleuze \& Guattari 1987:562) Where Foucault understood 'power' as an effect of multiple discursive strategies, Deleuze and Guattari undertook a philosophical investigation that took 'intensity' as a difference variously expressed by multiple assemblages. Throughout their work, the authors emphasise that multiple 'lines of force' are involved in organising different topologies, temporalities, and textures of governance. With a thousand tiny examples, they show me how differences in material-semiotic operations make multiplicities of governing assemblages take different forms in different times and places. With their work, I come to see how the fabric of governance is variously constituted by these differences in technique. As with Foucault, Deleuze sees power as composed with knowledge (Deleuze 2007:340).

The 'lines of subjectivation' (Deleuze 2007:340-341), on the other hand, indicate a process through which one becomes 'subject' to, in, and through an assemblage. Lines of subjectivation pose the final and perhaps most complicated dimension to the apparatus or assemblage. What is most important in this line of thought is that it becomes the very process of assembling that provides the subject with agency. Agency - the ability to act - is not a property of 'human' subjects. The specificity of the subjects and objects assembling in any given 'agencement' (Despret 2013) is what enables and constrains that assemblage to acting in one way rather than another.

If Deleuze and Guattari help me to grapple with the different components of a governing assemblage, Foucault helps me think more deeply about the subjects taking shape through them. While the earlier work of Foucault attended to subjects of punishment, discipline, and control, towards the end of his career he started becoming more interested in what he called techniques of the self. Through this work we find that subjects can become accountable

\footnotetext{
22 For a similarly different conclusion, see Woolgar 1986.

${ }^{23}$ I will return to Foucault's notion of the medical 'gaze' in the following chapters.
} 
through practices of care and not only of control. To better understand how these lines of subjectification operated, Foucault turned back to the apparatus of the city-state in ancient Greece and to the relational practices that constituted their 'citizens'. Foucault's interest in technologies of sexuality took him back to this time and place in order to investigate how the apparatus of governance was situated within the body of 'free men'. By this I mean that exclusive group of subjects that discounted (and depended on) children, women, the sick, the elderly, and slaves. Here we find the subject who, in taking account of his body, his household, and his sexual relations with his wife and boys, comes to govern himself and others through both asymmetrical and symmetrical plays of power.

Before bringing this back to bear on the subject of HIV governance, I want to venture a little further into this work on governing subjects and different ways of taking, making, and giving care. Through a meticulous regard for his 'soul'24 (Foucault 1986:43), we are shown how the citizen-subject was materialised in the body of Greek society. In the Use of Pleasure (Foucault 1985) and the Care of the Self (Foucault 1986), Foucault showed us the structure of the oikos (the private realm) in the societies of Hellenistic monarchy and Roman imperialism. In his account, the oikos was a housing for an essentially asymmetrical relationality. The 'heads' of these houses were always men who not only governed over the family and home, but also represented their oikos to the polis (the public realm). Women and slaves on the other hand were kept in different quarters of the home. Their invisible work formed the 'body' of the hearth; they took care of blood relations and domestic chores. It seems to me that this account holds a valuable way of understanding accountability relations and subjectivity-in-themaking.

While I am not too interested in the specificity of the Greek oikos, it provides me with a first example to think about accountability relations in practices of governance and care. Accountability for the oikos was asymmetrically distributed. The husband was responsible for guiding the house, instructing it, and directing it. He had control over the enterprise of the home, but only with and thanks to the administrative care of his wife. Outside of the home on the other hand, the erotic relations that men commonly had with boys at that time were different still. The role of erastes and eromenos - the lover and the beloved - was distributed, but it was not fixed as in the case of husband and wife. In contrast to the matrimonial relation, erotics was "a matter of forming a bond in which the equality is so perfect, or the reversibility so complete, that the role of the erastes and that of the eromenos can no longer be distinguished." (Foucault 1986:225) Of course, this symmetry was not given, but had to be made and practiced. The possible symmetry of an erotic relation was considered no less open to

\footnotetext{
24 "A 'soul' inhabits him and brings him to existence, which is itself a factor in the mastery that power exercises over the body. The soul is the effect and instrument of a political anatomy; the soul is the prison of the body.” (Foucault 1977:30) In this sense, 'having' a soul poses a similar problem to 'having' a name, a sexuality, or even an HIV status at that. This is, of course, only a problem when multiplicity is excluded. Because of this I think that Foucault's approach, and my own for that matter, are very much about facing the multiplicity of daemons materialised in practice. But I don't think Foucault wanted to get trapped in the irrelevant question of whether a soul 'has' a body or whether a body 'has' a soul. Instead, there is multiplicity and heterogeneity.
} 
domination and to the detriment of the self and the other if not handled well in practical ways. However, the erotic relations of accountability between boys and men contained this versatile possibility in contrast to the fixed asymmetry between husband and wife or man and slave at that time. Contrary to the economics of the oikos, the erotics of eros practiced a cultivation of the self through the cultivation of the other. To take pleasure in a boy was ethically wrapped up with the art of governing desire; of taming pleasure and of caring for the self while doing so. Foucault thus shows how sexuality was handled differently by Greek men in their use of pleasure than would come to be the norm through the Christian and modern times thereafter.

Some historians disagree with the interpretations given by Foucault of historical events, but whether or not Foucault got all the facts right about Greek society matters little to me for my purposes of studying the accountability relations of the fast-track assemblage and the operations of subject-making entailed by its effort to govern HIV. This work was also cut short. Foucault had planned to proceed with his historical-philosophical work through Christianity and into the present. Due to his death from AIDS related illnesses in 1984, Foucault never got to introduce us to the range of subjectivities that governing assemblages have generated throughout the ages and into the present. I will return to the topic of subjectivity later in this chapter, but before I proceed, I want to explore a remaining question that I think comes along with the work of Foucault when thinking through the subject.

As is the case with any author or theorist, his work was situated at a specific moment and spoke to a specific concern, and these specificities matter. Foucault was concerned with an account of power that opened it up to relationality and open-endedness, something that he found missing in the dominant structural approaches of his time that mostly assumed a repressive form of power and saw conflict as the inevitable effect of governing regimes. While addressing this concern was a noteworthy accomplishment of his work, it is still often hard to flesh out the ethical implications of his work. For instance, he expresses an equal fascination with subjects of pain, power, and pleasure. While he composed a body of work that can be approached in various ways, the normative implications of this work could surely use some more attention. In other words, it remains quite opaque in Foucault as to which 'subjects' might count as desirable or 'good' at the end of the day. I mean to develop this kind of attention to normativity through my study of the fast-track assemblage and the relations of accountability it draws together and produces. While I find these authors helpful in thinking about governing assemblages as the means through which we discover the subjects we are or refuse them (Foucault 1982:785), I also want to affirm and care for the subjects we are becoming.

\section{2 'Treatment' is governing done otherwise}

If knowledge-power assemblages are so important for governing and for the production of subjectivity as post-structuralist philosophy teaches us, then it must be important to investigate in detail exactly what and how these scientific and technological practices organise. The field of Science and Technology Studies, a.k.a. Science and Technology in Society or 
STS, provides me with a bundle of sensibilities and methods ${ }^{25}$ to do so in an empirically situated manner. In the late 1970's, the anthropologist and philosopher Bruno Latour teamed up with the sociologist Steve Woolgar to write a third person account of their first-hand experiences doing ethnographic work (Latour \& Woolgar 2013) at the Salk laboratory. Following the scientists and their objects throughout the laboratory allowed these ethnographers to demonstrate that reality is not just discovered in the lab, but socially and materially constructed. For these scholars, the laboratory secretes 'matters of fact' in the form of 'inscriptions' that have undergone a series of trials to test their capacity for resistance. This prompted a field of research that became known as 'laboratory studies' - a collective and emergent effort that continues to observe and describe the politics of science by telling stories about the things scientists do in practice. As it turns out, what scientists do has a lot to do with technology. In fact, Latour came to refigure the object of this field as 'technoscience' (Latour 1987:29), inspiring the ongoing and specialised studies of how science and technology becomes accomplished in practice. I find in this work a valuable way of understanding how Swedish HIV 'treatment' is an assemblage of governing practices.

While Latour also sees technoscience as political, he makes use of quite a different strategy to make sense of politics than Foucault, as well as much of contemporary biopolitical thought. Latour and his colleagues worked to show how matters of fact were constructed in technoscience through a process of translation. Through the translation of various materials scientific instruments, glass vials, animal flesh, chemical agents and notation devices - the laboratory inscribes ${ }^{26}$ the interests of other actors into the reality that it generates. But importantly, these 'inscriptions' are not metaphorical. The laboratory study presented by Latour and Woolgar (2013) described in detail how the members of the Salk laboratory coordinated a variety of materials in order to produce a specific trace of data that could be counted as 'factual'. It is through this process of translation that artefact becomes fact. Their account equips me with a way to assemble the material-semiotic traces that produce the very reality of HIV as a technoscientific fact.

Science is political, because in order to construct a fact that will hold together better than that of another, scientists must construct objects that align the interests of others with their own program. Using the case of the 'microbe' to demonstrate this point, Latour (1993) shows how Pasteur and his findings were not taken seriously until they were aligned with 'hygienists'. These hygienists, a group of professionals concerned with a particular version of hygiene as their valued agenda, were initially not interested in what Pasteur did in his laboratory. At that time, they had their hands full in dealing with the illusive 'miasma' that was known at that time to be the source of widespread disease. Pasteur and his colleague-friends had to extend their laboratory experiments to farms in order to convince the hygienists that

\footnotetext{
${ }^{25}$ For a good overview of STS as a method assemblage, see Law 2016.

${ }^{26}$ Akrich \& Latour put this in the following way: "The aim of the academic written analysis of a setting is to put on paper the text of what the various actors in the settings are doing to one another; the de-scription, usually by the analyst, is the opposite movement of the in-scription" (Akrich \& Latour 1992:259) See chapters 3 and 4 for a further discussion of these 'inscriptions' in Swedish HIV treatment practices.
} 
microbes were more interesting for them than miasma. When successful, this translation resulted in a knowledge-shift. But compared to the doctors, the hygienists were actually convinced rather quickly. The program of the doctors had them concerned not with the end of disease, but with the care of sick patients: "The vaccine, which was preventative, rubbed physicians the wrong way, since it deprived them of patients who could pay. The serum, invented by Roux and his colleagues, was on the contrary a therapy that was used after a patient had been diagnosed sick." (Latour 1993:127) It was thus only by way of further technological translation that 'serum' could become a part of the treatment toolkit. Through it, the doctors' concerns were able to follow the program of Pasteur and they came to accept 'microbes' as real entities that could and ought to be taken into account.

According to Latour, translation is a twofold process. While at first the strategy of translation works through a series of displacements that enrol other actors, once this has been achieved, a second movement can occur that attributes responsibility for success to the new object or subject that has emerged. While Pasteur was in no way singularly responsible for the work that proved the microbe into existence, after all these trials and tactical moves it is indeed Pasteur who becomes attributed with the responsibility for microbial discovery. What makes scientists different from politicians then, is that while the latter make themselves mouthpieces for groups of people, the former do the same, but for objects instead. Through the translations, Pasteur faithfully came to speak for microbes. He came to represent them.

The notion of translation then, conveys not only linguistic, but also political and topological meanings as well. Technoscientific facts must be able to hold together, but they also have to travel outside of the lab. If that fact is supposed to be the same everywhere, it also has to arrive at its destination in the same form as it left. This requires a network that is vast enough to mobilise the fact and strong enough to keep it the same as it passes through each intermediary. Latour (1986) thus came to characterise scientific facts as immutable mobiles; they hold their shape while they move from place to place. When scientific facts are assembled well they can be mobilised as objects that endure through their stability. These notions of translation and immutable mobiles were central to early actor-network theory (ANT). Rather than a theory 'of' anything in particular, ANT became a distinctive approach to the study of technoscience by treating any given actor - human and nonhuman alike - as an emergent effect of the same actor-network within which it is situated. For example, through a style of writing and knowledge-making principled by agnosticism, generalised symmetry, and free association, Callon (1984) told a story about the translation of interests between scientists, scallops, and fishermen. What makes this story interesting is that Callon describes both human and nonhuman actors - the scientists, fishermen and the scallops - as mutually performing the work of translation. Here both humans and nonhumans become agents that participate in the making of worlds that are simultaneously social and natural. The actor-network approach or material-semiotic analysis is in this way radically nonhumanist (Law \& Mol 1995). Agency is understood as a network effect that takes shape through practical assemblages and devices. Similar to the post-structuralist work in the previous section, this material-semiotic sensibility does not assume agency to be an essential property of 'human' actors. Actor-net- 
work theory proposes an analysis that starts from an odd but rather simple position. In this theory, any entity can be empirically approached as an 'actor' situated in a broader 'network'; every network can also be handled as an 'actor' that acts in a specific way. Networks are composed of actors-in-relation and these actors are made to act and perform in particular ways due to the network of relations that constitute them as one agencement and not another.

John Law (1994), another proponent of early actor-network theory, took a similar material-semiotic approach in his study of the management work going on at a scientific laboratory. Through a reflexive account of his ethnographic engagements in this laboratory, Law came to identify various 'modes of ordering' at work in this lab - recursive patterns that organise social and material worlds. Each of these modes were shown to be incomplete in themselves and they therefore aligned with each other to perform rankings, hierarchies, accountabilities, and subjects in different ways. With this analytic strategy, Law builds on Foucault's notion of assemblage, but also departs from him, as the modes of ordering described by Law are much more small-scale, emerging, and they do not span an entire epoch. While Foucault empirically studied rather large material-semiotic assemblages, Law takes a detailed look at the micro-relations and translations that occur in practice, exemplified by the empirical description of the management and organisation going on at a laboratory.

While many found that actor-network theory ${ }^{27}$ was a useful way to approach the study of technoscience, some took issue with Latour's idea of the immutable mobile. Against the consistency of immutable mobiles, for instance, Annemarie Mol and John Law have drawn attention to fluidity (Mol \& Law 1994). In another paper, Marianne De Laet and Annemarie Mol argue that some objects, such as the Zimbabwe bush pump that they took as their case, could be better understood as mutable mobiles (De Laet \& Mol 2000). Rather than keeping a single form throughout their travels, the pump worked well and endured precisely because it changed in form and content from one context, site, and practice to another. Against the solidness of construction metaphors, Mol suggests the theatre inspired metaphor of enactment, to draw attention to the ongoing, situated endeavour of world-making (Mol 2002). These moves draw material-semiotic sensibilities towards relationality, multiplicity and heterogeneity.

In The Body Multiple (2002), these sensibilities are put to work in the study of a disease. According to Mol, the medical object that professionals call 'atherosclerosis' is not a unified reality underlying the symptoms the patient describes or the measurements of obstructed arteries in the clinic. Mol locates the disease not within the body of the patient, but in the relations that sustain its various enactments. Visualisations of thickening cell walls and numbers representing the blood as it flows through the patient body come to indicate progressions of diseases that Mol argues are best understood as enactments of a disease 'multiple'. To illustrate this, Mol provides an account of atherosclerosis care that shows how it is enacted as different realities - for example a clinical reality that has to do with patients and their pain when walking, and a statistical reality that tells of demographics and mortality rates.

\footnotetext{
${ }^{27}$ I will return to early actor-network theory in chapter 3 with a discussion of power as a material-semiotic 'script'.
} 
Each of these realities come with different consequences for what it means to live with and to care for atherosclerosis. In some settings, they may align, such as when pain complaints are later corroborated by a clotted artery found by the pathologist. Elsewhere, they may clash and interfere with each other. As a consequence of taking seriously this multiplicity, it comes to matter a great deal how interferences between objects become knowable and governable.

While biopolitical studies tend to emphasise the methods of control that aim to govern life, STS takes a slightly different approach by studying the methods through which 'ontologies' are realised in practice. In STS, the word 'ontology' also means something quite different from the way this term is used in philosophy more generally. Rather than 'ontology' being thought of as the study of what there is and what is real, methods from STS enable us to describe the ways in which things (and people) are realised - made real - in practical ways with political effects. This study and engagement with ontological politics emerged from a concern with what Mol calls 'perspectivalism'.

"Perspectivalism broke away from a monopolistic version of truth. But it didn't multiply reality. It multiplied the eyes of the beholders. It turned each pair of eyes looking from its own perspective into an alternative to other eyes. And this in turn brought pluralism in its wake." (Mol 1999:76)

Pluralism, as an effect of perspectivalism, ends up rendering the very objects and subjects of technoscience, biopolitics, or medicine unaccountable and immaterial. Mol disrespects this division of knowledge-labour that pluralism brings about by leaving behind the study of illness as a purely social phenomenon and attending to disease instead as a material, relational, and practical activity. This material-semiotic sensibility enabled her to describe the multiplicity of bodies with diseases and to propose a radical politics that handles with care their multiple realities. Realities do not always add up to a coherent whole. In practice, there are often frictions and tensions that are not entirely smoothed away. This literature forms an invitation to trace how a medical condition such as HIV infection is made real by the social and material conditions that are coordinated throughout - amongst other points in other networks - the laboratory, and the clinic. Multiplicities of infectious diseases may distributed through patient trajectories, surveillance reports, and indication criteria, and yet they hold together and include each other in different ways. These differences can then be compared and described as well. Contrary to the laboratory, the practical activity in the clinic is not usually organised around a discussion of 'which reality is more true', but (also) around the opening up or closing down of possibilities for care - for figuring out 'what to do'.

If multiple realities of HIV are being made in different practices, then it becomes a political question as to which realities we want to intervene in and what kind of politics we want to enact. This version of material-semiotics therefore leads us away from an effort to describe the politics of translation into singularity, but rather toward what Mol calls an ontological politics (Mol 1999) of multiplicity. Ontological politics attends not only to concerns about 'who' is included and excluded in practice, but also about 'what' gets to count as well; ontological politics becomes about the ways in which some things become accountable and others 
become discounted. This approach thus speaks to a concern with the ongoing enactment of reality. Since different practices are generating multiple realities, the aim of what Mol calls a 'praxiographic' approach is to investigate the relations between different objects in their real particularities. As this work can account for, attending to diseases and infections as materialsemiotic events can be done by 'unbracketing the practicalities'; that is, in focusing my descriptions on the details of the material-semiotic techniques and practices that enact my relation to Swedish HIV as subject to care and control. Stories generated by material-semiotics offer a reconfiguration of things as practical matters to be handled in their messiness and complexity. As a way doing post-structuralist philosophy through empirical research, material-semiotic methods allow me to care for HIV as an infectious disease situated in a political ecology of practices, each practice generating a different reality. Thinking through the ontological politics of care rather than only the biopolitics of control will provide me with the theoretical tools I need to study the fast-track assemblage into practices of Swedish HIV treatment. These tools will equip me with the means to investigate the governing of Swedish HIV through 'treatment' and to describe the situated subjects that emerge from these governing practices. Having now sensitised the reader to the politics of technoscientific practice - at how science and technology are inescapably part of social and political relations that come to matter in particular ways - I will now unpack the specificities of the methods and materials I drew on for this particular study.

\subsection{Decentering the subject with praxiography}

I want to write about practices that make me subject to specific ways of governing HIV infection, while also becoming sensitive to the normative implications that these practicalities have for myself and others. In praxiography I find a method well suited to this interest. "Because as long as the practicalities of doing disease are part of the story, it is a story about practices. A praxiography.” (Mol 2002:31) In this section, I will account for my method of praxiography as an ethnographic strategy of following and describing the dependent, multiple, intransitive, and relational practices through which subjectivity becomes accomplished. I will thus unpack what I mean by these terms and what they do for me methodologically. I will show how praxiography is a radical approach to relationality. But how then does it work differently from other ethnographic methods? What does it foreground and what does it background? What might it do for my study of HIV infection? In short, how does praxiography mediate the subject?

Praxiography is a method that emerges from and 'after' ANT (Law 1999; Gad \& Jensen 2010). Latour (1994) turned ANT into a poignant critique of sociology by claiming that most approaches to studying the social assume too much of the world to be intermediaries. For most sociologists, the social is limited to the realm of 'human' activity. What is then considered 'nonhuman' is then relegated to the domain of passive objects that may embody culture, but that never actively participate in cultural activity. Refusing to limit his analysis by interpreting 'materiality' as a tractable carrier of a more active but ephemeral 'society', Latour showed that the activities of mediators are far more interesting and quite a bit 
more recalcitrant at that. This enabled him to argue for a different way of doing 'social' science, what he calls 'asociology' or a science of association. In a Latourian reading, any given 'subject' is always already mediated by a heterogeneous assemblage of human and nonhuman actants. Attending to matters of concern as they are enacted in practice can show how wild and unwieldy mediators become well aligned and stabilised into intermediaries that may become unremarkable and unaccountable. But the reverse process can also occur where mere intermediaries turn into important mediators that must be taken into account. Latour takes his inspiration, among others, from the philosopher Michel Serres. Serres' work enables me to study how the subject of Swedish HIV treatment is constituted in dependency.

Thinking through the problems of science and technology - from the devastation of Hiroshima and Nagasaki in his youth to the advances of the World Wide Web in more recent years - Serres came to illustrate a remarkable image of relationality by sketching out the figure of the parasite (Serres 2013). For Serres, the parasite is animated by many more agencies than the tiny invertebrate organisms sequestered into the science of parasitology. Taking departure in the etymology of 'parasite' as meaning more aptly 'to eat next to', Serres delivers us to a host of figures that mark out the parasite as the uninvited guest: "The host is not a prey, for he offers and continues to give. Not a prey, but the host. The other one is not a predator but a parasite." (Serres 2013:7) The figure of the parasite gives me a foothold to approach HIV in a way that works beyond the relation of predator and prey, as do the more dominant approaches in (not only) social science. As I will come to show in this thesis, the parasite offers a radical way of perceiving material-semiotic relationality. Instead of a system that preys upon a lifeworld, we are given a lifeworld that parasites systemically. The figure of the parasite is directed to be sure, but it is not necessarily in direct conflict with others all the time. Enabling me to think beyond war and conflict, the parasite allows me to handle with care my relation to 'wretched' (Marx 1844) subjects of many kin and kind.

The parasite may offer to its host a beneficial advantage, and it sometimes does. But most importantly, Serres depicts a parasitic ecology and series of worlds in which parasite and host are permanently entangled in a shifting relation of dependency. The parasite is left helpless and vulnerable without a host, but even the host is parasite to another. Thinking through mediating parasites in relation to my field, we can see that a virus (HIV) is parasitic in that it depends upon a host (a human) to proliferate. But so too are patients parasitic in that they depend upon a doctor for treatment. The doctor depends in turn upon other medical personnel to make a diagnosis; the lab depends upon a market for devices and pharmaceutical reagents; the market for anti-HIV treatment and prevention drugs depends upon patients becoming infected with HIV and being treated. Serres even uses the idea of parasitical noise and what he calls 'translation' to approach sickness as a material-semiotic mediation:

"Sickness, of whatever variety, intercepts a function; it is a noise that mixes up messages in the circuits of the organism, parasiting their ordinary circulation. (...) Sickness is a parasitic noise. And the doctor eats by translating this noise." (Serres 2013:197) 
Parasites do the work of translation. Virology knows this very well, of course. Translation caries out a script, and translation can turn one script into another. But the meaning of translation need not be limited to the molecular function of HIV in the body of its host. The host itself becomes translated into something unanticipated by the introduction of the viral parasite as it comes to mediate their relation toward others. So too, is the virus translated again through the mediation of treatment and care. Parasitic monsters change the 'responseabilities' (Haraway 2016) of the actors they relate to in differential ways. So if parasitic practices of translation make for different subjects, then praxiography becomes a valuable method for my study through its ability to empirically attend to the relations of dependency that make me subject to Swedish HIV treatment in various ways. Praxiography enables me to follow the translations and coordinations through which subjects and objects come to be known and realised for what they are. In other words, it shows how subjects, "depend on practicality" (Mol 2002:160). But while relations of dependency play a critical role in my praxiography, they are not the only relation worth exploring either. In praxiography, relations are multiple. If dependency is thus my first principle of method, then multiplicity becomes my second.

To give an example of this, Mol (2002) shows how one version of a disease may depend on a technology it calls a 'micro-scope' to make it visible, while another version of the same disease might depend upon a 'macro-survey' instead. The reality of a disease thus depends on the practices that enact it, and as Mol puts it, "reality is distributed" (Mol 2002:96). In the practice of the clinic, what a disease 'is' depends on situations emerging from a doctorpatient conversation; it depends here on the patient locating and giving a voice to their pain or the embodied problems in their life. In the laboratory on the other hand, the reality of a disease might be enacted through diagnostic machines instead; it depends there on a variety of standardised routines and materials. Different versions of a disease 'here' and 'there' may be calibrated to produce a singular disease, but they might also work alongside each other without including one another or causing any friction. In another situation elsewhere, a surgery for example, a disease may depend on techniques to push it aside, circumvent it, or take it out of the body. Praxiography takes to task the making accountable of our dependencies to such a variety of things, each differently situated and situating the subjects that we become. So in other words, praxiography is a method of following the interdependencies of subjects and objects enacted in practice. It is a method that can be used to follow and map the enactment of multiplicity.

Praxiography thus equips me with a method to show how the subject of HIV infection is enacted as, "more than one and less than many" (Mol 2002:55). This is what is meant by the term 'multiplicity'. Through practical activities, subjects are folding together and folding apart in multiple ways; subjects are manifold. However, this does not mean that the subject of HIV infection can become anything, anywhere. In praxiography, the multiplicity of subjects and objects is situated in practical techniques and events (Mol 2002:53-55). But the 'singularity' (Mol 2002:119) of a subject or an object can also be accomplished with practical, technical, and political effects. 
One peculiar aspect of this method however, is that the subject and the object cannot easily be distinguished a priori. What then makes a praxiography interesting and also complex, is that all of the actors in the story may come to change quite dramatically depending on the other actors - human and nonhuman - they come to be involved with. How then to compare and contrast different versions of subjects and objects? This third principle of my praxiography can be articulated as intransitivity (Mol 2002:143). To better understand intransitivity, Mol also turns to an example from Serres that illustrates how the relationality and topology of inclusion is manifold: the box vs. the bag. When thinking about the ways in which two 'boxes' might contain each other for example, we tend to think about nesting effects that produce transitive relations. A smaller box might go inside a larger box for example, but the scale and shape of the boxes stays the same in this imaginary. Mol uses Serres to show how bags-as-containers might do things differently; a bigger bag might just as easily be folded up into a smaller bag or they might even both swallow each other at the same time. Through an intransitive relation, the bags may become mutually incorporated without being assimilated; different without being in opposition. Praxiography is thus also a craft that can be used to learn something about what it means to be, "holding what is other inside the self." (Mol 2002:143) This intransitive image captures something very specific about HIV infection in a way I find valuable for my personal and professional work. Again, what is 'other' and what is 'self' becomes an effect of the practical ecology that situates these entities. In one situation 'self' and 'nonself' may be in conflict, in another they may depend upon each other: "This image, that things opposed to one another may also depend on one another, is a rarely drawn one." (Mol 2002:144)

So praxiography is a method that enables me to follow and describe the subjects that emerge in a variety of practices. My praxiographic method will enable me to empirically investigate the specific was in which the multiple subject of governing Swedish HIV depends on practical techniques and how different versions of the subject relate to each other intransitively. Praxiography enables me to handle my parasitic and manifold relations to Swedish HIV and to care for the intransitive subjects I variously become in multiple practices of governing. As a method for investigating and interfering with reality in practice, praxiography is thus an ethical and political practice. Ethics and politics are necessarily bound up with the logics of practical activities. What does this mean for the study of my infectious disease?

With a praxiography of diabetes, Mol (2008) shows me how a logic of care runs counter to a logic of patient choice. As there is an increasing emphasis on 'patient choice' in contemporary medicine, Mol describes how this logic relates to the patient in at least two distinct modes: as a customer and a citizen. Albeit in different ways, these kinds of patient-subjects become tied to the ideal of 'choice' above all. The patient should be able to choose the kind of care and treatment they find desirable just as a customer chooses a product to purchase or as citizens do when expressing their views in the polis. In this logic of choice, patients should be made autonomous and free spirited, they should be made able to transcend the constraints imposed by ill bodies. Mol shows how such ideals make an ill fit with the realities of living with diseases and fragile bodies. Contrary to these normative-subjects, in the 
logic of care, the patient-subject is quite different. Instead of representing the patient through choice, practices of care would work to craft, "more bearable ways of living with, or in, reality." (Mol 2008:53) Mol uses the lesson learned from the women's movement to show this how patient emancipation idealised in the logic of choice is a problematic ideal for the logic of care.

In pushing for equality, some proposed that women should be treated just like men, but this would still perform men as the standard to which women ought to adhere. Mol and others aim to do better than this. In their hands, 'feminism' thus becomes a strategy that offers an alternative by interfering with the very standard of masculinity. Mol suggests a similar strategy for the patient movement in what she calls 'patientism': "It does not seek equality between 'patients' and 'healthy people', but tries to establish living with a disease, rather than 'normality', as the standard. (...) While citizenship requires us to control our bodies, to silence them, or to discard them, patientism seeks ways to be kind to our bodies, to allow them to exist, and even to cherish them. Where to find repertoires for doing so?" (Mol 2008:35) With this project, I aim to develop such repertoires with an attention to the practical complexities that differentially make me accountable as a manifold subject of health-care and disease-control. However, while comparing the subjects I become in these practices, I also do not want to imagine them as fundamentally in opposition. As Mol points out, the opposite of 'care' is neglect and in this way at least 'care' aligns with 'control'. By proposing a shift from fast-tracking to slowing-down governance, I do not mean to propose some sort of neglect for bodies and selves; quite the opposite in fact. Slowing-down with praxiography allows me to pay a closer attention to the manifold subjects that become accountable to and for Swedish HIV in practice. I will furthermore situate my praxiography in my personal experiences as a patient undergoing Swedish HIV treatment.

Traditionally, including personal experiences in academic work has not been without controversy. The sociologist, scholar of HIV biomedicine, and auto-ethnographer Eric Mykhalovskiy (1996) reflects on ways of doing so and lets me consider how this work might be received in the academy. Mykhalovskiy drew on familial experience and self-narrative in order to say something about: "forms of categorisation through which gendered subjectivities are partly accomplished." (Mykhalovskiy 1996:132) He describes how, as a response to his own analysis of self, his work was dismissed as unimportant and even 'self-indulgent'. Through this 'charge of narcissism', Mykhalovskiy found a way to reflexively account for the exclusion of auto-ethnographic method from 'proper science': "the production of proper academic subjectivities comes at a personal cost of self-regulation, guilt, pain, the denial of pleasure and the silencing of voice." (Mykhalovskiy 1996:132) His work thus shows me how the accusation of self-indulgence misses the way in which writing about 'the self' is always necessarily writing about 'the other'. Taking my own case of dealing with HIV into account is thus not only about the art of reflexive writing. By caring for the subject I am variously becoming, my praxiography is also a political effort to include 'the personal' in such a way that extends beyond my person alone. Praxiography provides me with a method to investigate the differences in normativity that enact the subject of Swedish HIV technoscience. It enables me 
not only to address my own matters of concern, but it also provides me with a way of handling my matters of care for and with HIV. As I have been discussing, the subject of HIV technoscience or biopolitics is not given, but is made and remade through practicalities that are often bracketed. This means that we ignore a great deal of complexity in order to navigate and carry on with everyday life. But if we want to better understand the subjects of technoscience, health-care, and disease-control, then I think we had better slow down and look at how they hold together in practice and how they relate. Since I am part of these practices, the situated character of my praxiography attunes this thesis to a manifold of issues that other patients living with HIV also face. While somewhat 'auto'-ethnographic, this praxiography is one however, that puts the 'auto' or 'self' into question. Instead of aiming to represent the multiplicity of 'the patient' by describing and analysing patient experience alone, I will attend to the practices that make them/us patients to begin with. I will investigate how 'selves' become what they are in governing practice.

Drawing on my own experiences of living with HIV in Sweden, my work thus carries with it a concern with the reflexive and normative dimensions of research practices. By investigating the various 'goods' and 'bads' that are entangled with different subject positions, my work aims to interfere with the idea of a single patient perspective by highlighting the multiple ways that subjects are enacted. However, the goal here is not just about the articulation of multiplicity, but rather to craft better ways of handling the multiple objects and subjects of Swedish HIV care in practice. This is not merely an identity politics. Although, of course, my experiences do speak to broader characteristics of life with HIV, in line with the heart of this argument, I will not relate my personal experiences as representative of some category or broader community, e.g. of gay white men. Instead, I will situate a variety of personal, political, scientific materials to interfere with the ontological politics that enact the subject of HIV, both in Sweden and beyond. This brings me to the topic of reflexivity, often thought of as either a virtue or a vice. A reflexive relation is one that bends back on the subject, referring to and affecting the subject that is performing the action in question. While reflexivity is thus important to my work, I find it just as important to experiment with different ways of doing reflexive work. Instead of either 'eschewing' or 'celebrating' reflexivity, I want to ask instead what a reflexive approach might do in the case of Swedish HIV and how we might do it differently. So this is not a form of detached reflexivity that Haraway among others critiques (Haraway 1988), and neither is reflexivity 'nowhere' in my work. In the approach I take, I argue for a situated reflexivity, by which I mean a method of attending to the dependencies that make me subject to HIV in different ways. I argue that this approach helps me to explicate how the personal and the political are entangled through my methodology, how I am invested with a multiplicity of interests that shape my research, and how these multiple interests manifesting through multiple techniques come to constitute the manifold subject.

Material-semiotic sensitivities provide me with the means to explore personal domains in a way that attunes my account to the practicalities through which subjectivity becomes accomplished. Law, for instance, uses the study of an aircraft to describe five modes of ordering that enact his subjectivity in different ways. Coming across this aircraft on more 
than one occasion, he became fascinated by the aesthetic qualities and machinery of this object. He also found it to be an interesting case for ANT, a story that would no doubt involve a variety of political and ethical concerns. Equipping his account of subjectivity with Haraway's sensitivity to overlapping patterns that generate frictions and interferences, Law describes the immobilising effect of being interpellated by some modes at the expense of others. In his case, a normative and political concern came to override the ethical and esoteric concerns he also cared deeply about. The entanglements between different practices of producing subjectivity can at times create lines of illumination, but interferences between different modes of ordering the subject can also cancel each other out and produce a shadow. What I find most valuable about the account Law provides is that subjectivity and 'the personal' are not located in bounded persons or things alone. As my work will demonstrate, modes of ordering the subject run through people, things, animals, ideas, machines, materials, and all kinds of matters. Practices are constantly organising subjects and objects in a variety of ways.

My praxiography will therefore 'follow' (Latour 1987) the subject through the practices of governance that enact and transform my own subjectivity as a person living with HIV, a political activist, and most importantly here, a researcher. It will provide an account of the material-semiotic organisation of accountable subjects emerging from Swedish HIV governance. Following the subject of Swedish HIV enables me to describe the folding of the subject into practices of regulation, diagnostics, surveillance, and treatment. Describing the variations in 'myself' as subject to a manifold array of practical dependencies allows me to decenter the subject through storytelling. Through the method of praxiography, the very stability of the 'self' as a singularity is put into question by the empirical description of multiplicity. I consider this a necessary approach to take in order to say what it means to become accountable as subject to Swedish HIV treatment and the fast-track assemblage. The material-semiotic sensitivities of praxiography as a method will attune my account to the situations in which the subject of Swedish HIV is differentially enacted. Following the subject of technoscience through physical examinations, blood tests, algorithmic calculations, and status disclosure practices, I will undertake a praxiography of the stakes involved in producing matters of accountability for this disease.

\subsection{Assembling a manifold of materials}

Slowing down the fast-track assemblage provided me with a strategy for locating relevant actors and their practical activity. Praxiography as a material-semiotic method enables me to follow the 90-90-90 goals into the Swedish HIV diagnostic and treatment practices; their acclaimed achievement of these targets thus become interesting to investigate in empirical detail. By following the fast-track goal of lowering incidence into the practices that are said to accomplish this aim, HIV surveillance thus becomes a relevant site for study. In this way, studying the fast-track as a material-semiotic assemblage led me to engage in participant observation with diagnostic, treatment, and surveillance practices. Following the subject through the fast-track assemblage also generated material on the local particularities of regulatory and legal practices that became critical to explore. In this sense, my study mobilises the 
methods of 'analysis as assemblage' (Pryke, Rose, \& Whatmore 2003:134) which involves a juxtaposition of the stories and stuff I encountered through the process of doing this research.

In another sense, my entrance to the field took place in the Spring of 2016 when I received an HIV positive diagnosis. While I hope to have found a somewhat reasonable articulation of the complexities I encountered, in practice this fieldwork was a mess ${ }^{28}$. I thus started this fieldwork with my doctor, discussing my professional interests and asking for consent to record my further diagnostic and monitoring visits for my situated study. With the approval of my HIV specialist, STI specialists, nurses, and a handful of different medical students on various occasions, along with a recording device between us all, I have recorded most of my clinical examinations since the time of my diagnosis. Doing participant observation in this infection clinic therefore gave me access to diagnostic and treatment practices from the standpoint of the patient living with HIV. From that time on, I also kept a patient journal in which I write my thoughts and reflections on living with HIV in Sweden. This allows me to record my HIV related experiences as a kind of auto-biographical account of living with HIV. I also participated in a weekend event organised by a patient organisation in Stockholm. While discussions with other patients at this event and in my own private life have given me much to think with, I do not record this material for primary use, but it nevertheless influences my work and the motivations for my research. While not explicitly part of my 'data', these stories and reflections serve to sensitise me to the shifts and changes in the materiality of HIV in Sweden and beyond as I experienced a multiplicity of technoscientific and personal positioning. This enabled me to analyse the manifold subjects I have accounted for.

Apart from this ongoing fieldwork at the infection clinic and STI clinic through my person, I also did fieldwork at three different laboratories of the same hospital. Through interviews and observations in these labs, I was shown the practicalities and technologies of clinical microbiology, immunovirology, and haematology as they relate to the diagnosis of HIV and beyond ${ }^{29}$. Access to surveillance practices proved to be the most challenging engagement I undertook. While aiming to conduct an extended period of participant observation with HIV surveillance practices at national or ECDC levels, this was not realised in the manner I desired to participate in originally. With limited access, I then contacted the entire expert panel of scientists and advisors listed on a UNAIDS report I found in a document from the previous year, to which I received two replies from epidemiologists who were willing to discuss their work over Skype. Towards the end of my fieldwork, some of the epidemiologists working in national and international public health agencies, and eventually even the Swedish Public Health Agency and the ECDC, were also able to discuss the practicalities of their work with me through interviews over Skype. These were professionals working with surveillance practices in Sweden that I had studied through the literature, so I was able to contact these professionals with some questions and concerns to better frame my interview request. The last activity that comprised my fieldwork took place at the 2018 AIDS international conference that

\footnotetext{
${ }_{28}$ And then again, it usually is (Law 2004; Law 2007).

${ }^{29}$ Some of these techniques are practiced differently in diagnostic and surveillance contexts.
} 
was held the same year in Amsterdam. Signing myself up as a volunteer, I gained access to the conference as an attendee for the first three days, and then as part of the staff for the last two days. This allowed me to observe, photograph, and film HIV technoscience, industry, and activism as a partial insider to the assemblage. Understanding how these diagnostic, regulatory, treatment, and surveillance technologies work in practice was a critical way for me to get past the more 'standard' interpretations of what professionals often say they do, and to attune my analysis to the forces that run through these practical assemblages as they churned in vivo, in vitro, in silico, and in situ.

Most of the interviews I conducted could be classified as 'semi-structured'. These I used when interviewing a new informant from a practice I was not yet familiar with. After explaining my project and general interests, I would usually start by asking the informant to describe their practice, their patterns of work, their day-to-day tasks, and the tools and techniques they depended on. However, there were often questions that only became relevant to ask and more interesting to observe in practice after some reflection, analysis, and writing. In some cases I therefore also conducted 'unstructured' interviews where I simply participated in clinical and laboratory settings to investigate the processes that my informants worked with as they played out in process. Along the way I also undertook a substantial discourse analysis of scientific papers, policy documents, medical guidelines, surveillance protocols, technical updates, governance reports, etc. as a method to understand techniques governing HIV and specifically how the surveillance of my own epidemic was accomplished regionally, nationally, internationally, and locally. My professional and personal field notes, descriptions of participant observation in practice, as well as both these sorts of interviews, allowed me to generate a thicket of textual material I relied on to analyse the practical assemblages of my fieldwork. This archive allowed me to analyse the utterances that articulate Swedish HIV and fast-track assemblages through specific and practical concerns.

My participant observation in the infection clinic and the connected laboratories, next to my field notes, auto-biographical journal, and transcriptions also generated over a hundred images of machines, signs, posters, forms, blood samples, diagrams, etc. During my participation at the 2018 AIDS conference I then generated a further 157 images and videos on the topics of algorithms, testing devices, strategies, activism and patient issues, along with the politics of HIV identification, classification, and care. To complement this visual archive, I also found useful the addition of around two dozen images I came across in HIV policy discourses, in scientific articles, on Wikipedia, and on patient information websites. This visual archive has become an important feature of my analytical work. While only a fraction of these images have made it into this thesis as figures 1-22, the ones I have chosen to include in my storytelling are often those that introduced a moment of ethnographic disruption, moments when my encounters in the field generated a strangeness or a problem that I found important to think with. Other times, the images provide an important dimension to the conversations with scientists and technicians, allowing me to bring the reader closer to the practical setting I describe. I therefore find the visual to be an equally important element to the verbal articulations of my field and a helpful addition to my method assemblage. Not only do pic- 
tures and films produce a kind of material that may be shuffled and combined with journal notes and revisited for analytical value, but the description of these materials has also sensitised my analysis to the visibilities that I navigated through this fieldwork. Like words, images serve to foreground particular realities and normativities of HIV and come to exclude others.

In total, this fieldwork resulted in interviews with 15 different professionals and a handful of students on various occasions regarding the testing, treatment, monitoring, surveillance, and regulation of HIV - with me participating too of course. As I previously mentioned, I often had to return to these professionals and follow up on their stories and practical experiences with further questions. This generated a total of 22 audio recordings that I transcribed and analysed. All of the conversations that I had with these professionals were initiated with me telling briefly about my work and asking for their consent to record interviews for my $\mathrm{PhD}$ research. In addition, I have made all of my interlocutors anonymous in this monograph by replacing their actual name with a random name before transcribing this material.

\subsection{Conclusion}

In the previous chapter, I argued that the 'fast-track' can be understood as a materialsemiotic assemblage. The focus of this chapter has been to articulate the theoretical resources from post-structuralist philosophy that allow me to conceptualise and study this assemblage and to begin describing the ecology of governing practices in which I will empirically situate my work. Relating to the field of Science and Technology Studies (STS) then helped me outline my understanding of power and subjectivity as an effect of material-semiotic practices. I then showed how a method called praxiography was uniquely equipped to study the practical relations of subject-making in the form of ontological politics. This approach attunes my account toward practices of care rather than only emphasising the control often emphasised in studies of governance. Studying (and therefore doing) the ontological politics of Swedish HIV thus helps me to sensitise my account to differences in health-care and disease-control and how these practices differentially enact 'the subject'. By participating and observing in practices of Swedish HIV health-care and disease-control, I become able to account for the subjects that are enacted in these practices. I do not, however, claim to account for 'everyone' working or living with Swedish HIV. My account is situated in my personal experiences. However, in describing the specificities of the approach I took in generating material, many anthropologists, sociologists, and empirical philosophers will no doubt find themselves familiar with many if not all of my methods. What then makes praxiography uniquely suited for the study of Swedish HIV is the situated texture that it brings to my study as a partial insider of the fast-track assemblage and its local instantiations of Swedish HIV governance, control, and care. The following chapters will now situate the practical and political issues at stake in the field I studied and the event (Stengers 2011) I experienced as HIV infection. 


\section{iii // Policing the unwell}

\subsection{Introduction}

In the first chapter of this thesis, I introduced my reader to the fast-track assemblage and the rationale of this thesis: slowing down the fast-track. In the second chapter, I then gave an account of the specific sensitivities that allowed me to perform this praxiography. In this chapter, I will now follow the fast-track into the practices that have been said to accomplish this agenda, practices that I experienced firsthand in the events that followed my own HIV diagnosis. By describing the principles and principalities I traversed through these events, I will argue that there is an ongoing violence being enacted in Swedish HIV treatment, a violence I refer to as 'policing'. I argue that this policing produces a tension between the protection and prosecution of the subject. This story is thus an account of the policing of Swedish HIV and of the unwell subject enacted by this practice. Through the juxtaposition of heterogeneous regimes or assemblages of governing, I will show how the subject of Swedish HIV treatment undergoes this process of policing through what are seemingly mundane governance technologies. This analysis enables me to question whether a 'policing' accountability is the most desirable for the care of those subject to Swedish HIV treatment.

Upon receiving my seropositive status, I received a document that outlined the responsibilities and obligations that came along with this status. Analysing this document allows me to show how accountability for Swedish HIV is governed by what I call the 'policing script'. I will show how this script is formally realised through three legal obligations: disclosure of my HIV status, adherence to my anti-retroviral treatment, and my compliance with treatment protocol. Making use of the vocabulary from early actor-network theory (Akrich 1992; Akrich \& Latour 1992; Callon 2007), I argue that these are obligatory points of passage for the subject living with Swedish HIV. I then relate this process of 'policing' to the historical and contemporary constitution of Swedish disease-control and the governing of sexual risk. By looking closer at how this policing translation of the subject operates in practice, I show that this plays out not only in public domains, but also in private and intimate spaces. I thus show how the patient undergoing Swedish HIV treatment is made to pass through three obligations that may be variously contingent on each other at different points in the treatment trajectory. This chapter will thus tell the story of the subject becoming accountable as 'well-treated'. In slowing down and problematising the acclaimed success of the Swedish approach, my analysis will also make sense of the simultaneous policing of subjects 'unwell'.

\subsection{Swedish HIV 'treatment' as protection or prosecution?}

In this story I want to describe how bodies are given responsibility for HIV in Sweden and how subjects are made accountable in medico-legal ways. So who then are the relevant bodies with whom 'power' and 'responsibility' for Swedish HIV treatment lies today? How are infectious diseases, and HIV infection in particular, presently classified here in Sweden? At the time of this writing, responsibility for infection seems to rest with Folkhälsomyndigheten 
or The Public Health Agency of Sweden (PHAS) ${ }^{30}$. Upon visiting their public web presence, a reader will find the following description of this responsibility:

"The Agency has overall responsibility for protecting the population against communicable diseases and is responsible for national coordination." ${ }^{31}$

The value of 'protection' is thus being emphasised in this statement by Swedish HIV governance. Here we find that responsibility for communicable diseases, such as HIV infection, is also said to be distributed between a number of other governing actors. There are collective actors such as 'the Agency' (PHAS), entities known as 'county councils', and others like 'child health services', as well as individual actors such as the 'County Medical Officers' and 'physicians'. These are the doctors who come to care for and manage patients living with HIV in Sweden. Does this mean that accountability for HIV rests solely with these governing authorities in the Swedish healthcare system? Not quite. There are, of course, also others becoming accountable as people living with HIV. These subjects are often becoming-accountable by means of prosecution. A document composed by RFSL, The Swedish Federation for Lesbian, Gay, Bisexual, Transgender and Queer Rights, introduces this problem in the following way:
"Sweden is the global leader of prosecutions for HIV exposure or transmission amongst the countries that have prosecuted five people or more, with more prosecutions per capita than any other country in the world. Sweden has been one of the worst offenders of the human right of lack of interference in private life by overly interfering in the private lives of individ- uals diagnosed with HIV." 32

So here we see another kind of responsibility being given to different bodies; subjects marked with difference through the diagnosis of HIV infection. Emily Martin, an anthropologist who worked with AIDS in the early years (Martin 1990; 1994), provides me with an insight to start making sense of these prosecutions: "Although the metaphor of warfare against an external enemy dominates these accounts, another metaphor plays nearly as large a role: the body as police state" (Martin 1990:412). In the introduction to this thesis, I showed how the fast-track strategy as a material-semiotic body and biopolitical assemblage that desires to end HIV has come to frame the problems of HIV and AIDS as a matter of war. But while the fast-track stages HIV as an external threat, an enemy 'outside' the self, the practices I will

\footnotetext{
${ }^{30}$ Founded by the new government in 2014, this agency took up and merged responsibilities from what were previously known as the Swedish Institute for Communicable Disease Control and and The Swedish National Institute of Public Health.

31 https://www.folkhalsomyndigheten.se/the-public-health-agency-of-sweden, accessed 2020.02.18

32 http://www.hiv-sverige.se/wp-content/uploads/rfsu2011_hiv_crime_and_punishment_2.pdf accessed 2020.04 .07
} 
now describe imagine the threat to be lurking within; a threat congealing on the 'inside' of the Swedish body. Whether the HIV is imagined as an external or internal risk, these metaphors both pivot around the construction and contestation of a boundary between HIV and the subjects affected by it. In this chapter, I want to ask how this boundary is formed by informational practices. By what material-semiotic translations are patients who should be 'protected' and cared for instead becoming 'prosecuted' and punished for becoming-unwell? This is a story that addresses this question.

\subsection{The historicity of Swedish disease-control}

In light of the progressive image Sweden is often given in global discourse - as an ambitious front runner in feminism, energy transitions, and social democracy - to the present day, Swedish HIV policy has played a surprisingly stringent role in its governance of HIV. In analysing the intersections between Swedish HIV/AIDS governance strategies in relation to discourses of ethnicity and 'race' in the period between 1985-2005, Anna Bredström (2008) shows that ever since 1983, only two years after it emerged as a 'global' cause for concern, AIDS was classified in Sweden as a disease that must be reported to the public authorities upon diagnosis. Not long after in 1985, both the HIV virus and AIDS were incorporated into the Contagious Disease Act or Smittskyddslagen, a law that was originally constituted in 1968. The work of Bredström provides me with a key insight to the accountability relations at stake in this Swedish constitution of HIV infection - the historicity of Swedish disease-control as embodied by, embedded in, and enacted by Smittskyddslagen. The legal formulation of HIV as a particularly alarming disease granted the authorities with the power to isolate persons against their will and to conduct compulsory HIV testing if there was deemed a risk of infection (Bredström 2009:60).

In contemporary practice, this formal responsibility also makes of HIV doctors a legal authority in relation to not only the medical, but moreover the legal obligations their patients must abide by, a peculiar situation that I will discuss further. Interestingly, Smittskyddslagen also categorised HIV/AIDS as a 'venereal disease' during its 1983 incorporation. This classification reflected the attention given by the authorities of health and disease to what were then known as 'risk groups' and 'risk behaviours', essentially framing HIV infection as mostly a concern for 'gay men' and 'prostitutes' (Thorsén 2013:475). In $1995^{33}$ however, a new category of risk identification emerged - the 'risk group' or what is less controversially known as a 'population' affected by HIV. The 'migrant' population thereafter became the primary cause for concern and a new target for public health intervention. This story that Bredström tells sensitises my account to the boundary work of what is perceived as 'national' and 'foreign', and how this boundary has come to produce the category of 'migrant' as a subject of concern

\footnotetext{
${ }^{33}$ Bredström explores the discursive shifts in policy from what she calls a 'pluralist strategy' that valued multiculturalism to a 'neo-assimilationalist' approach that came to dominate HIV governance in Sweden after the 1990's. Her work shows a distinctive preference given to what is deemed 'national' over 'the global' in Swedish public health discourse and reveals both the subtle and sometimes even blatant ways that racism and the exclusion of 'otherness' was and continues to be performed through the drawing of boundaries around sexual risk.
} 
to Swedish HIV/AIDS policy.

Yvonne Svanström works with a related boundary involved in practices of making and shaping 'sexual risk' in the Swedish context - the boundary between licit and illicit sexual activity. Svanström (2000) takes us back to earlier times and places to illuminate the emergence of the Swedish system of sexual regulation and policy execution. Her historical account of governing of sex work also points to a shift in the perception of venereal disease that would come to be embodied in Smittskyddslagen. By the 1850s in Sweden, it was predominantly the categories of 'public woman' and 'lecherous women' that were attributed with responsibility for venereal disease. Svanström shows how before this time, the sexual dimensions of these diseases were unapparent; venereal disease was thought to spread through the lower classes due to close quartered living conditions, and both men and women were attended to by public health activity. The late 1800 s would see the rise of new regulation practices. These would shift legal and medical interventions primarily towards women and were executed by a designated police force who could confront any woman deemed suspect to risk.

Women deemed suspect of breaching the boundaries of sexual normativity were held to account for their sexual health by providing these police officers with the dates and results of recent medical consultations, often documented in small booklets and carried on their person in the case of a confrontation with the police. At the same time, the police officers would exercise caution in who they approached. Were she not a sex worker, a woman from an influential strata of society could seek repercussions for damages inflicted to her person by such a confrontation. Sex work, moralised as it was and still is at this time and place, was nevertheless viewed as a necessary alleviation to the 'needs of men' and was likewise thought to guarantee the safety and health of 'honourable women'. Svanström shows how those considered men were historically thought to have differentiated needs than those considered women, and thus women were socially assigned the task and duty of subserving these needs. What we learn from Svanström is that the publicly sexual subject in Sweden has not only been historically and politically constructed, but has been thoroughly multiple throughout. While 'public men' were identified as the ideal political subject, the category of 'public women' was demeaning and marked with the stigma of prostitution. Still, this regulation of venereal disease and sexual activity provided those categorised as 'public women' with a higher status than 'lecherous women' who worked through more private and undocumented practices. The lecherous subject was one who attested or rejected regulatory practices and was therefore not to be treated by police as subject to the law. She was not only left vulnerable to disease, but also to arrest, rape, and other violences. The categorisation and regulation of HIV/AIDS as a 'venereal disease' carries this story of regulating sex along with it.

But the regulation of what is deemed sexual 'risk' is not an event of the past alone. Both governing bodies and bodies governed in the present become what they are through this historicity. From the very earliest years of its history, HIV emerged as an object deeply entangled with practices that take risk as their object. The work of Boel Berner shows me how HIV takes shape not only through boundary work, but also through ties and connections that flow and clot throughout the social body. Having only just achieved the declassification of 
homosexuality as a disease four years earlier, organisations such as RFSL were already willing in 1983 to advise members of their community to refrain from donating their blood to the Swedish blood supply. This was because HIV was becoming perceived as an object borne through blood, one that could put the Swedish body at potential risk. Berner (2011) describes the action by RFSL to urge homosexuals not to donate blood can be seen as a way of, "taking responsibility for general public health rather than claiming an individual or group right to participate in a socially valued practice" (Berner 2011). She compares this to the alternative approach that was exemplified by France. The LGBTQ community in France was more concerned about the possibility of discrimination by withdrawing from the blood supply. Berner speculates on the link between what she understands as 'inaction' and the high rates of HIV infection by blood transfusion in France. Perhaps this story even shows the valuing of protection for bodies rather than identities. But what also seems to characterise this valuing of public protection, is the 'policing' of individuals that has come to exemplify Swedish HIV governance since then. This is what this chapter will now show.

Just two years after making this announcement, people infected by Swedish HIV became accountable to Smittskyddlägan through legislation. In 1985 an amendment was made that altered Smittskyddlägan by not only classifying HIV as a cause for concern to public health quite generally, but by specifically obligating those individuals marked as 'infected' to disclose their HIV status to others who might be put at risk of infection. The amendment also made involuntary isolation possible. The following year in 1986, the Swedish government enacted a law that discouraged collective sexuality, effectively making collective sexual activity a 'risky' affair that must occur in private, away from public eyes. This became referred to as the 'sauna club-law', as this law forced the gay saunas to close down ${ }^{34}$. While RFSL urged the governing authorities to reconsider, a strategy of containment came to govern not only Swedish HIV, but came to police sexual bodies as well. Through these events, the lecherous subject was once again driven out of the public sphere and forced to become invisible and private.

What emerges from these historical accounts is the way in which political mobilisations of HIV and AIDS in Swedish public health discourse have often surfaced at the border of a contentious boundary. HIV/AIDS are objects that ignite the veil between public and private, individual and collective, self and other. The feminist biologist and biopolitical philosopher Donna Haraway (1991) shows me how the Swedish handling of HIV/AIDS and the subjects they affect, has always been both 'biological', 'informational', and 'political'; "Disease is a subspecies of information malfunction or communications pathology; disease is process of misrecognition or transgression of the boundaries of a strategic assemblage called self" (Haraway 1991:283). In other words, these boundaries that emerge from the historicity of Swedish HIV treatment are not only 'political' or 'biological', they are biopolitical. In the following section, I will describe how this biopolitical treatment of Swedish HIV has come to be organised today.

\footnotetext{
34 https://www.rfsl.se/en/about-us/history/, accessed 2020.04.07
} 


\subsubsection{The policing script; becoming-obligated to pass as 'well-treated'}

To study the contemporary practices that enact Swedish HIV, I will now show how these historical and political strategies of disease-control and the governing of sexual risks have become materialised in what I call the policing script, that is, a mode of governing Swedish HIV through a rigid and violent coding of conduct. The policing script, as a juxtaposition of medical and legal power, is recursively materialised by a simple and rather mundane governance technology (Woolgar \& Neyland 2013) - a document. This piece of paper is given to those who test positive for HIV in Sweden and to those who have become identified as subject to risk by Swedish practices of contract tracing and disease notification.

In one of the seminal works of actor-network theory, Madeleine Akrich (1992) used the idea of a 'script' to explore the way in which scientific and technical objects, "define a framework of action together with the actors and the space in which they act" (Akrich 1992:208). Scientists and technologists materialise these scripts to achieve different effects. For Akrich, a script is a program of action that can be read from any given setting, provided the analyst attends to the processes through which it is materialised and delineated. A door comes to replace the work of tearing a hole in a wall and building it back up again in order to pass. A seatbelt becomes a noisy obstacle for a driver until it is buckled. In each instance, the program or script of the actors becomes modified by the materiality of objects, enabling and constraining it in different ways. Agency, the power to act or not to act, is modified in the relations of the setting. If the door is fitted with a hydraulic operator, it will once again displace the work done to manually open and close it. Putting a speed bump in the middle of the road ensures that even drivers who wear their seatbelts will still slow down. ${ }^{35}$

The material-semiotic vocabulary co-authored by Akrich \& Latour (1992) provides me with a useful way to begin describing the accountability relations staged by the document I received. I will show how the accountability relations enacted by the document constitute HIV as a medical, scientific, and political actor; a subject of governance. The notion of proscription furthermore enables me to make evident the boundary or delineation that is generated by this moral, legal, biological, and political script of Swedish HIV governance in its specificity. Akrich \& Latour define prescription and proscription as, "what a device allows or forbids from the actors - humans and nonhuman - that it anticipates" (Akrich \& Latour 1992:261). Proscription and prescription thus point to the moral, technical, and political boundary of the subjects, devices, and settings that are enacted by this document. This $p a$ tient-information document (see figure 4) is delivered to those identified as 'infected' or 'at risk of infection' through testing and contact tracing. ${ }^{36}$ This document provides me with the material to begin investigating the coding of conduct and legal relations of accountability to Swedish HIV.

\footnotetext{
35 These examples come from Bruno Latour (1992) who mobilised a few mundane artefacts to demonstrate Madeleine Akrich's notion of the script.

${ }^{36}$ A practice I will attend to further in chapter 6.
} 

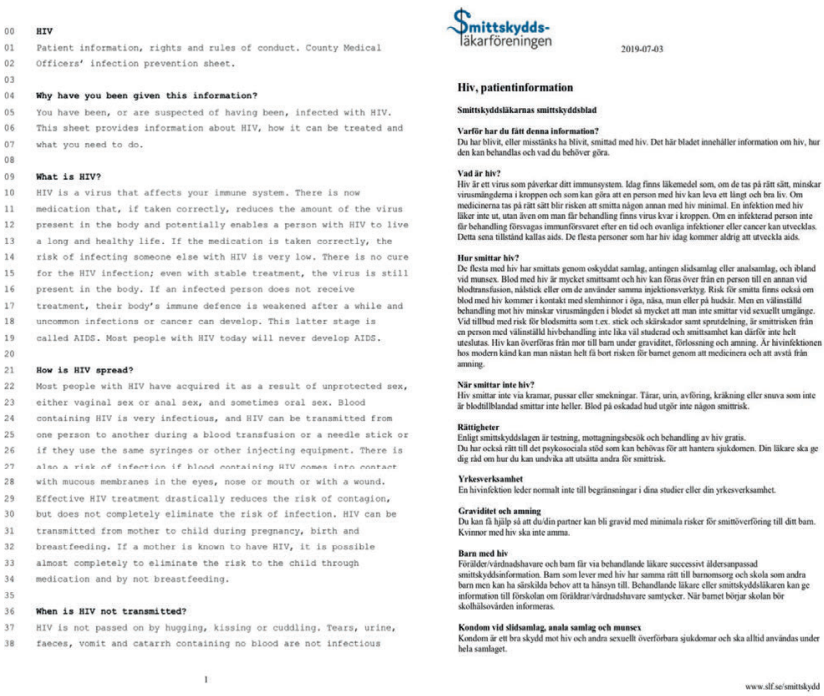

Figure 4: the patient-information document as a policing script ${ }^{37}$

Figure 4 shows the document I originally received in 2016 from my treating physician upon receiving an HIV positive result (figure 4, left) next to a version (figure 4, right) of this same document that was updated in 2019. My original version came to me translated into the English language, which I later transcribed and enumerated for textual analysis as I show in this image. As an effect of the historical and contemporary practices of disease regulation and the governance of sexuality, this document informs the HIV positive tester of the legal rights and obligations to which they now will be held accountable. Upon receiving a positive diagnosis, the patient is given this document to take home with them. Let me describe it in some detail. The first line of text provides the document with a rather short title - HIV. The next lines situate the document as both a, "Patient information, rights and rules of conduct" document, as well as a "County Medical Officers' infection prevention sheet". The 'reader' of this document is therefore the subject who has or may have been infected with HIV - the subject who is finding themselves to be a 'patient' through this document.

The agency who issues the document however, its 'author', is known as: 'Smittskyddsläkarföreningen' (Medical Society for Infectious Disease), the medical authority managing inter-regional disease-control and issuing such documents to regional authorities, such as the 'county medical officer' mentioned in the title. When I first received this document back in 2016, I tried to find some information about this agency on the web so as to contact them. I found instead a webpage that provides doctors and medical professionals with a platform to report the diagnosis of infectious diseases to Folkhälsomyndigheten. What I remember most notably was the image (see figure 5) of disease-control that I encountered in doing so:

\footnotetext{
37 See appendix.
} 


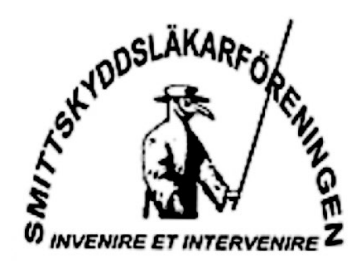

Figure 5: the plague masked figure of Swedish disease-control38

The figure wears the rather ominous looking 'plague mask' that was worn by medical practitioners in the 18th century in an effort to protect them against airborne diseases. It is furthermore equipped with what seems to be either a sword or a staff. While the name of this agency, Smittskyddsläkarföreningen, forms the top arch of the logo, the Latin words 'invenire et intervenire' form a base of text below the figure. A quick check with Google tells me that in English, this message translates as 'find and intervene'. These words articulate a program of action that this agency of disease-control desires to accomplish. In Sweden, any positive HIV test results are reported by doctors and medical professionals using this online portal. The healthcare professionals pass along the diagnostic information to disease control practices, and disease control practices inform the patient of formal rights, risks, and responsibilities through the document that is given to tested subjects upon a positive diagnosis. Upon being tested and found positive, this figure and document presented me with a simple and formal fact: "You have been, or are suspected of having been, infected with HIV." Within the first few lines of this 'patient-information' document, I thus become interpellated as a suspect.

As such, this document performs morality, legality, science, and politics. Instead of 'the right to remain silent' however, this document obliges the suspect to 'disclose', 'adhere', and 'comply' with Swedish HIV treatment. Due to this practice of documented regulation, I will show how a formal, legal, and rigid mode of ordering accountability relations enacts not only the well-treated subject, but the unwell-treated subject too. I will argue that the difference between these subjects is an effect of this document which a subject encounters at the start of their relation to Swedish HIV treatment. In order to become a regulated subject and receive legal and medical care, the subject living with Swedish HIV who is deemed 'risky' or 'at risk' by testing practices and contact tracing must pass through three obligatory points of passage (Callon 2007) that become articulated with this documented regulation. Drawing on actor-network theory, I will thus show how these obligatory points of passage are constructed through material-semiotic devices that make me subject to risk and regulation in different ways.

\footnotetext{
38 https://www.sminet.se/, accessed 2016.10.30. I thank a reader during my final seminar for pointing out to me that the website and logo I describe here, as well as the legislation itself, have been updated since the time of my writing. As the reader pointed out, this effectively renders my account a contemporary history of Swedish HIV governance - a term which I rather like I must say.
} 
The document itself contains no less and no more than 155 lines of text that provide the patient with some facts about their new condition in both medical and legal senses. In the following analysis, I have performed a close reading of this document, and have related it to further conversations that I took up with a variety of professionals in the biomedical domain. I have summarised the contents of this document into the following three obligations. My analysis shows how these three obligations provide the patient with a medico-legal script that both proscribes (e.g. specifics what the subject must not do) and prescribes (e.g. outlines what the subject must do) the subject in particular ways, thus shaping the newfound subjectivity of a person living with Swedish HIV. I will thus show not only how the document performs a medico-legal script, but moreover how this script comes to play a political role in its own right. The script that governs the subject of Swedish HIV does so through three obligations. These obligations are furthermore situated in sites of risk. In other words, the document provides an account of the situations in which the 'policing' obligations must be followed:

\subsubsection{The obligation of status disclosure}

A first obligation that is given to someone who tests positive for Swedish HIV is that of disclosure. In this document, HIV attains the status of a 'public health hazard'. Along with this classification comes the duty to 'protect other people from the risk of infection'. In a rather reflexive stroke, the next line again designates any situation where there is ' $a$ risk of infection' as one that obliges the HIV positive individual to inform the other person of their HIV status. However, situations that pose such a risk are then further clarified as, 'unprotected sex, either vaginal sex or anal sex, and sometimes oral sex'. While the form of 'protection' remains unspecified in this statement, the implicit assumption is that sexual fluids may carry HIV, and thus present a risk. But the document does specify another fluid site of risk: blood. While much time has passed since the start of the 1900s when viruses were known as "contagium vivum fluidum"39 (contagious living fluid), the politics of HIV in Sweden show that this image is still alive and well today. The document first calls attention to 'blood transfusion' or the use of 'syringes or other injecting equipment' as sites of risk. It then points to the risk in situations when, 'blood containing HIV comes into contact with mucous membranes in the eyes, nose or mouth, or with a wound'. This document plays its role with an affective and moral force. The bold letters that display the heading 'Blood must always be handled as infectious' are not easily forgotten, even when the document itself may be..$^{40}$

The document also clarifies those situations in which there is no risk of transmission. These include 'hugging, kissing or cuddling'. It further states that, 'tears, urine, faeces, vomit

\footnotetext{
39 https://en.wikipedia.org/wiki/Martinus_Beijerinck, accessed 2020.04.07

${ }^{40}$ I first really remember reading this document on the train while preparing to start my anti-retroviral regimen during the week proceeding my diagnosis. I also remember being overwhelmed and throwing it out after reading it on this train, which perhaps says more about the patient I was than I would like. While I had read my formal rights, responsibilities and obligations in this document, I had not been able to fully digest them at that time. It took further conversations with Swedish friends and colleagues to fully understand my concerningly real legal status.
} 
and catarrh containing no blood are not infectious' and that 'blood coming into contact with undamaged skin does not present a risk of infection'. As a complement to these situations that present a risk of infection, the document points out several non-sexual situations that call for the explicit disclosure of one's HIV status. This includes the notification of HIV status to school healthcare services in the event of an HIV infected child. It also includes situations where people may be put at risk by contact with the patients' blood. The patient should disclose their HIV status when anyone else, 'gets your blood in their eyes, nose or mouth', to those encountered when 'you seek dental or medical care where personnel may come into contact with your blood', and before the procedure of getting 'a tattoo, to have your ears pierced or have any other treatment involving the use of sharp tools and where bleeding may occur, e.g. body piercing'. These specificities clearly show the "transformation in embodiment" (Martin 1992:132) that is enacted by this document. The subject reading this document after receiving a positive diagnosis will come to relate to their body quite differently than before. Here the HIV infected body is enacted as a leaky device of containment for what are pictured as volatile fluids that may spill out and infect what is imagined to be a pure and innocent social body. What is more, these relations will not only play out privately, but through this documented mode of governing the subject, protection for the Swedish state and its social body becomes institutionalised and policed. One of the ways Swedish HIV treatment thus plays out, is through this first obligatory point of passage: the obligation of status disclosure. The final situation in which disclosure is mandated is presented by the document as follows:

"You must inform your sexual partner that you are infected with HIV before sexual contact which presents a risk of transmission of HIV. There is a risk of such infection during all types of oral, vaginal and anal sex. As condoms can break, you must disclose your HIV status even if you are planning to use condoms."

While the document does contain one sentence that informs the patient that these rules, 'may change over time', I was not initially informed by my doctor or any other healthcare professionals as to when they would change or under what conditions. Apparently, this is quite a common situation for the patient undergoing Swedish HIV treatment. A recent study published by Folkhälsomyndigheten (2018) evaluated doctors and patients in their overall application of the codes of conduct enacted by Smittskyddlägan, the aforementioned Swedish law governing Swedish HIV.

"The majority of respondents living with HIV (84 per cent) perceived that they had not been given rules of conduct by their treating physician, 9 per cent perceived that they had, and 7 per cent answered that they did not know. (...) Among the respondents living with HIV, four out of ten stated that they received no support in how to talk about HIV with a sex partner." 41

\footnotetext{
${ }^{41}$ https://www.folkhalsomyndigheten.se/contentassets/d743f8d73c544980bfd5bdafc1e320a7/tillampningsmittskyddslagen-forhallningsregler-hivinfektion-18015-webb.pdf, accessed 2020.04.07
} 
This study furthermore mentions, "the importance of medical records, including individually formatted rules of conduct, and including exemptions from the obligation to inform sex partners" as a way of providing this support. In chapter 6, I will provide an alternative evaluation of the individual and collective care that I was given in becoming 'well-treated'. For now, I want to stick to outlining the obligations given to subjects undergoing Swedish HIV treatment.

As it turns out, this document I have been describing is not quite 'one document' and neither is it 'many'. There are a few distinct versions of this document that I have come to encounter throughout the events I experienced. First, there is the 'patient-information' document I showed in figure 4, a document I received upon my diagnosis in 2016. But in 2019, a change was made to Swedish HIV treatment policy, and this change came along with a new document that I have shown in figure 6 (left). Upon hearing about this change from colleagues working with HIV, I also came to find a third document (figure 6, right) that provides 'doctor-information' and guidelines for conducting and managing the obligations of patients.
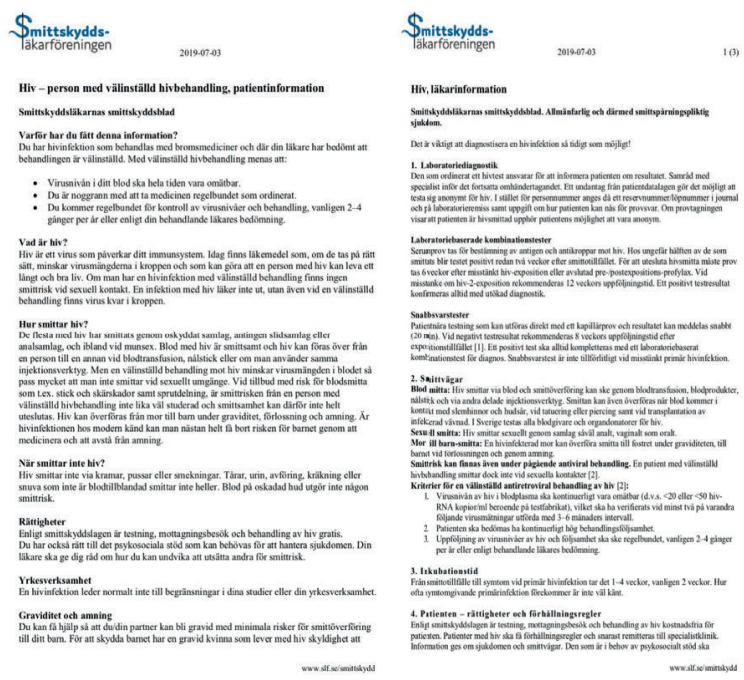

Figure 6: well-treated-patient (left) and doctor (right) information documents

What becomes notable through this new material is a feature of Swedish HIV treatment that becomes outlined by these documents. With the 'well-treated' document comes along a change in the disclosure obligation for the patient. That is, once a patient is deemed 'well-treated' by their physician, they may be allowed exemption from their disclosure obligation during sexual activity. 'Well-treated' and 'unwell-treated' subjects are handled differently in Swedish HIV treatment practices and by their medico-legal professionals. As the 'unwell' subject that had just received an HIV positive diagnosis, I would not come to fully grasp my legal status immediately, but it would be through my research practice that I would come to learn more. Having undergone a year of treatment and successful viral suppression (more on 
this later), I was surprised to hear one day from my doctor about a change in my disclosure obligation.

Dr. Elin: And if you come to take the blood tests, and it looks good, and you don't have any other genital diseases, and you come to all your appointments, and I have a feeling I can trust you - which I have - then, when it looks like this, you don't have to inform a partner that you are HIV positive.

Jeffrey: oh really?

Dr. Elin: But, according to the law, you have to wear a condom.

Jeffrey: yeah, yeah ok.

Dr. Elin: but you don't have to inform.

Jeffrey: did that change or something?

Dr. Elin: yes, its changed. The change came about two years ago, but before I can say...it's...I have to decide that you don't have to inform, it's my responsibility.

Here, my doctor takes responsibility for my legal obligation to speak about my condition. The document in figure 6, empowered by Smittskyddlägan, prescribes this role for my clinician. If I come to take my blood tests, if they look good, if I wear condoms during sex, if I am free from other STIs, if I come to all my appointments, if my doctor has a feeling she can trust me, then she can change my legal obligation. I will again be granted the same rights as everyone else and can choose to talk or not talk about, to disclose my HIV status at my own discretion. While individuals may come to govern themselves, they do not do so alone, and the governing individual is manifold to begin with. In the case of Swedish HIV, the patient is formally, legally, morally, and medically governed by their physician. This shows how responsibility may be fluidly shared and it may be rigidly distributed at the same time. I wanted to find out how other Swedish doctors handled this responsibility, so I got into touch with an infectious diseases specialist named Olle working in the same hospital. In discussing this Swedish strategy of medico-legal containment with Olle it was described for me in the following way:

Olle: We have a national guideline for the treatment of HIV patients, and in that guideline, not only do they recommend what should be the first line of treatment, etc. etc, they also recommend how often you should do for example the blood sample checkups and what types of tests should perform, how often. Then we just follow that guideline basically.

Here we see how the complexity of diagnostic practices gets attributed to the national guidelines for the care and control of Swedish HIV. The national guideline prescribes Swedish HIV treatment as a protocol or set of steps to follow in order to achieve 'best practice'. This prescription is enacted by the 'doctor-information' document I pointed out earlier in figure 6 (right). This provides doctors with a way of going about diagnostic work through the formal articulation of a path to follow. Formalisms are not, of course, always a bad thing. Diagnostic work needs both some solidity and some fluidity to work well (van Loon, Zuider- 
ent-Jerak \& Bal 2014; Zuiderent-Jerak 2015). But things get more complicated when this $d i$ agnostic normativity becomes juxtaposed with a legal normativity.

Olle: HIV is one of the infectious diseases that falls under a special infection law - Smittskyddlägan, the law for contagious diseases - and then its quite a specific concern in the regulations. If you're HIV positive, you have to abide certain regulations and those are compulsory basically. So it's not for me to decide, except for one that has been changed in the past three years or something. And that's the rule concerning revealing your HIV status prior to having sexual intercourse, some sort of sexual contact. It used to be compulsory all the time, but now we could remove that given the patient fulfils certain criteria. But that is the only part that I have any kind of influence upon. All the other others are just obligatory.

So in Sweden, the care and treatment of HIV and the patients living with it is not only prescribed by diagnostic protocols, but also proscribed by the law. This shows how the documents I have presented in figures 4 and 6 govern not only patients, but also doctors. Through this policing script, the patients and doctors become formally allowed to be and do some things and not others. Patient subjectivity is furthermore scripted with a marked boundary that is both medical and legal. What is particular here in Sweden, is that the medical figure of 'the doctor' has become authorised to make a decision about the legal responsibility of 'the patient'. What becomes an obligatory point of passage for the patient - the medical-legal obligations governed and distributed by the doctor - become the only 'non obligatory' moment in diagnostic work. All the other medical and legal choices are already prescribed by legislation. Asking this same doctor what he thought about this change in the legislation and the responsibility it gives to Swedish HIV care professionals, I was given the following answer:

Olle: I think it's about time that they made that change. Our instructions are basically that we should discuss this with our patients and we should remove them [the legal obligation of status disclosure to partners] given they fulfil the criteria, so for me it's just part of the job basically. It's like, ok there is another checklist. And I guess for the patients it means a lot. Personally I think it is a good thing.

Here, the difference between 'what is good for the doctor' is also acknowledged as different from 'what is good for the patient'. This disclosure obligation today is thus a complex matter. Because it is strongly tied to the risk of infection, the disclosure obligation becomes the express domain of the HIV specialist who handles the care of patients affected by HIV. But due to the effective treatment now available, and strict adherence I underwent, my own blood was virally undetectable, that is, I was no longer biologically able to infect someone after only three weeks proceeding my diagnosis. So why was I only granted exemption from this disclosure obligation a year later? This is because the 'doctor-information' document outlines the conditions through which the patient may become known as the subject 
'well-treated'. These are listed in the doctor-document (figure 6) as follows (translated from Swedish):

1. The virus level of HIV in blood plasma should be continuously undetectable (i.e. $<20$ or $<50$ HIV RNA copies/ml depending on testing device), which must have been verified by at least two successive viral measurements performed at 3-6 month intervals.

2. The patient should be judged to have continuously high treatment adherence.

3. Follow-up of viral levels of HIV and compliance should be done regularly, usually 2-4 times per year or according to the treating physician's assessment.

The first of these conditions shows the criteria for the evaluation of a successful treatment. The patient subject must be shown to become the "undetectable subject" by demonstrating a good anti-retroviral adherence evaluated by laboratory testing devices as I will show in the following chapter. The second condition involves both a medical judgement and a 'feel' for the patient as I showed in my own example. Through this condition, the patient must be shown to be a "safe" subject. The third and final condition is even more complex. It involves the 'follow-up' of laboratory testing as does condition one, but also the 'follow-up' of compliance; these follow-ups must be performed regularly. The patient must demonstrate a full compliance with their doctors' orders to achieve the status of 'well treated' and receive exemption from their disclosure obligation. In my case, compliance with treatment protocol meant condom compliance confirmed by regular STI testing. In this case, the patient must become the "clean" subject. The disclosure obligation therefore enacts a difference between 'well-treated' subjects and subjects becoming 'unwell-treated' by proxy; not only in a biomedical sense, but also in a formal and, importantly, legal sense. Becoming a 'well-treated' subject means becoming "undetectable", "safe", and "clean"; these are not only rhetorical devices, but devices that identify me as a responsible and accountable subject - a good patient. Discussing this disclosure obligation with Arvid, an agent of disease-control at the Swedish Public Health Agency, I came to find that this ambiguous disclosure obligation is taken to be relatively unproblematic matter by some Swedish healthcare professionals:

Arvid: once you are on the proper treatment, the obligation doesn't exist anymore. And I mean, there has always been a reasonably high acceptance of it in Sweden because people don't want to infect each other.

Here we see how Arvid attributes the acceptance of this disclosure obligation and its management not only to professionals, but also to patients. What we also see here again is that 'proper treatment' comes to condition the disclosure obligation, but the practicalities of this treatment for the patient may become bracketed in order to attribute a high acceptance of the juxtaposed legal and medical obligations to a 'Swedish' cultural attitude towards the health of others. Here, Swedish HIV becomes particular through the particularities of its 'treatment'. By saying that the obligation does not exist under the condition of proper treatment, it also frames 'good treatment' as something that automatically changes obligations 
without the active role of the doctor in evaluating the subject as 'well-treated' or not. In practice, it is the doctor that informs the patient as to their medico-legal rights, obligations, and responsibilities and provides them with the documents that articulate these - or fails to in the worst of cases.

\subsubsection{The obligation of adherence to anti-retroviral therapy}

A second obligation in this policing script is adherence. Adherence to antiretroviral therapy, more commonly known as 'ART', is generally seen as the crux of HIV care, and not only in Sweden. In the previous section I showed that the disclosure obligation is further conditioned by adherence and compliance. I also showed how the 'governing script' is different for doctors and patients; individual responsibilities are distributed in practice. There are treatment guidelines for doctors to follow and there are treatment protocols for patients to follow. Both prescribe specific codes of conduct and both are documents that govern in different ways. In this section, I want to look closer at the second obligatory condition for 'good' Swedish HIV treatment - adherence to anti-retroviral therapy. Figure 7 shows how anti-retroviral drugs become a powerful actor, the star of the fast-track assemblage.

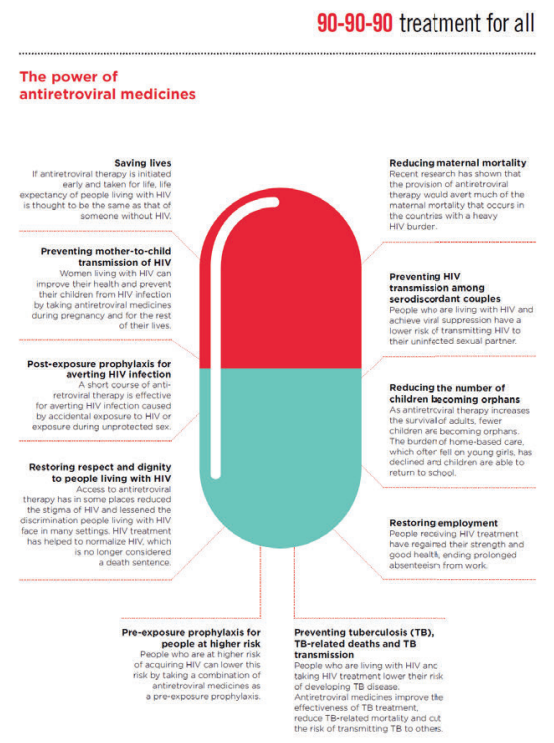

Figure 7: the 'magic bullet' image of anti-retroviral adherence ${ }^{42}$

While the person who tests positive for HIV in Sweden is not legally obliged to adhere to antiretroviral therapy, should they choose not to they are legally forbidden to engage in sexual activity with other members of the Swedish population. Should they do so anyway, they may very well be isolated by their doctor with the 'helpful' enforcement of the police

\footnotetext{
42 https://www.unaids.org/en/resources/infographics/power-of-antiretroviral-medicines, accessed 2020.04.07
} 
and charged with the criminal code. ${ }^{43}$ In this sense, while anti-retroviral adherence is not a legal obligation in itself, it forms the medical foundation for other rights and responsibilities.

Categorically speaking, anti-retrovirals (ART) do, in fact, include the drugs used as PrEP in HIV prevention, but more generally these chemoprophylactics refer to the kind of drugs taken by those marked as 'HIV positive' to avoid the multiplicity of diseases collectively known as 'AIDS'. Even after years of clinical trials, there has never been found a single case where a person living with HIV has attained the status of 'undetectable' through the socalled 'highly active anti-retroviral treatments' (HAART) that emerged in the late 90's and still transmitted HIV through sexual activity. This gives ART the ability to reduce the risk of transmission by $99.99 \%-100 \%$ being an impossibility in a statistical sense. For the sake of clarity, I will use the term ART to refer only to the drugs taken by those with the status of 'HIV positive' to achieve the status of 'undetectable' and use 'PrEP' to refer to those drugs taken by people with the status of 'HIV negative' in order to remain so. Because of the abilities of these drugs, they are often framed as a 'magic-bullet' that is critical to combat HIV/ AIDS, and perhaps, eliminate it altogether (see figure 7).

Online health forums and medical information websites often even call these drugs 'nukes', a nickname somehow derived from the more formal name given to a primary class of these drugs: the Nucleoside Reverse Transcriptase Inhibitors. Figure 7 also shows how agencies such as UNAIDS ascribe powerful abilities to these medications and place a great value on their role in the 90-90-90 targets of the fast-track assemblage. The image shows the fast-track treatment targets in the top right corner along with a slogan: "treatment for all". As a patient I can affirm that I believe in what this message stands for and that I am all for the sense of universal treatment coverage it conveys. As a praxiographer, I also find it very interesting to see the caption of the image: "the power of antiretroviral medicines". This figure shows how pharmacological power is not only said to save the lives of people living with HIV, of preventing sexual transmission or transmission through birth, and protecting the bodies of people "at higher risk", but it also shows how the effects of these drugs are more broadly acknowledged in the fast-track discourse as well. Here we see that 'pharmacopower', a term I will borrow from Paul Preciado (2013), is also said to give back dignity and respect to those affected through its ability to: "normalise HIV, which is no longer considered a death sentence". This optimistic image however, seems to be at odds with the policing of patients undergoing anti-retroviral treatment. In this image, anti-retrovirals are also said to be "restoring employment" and reducing the burden on young girls that might otherwise have to take care of their siblings after having parents pass away due to AIDS. While I do indeed believe that ART and PrEP do such things, I am interested in better understanding how they do so. What exactly is this form of power and how does it work through anti-retroviral technology?

In a vivid account of how these anti-retroviral biotechnologies come to change sexual practice, Tim Dean (2009) warns against the wholesale subscription to biomedical regimes.

\footnotetext{
${ }^{43}$ Chapter 6 will discuss a change in this possibility.
} 
He draws on the work of Preciado to produce an account of these drugs as a conduit or receptacle for a pharmaceutical power that aims to capture life and to cultivate both a psychic and a social form of control. For Dean (2015) 'pharmacopower' is said to perform a medicalisation of gay subjectivity; forms of gay sex such as 'barebacking' (a term often used to denote condomless sex in gay communities) while on PrEP are taking shape in our ${ }^{44}$ collective fantasies and desires as the result of a power that works through pornography, pharmaceuticals, and public health. He critiques what he perceives to be a rigid biomedical regime of HIV treatment and prevention and calls for some form of resistance to biotechnology.

But while I do find it important to actively resist attempts to capture and translate our 'erotic arts' (Foucault 1985:229) through the version of mediation Dean locates in pharmacopower, I do not think that this means abandoning or severing our attachments to the biopolitics of HIV, 45 to technoscience, or to ART \& PrEP, which seems to be in part what Dean desires to do throughout his work. But thinking through Preciado and Dean, I nonetheless come to see how pharmacopower is performative of a biopolitical subject, one that resists and embraces this power simultaneously. However, I wondered to what extent this theory would help me see other things going on in the situations I encountered. I found that other queer studies do things differently still.

Karsten Schubert (2019), for instance, works out a queer theory that unpacks a political ecology that anti-retroviral therapy can become situated within. While Schubert is just as interested in the subjectification ${ }^{46}$ that anti-retrovirals such as PrEP enact, the subject is understood, valued, and dealt with altogether differently from Dean. This leads Schubert to conclude that rather than being only repressive, these drugs are also productive as well: "effective not only for HIV prevention, but also for fighting homophobia and enhancing the quality of life for gays by destigmatizing gay sex" (Schubert 2019). In his account, these drugs can become a valuable way of reframing the risk of HIV infection in vulnerable communities. Moreover, the value of these drugs is also understood in this analysis as reaching beyond the biomedical. For Schubert, anti-retroviral therapy and PrEP are foremost political technologies that bear import for the changes they bring about to gay subjectivity.

\footnotetext{
${ }^{44}$ I use the collective 'we' and 'our' at times to situate myself as part of gay and queer communities, as well as with communities of people living and working with HIV.

45 Which, as I'm sure Dean would agree, is in any case impossible at the moment.

${ }^{46}$ Elegantly defined as, "the process through which social norms form subjects and their desires" (Schubert 2019:2).
} 
In the argument put forward by Schubert: "homophobia and homonormativity47 haunts gay sex even in liberal environments, and [these drugs] can serve as an entry point for the destigmatisation of gay sexuality and transformation of gay subjectivity" (Schubert 2019:1). While gay subjectivity is of particular concern to Schubert, I think these considerations have import for many other people affected by HIV as well. With these points in mind, I believe that Preciado, Dean, and Schubert rightfully describe PrEP as a new form of power that relies less on the change of sexual behaviours, as does the use of the condom, but more towards a dependency upon pharmaceutical agency. But in what sense are these biopolitical subjects 'desirable' or 'good'? By exploring my experiences in passing through these obligatory passage points of Swedish HIV treatment in chapter 6, I will address these questions more extensively. However, right now I want to focus on the other obligations that come along with status disclosure and adherence to anti-retroviral therapy as legally prescribed by the Swedish state. I want to investigate what these obligations collectively do to the subject.

For this I find work stemming from the Canadian HIV context to be particularly helpful: "Considered as a technology rather than a concept, adherence groups together a host of strategies designed to cultivate a particular relation of self to treatment" (Mykhalovskiy \& Namaste et al. 2019:318). In this sense, the obligation of anti-retroviral adherence is a technique for regulating my anti-retroviral conduct. As I will continue showing in chapter 6 , becoming dependant on drugs through the obligation of adherence has first and foremost a generative effect in subject-making. Only when specific interferences occur can 'adherence' be said to come in conflict with the selfhood of the patient ${ }^{48}$. Only then does dependency become a restraining force. Tension such as this can be shown with the next and final obligation: compliance.

\subsubsection{The obligation of compliance with treatment protocol}

A third and final obligation of this documented script I describe, together with my interlocutors, as compliance. Compliance may include a variety of stipulations by healthcare providers. For example, the 'unwell-treated-patient-information' document from figure 4 states that the HIV positive individual, 'must not share personal care items such as razors or

\footnotetext{
47 While queer theory has long since recognised 'heteronormativity', what Schubert calls 'homonormativity' is a little different still: "Homonormativity also constitutes a difference between 'good' and 'bad' gays and thereby leads to new forms of (internalised) homophobia (...) It is ok now to be gay, but only if you are a 'good gay'. If one lives a normalized, bourgeois and successful life, a life of homonormativity which follows heteronormative rules, gayness does not matter (...) But this acceptance comes at the price of a new exclusion. Trans* and gender non-conforming people, queers of color, and gay men who engage in different sex than with one stable partner in a long-term romantic relationship are excluded from this homonormativity (...) While guilt is not assigned anymore for being homosexual, it is even more assigned for engaging in non-normative and 'irresponsible' sex. Therefore, gay sex is constituted around an economics of guilt which stems from the liberal and homonormative refinement of homophobia, of which condoms are an essential part." (Schubert 2019:12-14)

48 While I have come across people living with HIV who have chosen to reject anti-retroviral therapy, this subject remains out of the immediate scope of my project. Their reasons for doing so and the effects of this decision in their lives seems perhaps a worthy topic for further care in its own right.
} 
toothbrushes with other people'. Furthermore, they must not, 'donate blood, organs or tissue for transplantation'. In this sense, while adherence to anti-retroviral treatment establishes the proper relation between the patient and their own body, compliance articulates the relation between the patient and the Swedish 'body' or population more specifically. The patient must not put the Swedish body at risk. The person living with HIV in Sweden must choose to act with discretion. The patient must comply with measures to contain Swedish HIV within their own body in circulation with treatment practices; in so doing, they may become the regulated subject, that is granted legal rights to healthcare and protection. But if they do not comply with treatment protocol or the codes of conduct articulated by this document, they may well be enacted as the criminalised subject. So this document proscribes or constrains the subject as well. None of these obligations however, are prescriptive or proscriptive alone. One of the paragraphs in this first document contained a heading with the text, 'Condoms for vaginal sex, anal sex and oral sex'. This begins with the following statement:

"Condoms provide good protection against HIV and other sexually transmitted diseases and must always be worn throughout the entire sex session. It is probable that female condoms also work, but this method has not been evaluated scientifically. In the case of stable treatment, condoms must still be worn during anal and/or vaginal sex so as to reduce the risk of passing on HIV as much as possible."

Interestingly, the degree or intensity of this 'condom power' is said to differ between 'female condoms' and their ungendered counterpart in this example. Condoms seem to be caught up in sexual politics in this sense as well. These prescriptions also become gravely serious when considering the possible consequences of failing to meet these requirements. This obligation of compliance is more complicated than it might first appear. While condom compliance was mandated by my treatment protocol, it was not the only part of the compliance obligation. My conversations with a laboratory professional named Astrid, in which I tried to stay as neutral as possible, allow me to show how this forceful mode of governance enacted by the policing script affects not only the feelings of patients and professionals in different ways, but also as a kind of power discussed on the radio and featuring on the news.

\footnotetext{
Astrid: I was actually listening to a radio program while I was driving. The legislation in Sweden about like, contagious diseases, it's really strong!

Jeffrey: yeah, it is...

Astrid: and it's very weird that you can, that actually a police can come and drag you to the hospital, and force you...ah its...

Jeffrey: yeah it's interesting.

Astrid: ah it's...feels like the nineteen-hundreds.
}

This encounter surfaced for me the rather strict form of 'policing' that is legally enforced in Sweden, one that may even be imposed upon the patient against their will. In 2004, the Swedish court saw the case of a man who had been diagnosed as positive in 1996. He was 
charged with having had 'unprotected' sex with eight men, seven of whom he had not disclosed his status to. Not considering himself to have posed a risk of infection due to his undetectable viral load, he was nevertheless found guilty and charged with reckless endangerment for not using condoms during sex. Not a year later, the European Court of Human Rights declared that Sweden had violated the right to liberty and security in the European Convention on Human Rights (Article 5 section 1) by holding another HIV positive man for seven years in isolation in accordance with the abilities afforded by Smittskyddlägan. Looking into the case, I found that he had been deemed a risk to others on the grounds of his alcohol dependency. There was even a testimony from a psychiatric professional:

"Having learnt that he was HIV-positive, the applicant reacted with a high level of anxiety, which he attempted to alleviate with alcohol. He has maintained that he drinks three strong beers at night in order to be able to sleep."49

What is also interesting about this case, is that sleep disorders are now recognised as a side-effect of anti-retroviral medication. Perhaps in this case then, the prosecution might even be said to have come about from this patient 'self-treating' the symptoms of his official HIV treatment. In any case, this patient was prosecuted, and isolated against his will for failing to comply with the coded obligation of condom use. A 2018 study of Swedish HIV treatment even found that, "many physicians responded that they regularly reminded their HIV patients about condom use, but it was less commonly reported to have given practical advice about condom use." 50 While the stories I have come across in my research often frame the individual as responsible for following protocol and/or failing to, it is less clear how these people were given 'practical advice' on how exactly to do so. While the exact number of cases is hard to pin down, in 2012 there was estimated to be more than 50 cases of criminal prosecution in Sweden using the criminal law or penal code, not including the over 100 cases where people had been isolated forcibly in accordance with Smittskyddlägan. This makes Sweden a global leader for prosecuting people living with HIV.

Discussing this issue further with the Swedish Public Health Agency, I was told that this situation was about to change due to a court case that would establish a new precedent. If it went well (which it did), then the criminal code would no longer apply to people who have a 'well treated' HIV infection. This would diminish the problem he said, because almost everybody in Sweden is said to have a well-treated HIV infection. This pending change would be contingent on the case ${ }^{51}$ in the supreme court that was then ongoing. At the time of my research, this case and its implications were simmering in the thoughts of my informants.

\footnotetext{
49 https://www.globalhealthrights.org/wp-content/uploads/2014/04/Enhorn-v.-Sweden.pdf, accessed 2020.04.07

50 https://www.folkhalsomyndigheten.se/contentassets/d743f8d73c544980bfd5bdafc1e320a7/tillampningsmittskyddslagen-forhallningsregler-hivinfektion-18015-webb.pdf, accessed 2020.04.07

51 http://www.hogstadomstolen.se/Om-Hogsta-domstolen/Nyheter-fran-Hogsta-domstolen/Hivsmittad-medvalinstalld-hivbehandling-frias-efter-oskyddade-samlag/, accessed 2018.10.25
} 
Arvid: It was a person who was prosecuted for having had sex with his partner while being HIV positive. The person was under treatment and was well treated and so on, so it was not a problem. And he was then charged by his partner and taken to court, and he was free in the first two instances of the court system in Sweden, and now taken to the supreme court to get sort of a final decision on how these kinds of cases in general should be handled. And that court hearing was two weeks ago, and now we are waiting for the response on that court hearing. And if this person is still not charged, then that will be a signal to the court system not to prosecute people anymore for having sex while being HIV positive. As long as they have proper treatment.

What I found most interesting about this story, and many others like it, is how it is the partners of those living with HIV that come to charge them. While the Swedish criminal code provides the means, it seems to be most often these partners that put the law into motion, that mobilise the law in these very cases of criminal prosecution. A few weeks after talking with this public health authority however, I was relieved to hear that the supreme court ruled in favour of the positive person. This means that the jurisdiction is now in place that should enable the possibility of legal care for people living with HIV. But importantly, this affects little the argument that I put forward in this chapter: that the assemblage of documents I present in this chapter, as a juxtaposition of medical and legal power, enact the 'well-treated' subject of regulation at the expense of the 'unwell-treated' subject who remains at risk through this policing script, even after this important legal change. While the biomedical devices of healthcare provide a diagnostic result, legislation and disease-control delineate their consequences and deliver their implications. Through these documents and the rendering of the subject enacted by this policing script and its obligations, care for the patient becomes folded apart from control of the HIV.

With this story I have thus shown how these documented practices of policing the subject come to enact accountability for Swedish HIV as a tension between protection and prosecution through their juxtaposition in these documents. This 'risky boundary' between bodies that is policed is not only a metaphorical figure that is experienced symbolically, but material as well; it is a material-semiotic boundary that is policed in various ways. RFSL, the agency once made by and for 'the homosexual', now states boldly on their website that:

"The best way to avoid HIV being transmitted is to use condoms when having intercourse, not let your mouth come in contact with sperm, and not share needles." 52

This shows how condoms are the political and practical measure that RFSL advocates to protect against HIV. I would later come to see through other events how condoms are val-

\footnotetext{
52 https://www.rfsl.se/en/organisation/health-sexuality-and-hiv/hiv/, accessed 2020.04.07
} 
ued as the only visible form of "safe"53 sex in Sweden. ${ }^{54}$ In the following section, we find them entangled with the fast-track strategy at Saviours, a local organisation that provides the service of rapid-testing - the rapid-testing service through which I received my own diagnosis. Condoms form a material-semiotic boundary that are often staged as the only means to protect the Swedish population from those infected by HIV. In playing this role, condoms become one of the means through which difference is tolerated while boundaries are maintained. As I have discussed, blood and sperm become 'risky' fluids that become policed with the specific measures I have documented in order to keep HIV circulating only within the infected body, the infection clinic, and regulated laboratories. The historicity of Swedish disease containment and its 'policing' measures sensitises my account to the way these distributions of responsibility mark HIV and certain forms of sexual intimacy as subject to risk. Once again, RFSL stages the relation between HIV and sexual conduct as a matter of accountability that requires the valuing of protection between (and also for) 'self' and 'other'. As in the case of the sauna club-law, the lecherous subject becomes further detached from collective bodies through the formalisation and policing of subjects deemed 'risky'.

\subsection{Conclusion}

As a physical object, these documents are rather ordinary and unimpressive. But the material-semiotic activity they perform make them also a peculiar set of objects that impresses themselves strongly on their readers. These documents play a critical role in linking those suspected of carrying HIV to testing practices and of proscribing and prescribing the conduct of people living with HIV in Sweden. The legal proscription and prescription of accountability and simultaneous translation/treason (Galis \& Lee 2014:4) of the subject allows for a governance practice that can control the spread of HIV infection quite successfully, but it does so at the expense of those living with HIV. What becomes most vivid in this account is the way that practices of health-care, practices that should be concerned with protecting the subject affected by HIV, become authorised as legal agents of disease-control. In effect, doctors become given the responsibility to proscribe and prescribe the measures of health-care and disease-control in the everyday life of the patient and to modify patient conduct through these codes and measures - measures of policing the subject unwell. Due to the particularity of this juxtaposition of medical power and legal power, I found this an informative and empirical case to unpack the governing framework that accounts for this policing of the subject.

Through this script of policing Swedish HIV and the subjects affected by it, these documents become actors in the prevention and containment of Swedish HIV. The script they embody works to relay a program of action from the Swedish Public Health agency and the

\footnotetext{
53 I use scare quotes here to signal my faithful treason to this chosen concept. In other words, I believe that "safe" sex can be practiced in many more ways than are made possible by the Swedish governance of HIV, as can also be said of practices wherein the subject becomes "clean". The multiplicity of the "undetectable" subject, however, is something I find important to explore further in the following chapter.

${ }^{54}$ Chapter 6 will also show how condoms are recognised as the only real form of protection by Swedish STI clinics.
} 
Medical Society for Infectious Disease. As the queer STS scholar, Kane Race (2017) describes, devices such as this document perform HIV-positive people, the rest of the population, and HIV transmission risks in particular ways:

"This framing of responsibility enacts the HIV-negative individual as an ill-equipped or unsuspecting sexual actor (...) HIV-positive people are framed as the primary agents capable of transmitting HIV-or preventing infection-while HIV-negative and untested individuals are dissuaded from testing or sustained, somewhat impracticably, in the "practical belief" that the law will protect them and/or that HIV-positive sexual partners will automatically disclose their status. From a certain perspective, this operation of the law might be understood as an instance of effective performativity, in the sense that the law does what it says: It renders HIV-positive individuals responsible for HIV transmission." (Race 2017:116)

This chapter has thus shown how matters of accountability are enacted by the treatment of patients becoming-accountable through diagnosis and documentation. I discussed three important conditions that emerged from this documentation and in this way analysed the legal obligations involved in the care and control of Swedish HIV - namely, status disclosure, anti-retroviral adherence, and compliance with treatment protocol. Through my analysis of the relations between a manifold of documents, conversations, and experiences, I have thus far shown how the subject living with HIV is treated in Sweden. As devices that communicate and delineate the duties that a newly diagnosed HIV positive patient must follow, the documents I have analysed were shown to proscribe and prescribe the legal responsibilities of the subject living with HIV in Sweden. While doing so, they enact the subject becoming well-treated and the subject becoming treated-unwell. While those 'unwell' become subject to risk and may become criminalised and policed through this documented practice, the subject deemed 'well-treated' becomes protected by the Swedish state and its medico-legal agents. It is in this way that accountability for HIV is formally prescribed and proscribed in Sweden. This very practice of juxtaposition is what enacts the subject of risk and the subject of regulation simultaneously. But importantly, the accountability relations I have been describing, no matter how repressive or otherwise they may be perceived, depend upon the productive capacity of diagnostic technologies - including but not limited to, self-testing devices that pose a challenge to the regulated system of governance. In other words, governing devices that come to operate through repressive measures are nonetheless dependent upon their possibility to generate a difference in subjects at all.

This difference can be seen through the careful analysis of the assemblage of materials I have accounted for. In clinical practices where the patient attends general STI checkups and HIV specific checkups the medical rights and legal obligations cause a tension running deep between care and control. On the one hand, 'the subject' is the patient that is given care and who receives care that is distinct from or different to the care given to the general population. On the other hand, 'the object' is the HIV that must be controlled in the body of the patient and the body of the population. In other words, Swedish HIV is not an imaginary entity or metaphor, it is a particular kind of material-semiotic subject that becomes realised through 
a flicker between the 'human' and the 'nonhuman'. The next chapter will now follow this flaming subject into the health-care practices that accomplish the treatment targets of the fasttrack assemblage. This will allow me to demonstrate how 'knowing your status' is accomplished in Sweden and will allow me to describe a different set of subjects than those enacted by the policing script. This allows me to develop my account of governing the manifold subject otherwise. 


\section{iv // Detecting the undetectables}

\subsection{Introduction}

In the previous chapter, I mapped and unpacked a set of documents involved in the governance of Swedish HIV. By describing the accountabilities enacted and variously distributed to doctors, patients, and testing devices in these documents, I showed how they are differentially performative of the well-treated subject and the unwell-treated subject. Through the juxtaposition of medical and legal powers enacted by Smittskyddlägan, the Swedish law governing Swedish HIV treatment, I argued that a legal mode of policing takes place. As a consequence of this policing, the subject is enacted through a tension; those marked as 'welltreated' become subject to protection at the expense of those 'unwell' subjects who are still undergoing tests and treatment, those who become subject to prosecution. However, I also closed the chapter by pointing out how this repressive treatment of 'nonhuman' Swedish HIV and the 'human' subjects affected by it is dependent on the productive ability of diagnostic practices to begin with. In this chapter, I will now take the discovery of my personal serostatus as an entry point to describe these diagnostic practices of HIV testing as an assemblage of devices that make an HIV status seeable and speakable as personal-realities-in-the-making.

My argument in this chapter is twofold. To start with, I describe how 'knowing one's HIV status' - the first of the three '90s' in the fast-track assemblage - is not only a powerful accomplishment of the biomedical disciplines and devices that perform diagnostic work, but also that 'knowing your status' depends on the work of rendering (Lynch 1985) a biomedical status as an observable and reportable reality that may be inscribed into more durable materials (Latour \& Woolgar 2013; Latour 1984; Law 1992) - including the patient body. In other words, not only do these diagnostic practices allow for the possibility of 'seeing' an HIV status, but they socially, materially, and simultaneously render HIV and the people who live with it as accountable agents engaged in permanent interlocution. Here I am interested in the materialisation and performativity of an HIV status as a biomedical, social, and personal reality. My analysis shows how my HIV status can thus be understood as an 'immutable mobile' a fact that stays the same while it moves with the subject to whom it applies.

However, in the following section I nuance my argument by showing how, rather than being merely a singular apparatus, a united assemblage that inscribes clear roles and actions in a deterministic and unchanging way, Swedish HIV care instead involves a more precarious arrangement of multiple testing devices that recursively enact the very reality of what an HIV status can be said to consist of. In the second part of this chapter, I thus describe a few more diagnostic settings to illustrate the multiplicity of inscription devices that differentially make accountable diagnostic values. This turn allows me to decompose my own account of the testing subject, enabling me to describe how each testing device enacts a different mode of knowing and enacting the subject of HIV along with a different 'politics of enumeration' (Verran 2001). I will thus show how each of these diagnostic enumeration devices enacts a different kind of 'undetectable' subject under different conditions; under some conditions the undetectable subject becomes desirable, but under different conditions this subject can become 
avoided, neglected, and ignored. My analysis shows how the ongoing enumeration of my antibody/antigen values, my HIV-1 RNA values, and my cd4 values each comes along with a different way of becoming accountable to, with, and for HIV. In practice, each diagnostic device come along with and performs a different philosophy, a different mode of enumerating and ordering their material-semiotic accounts, and thus a different mode of world-making. That is, I show how these are not 'just' epistemic devices of knowing, but they are moreover ontological devices of knowing and enacting the diagnostic subject. As I will come to show, the ontology of the subject, its reality, is enacted differently in each device. I thus find this subject of multiplicity an important one to investigate; this chapter will tease apart the differences in detecting multiple undetectables.

In contrast to the 'front stage success' presented by Swedish Public Health, this chapter takes a closer look at the 'back stage mess' that diagnostic practices deal with by attending to the accomplishment and handling of my ongoing HIV tests. In studying these diagnostic practices, I investigate the multiplicity of HIV testing to show how each of these devices comes to draw a different line of subjectification with different accountability relations. Instead of producing an immutable subject, I therefore show how these measures come to enact a manifold subject. That is, a subject folding in multiple ways through various material-semiotic devices.

\subsection{The self-testing device as a matter for concern for disease control}

One would think that locating 'healthcare' within the borders of a hospital or a clinical laboratory would be common sense. These days, however, the boundaries of health-care are far more porous. Today you can walk into a drugstore and buy a 'self-testing' device for HIV, or you may order one online and perform the test at home by yourself, with a friend, or with a family member. This poses a complication for the standards of the Swedish health-care system. To understand these testing concerns, I contacted the Swedish Public Health Agency, Folkhälsomyndigheten, and had a conversation with the head of their operations. When talking with Arvid, my informant from Folkhälsomyndigheten, I was introduced to the problems of self-testing devices as a matter of concern (Latour 2004) for this governing body.

Arvid: what's happening is this 'self-testing' and testing outside of the healthcare system, with these kinds of different self tests that are sold more and more. I think they are the most recent challenge to the system you could say.

Jeffrey: ok, and how is that a challenge?

Arvid: because otherwise we have a very sort of strong legal structure around HIV, and reporting of HIV positivity. I mean, if a laboratory finds a person that is positive for HIV they are made to report him or her to the authorities and so on. And those kinds of things we are struggling a bit how they should work when you get this more and more frequent testing outside of the healthcare system. Because these kinds of rules and regulations, they are very much connected to the health system. And actually it is the health system that are obliged to do it, not the individual. 
For Arvid, self-testing devices become an issue for the standardised reporting of Swedish HIV diagnoses. What we also see here is how the boundaries of 'the healthcare system' become drawn quite distinctly by this governing body. In the current system of Swedish HIV governance, it is said to be the hospital laboratory who comes to know the status of the individual, the subject tested. When the lab comes across people who test positive for HIV, they have an obligation to report these test results to the public health authorities. In this sense, the current system has changed little since the introduction of Smittskyddslagen in 1968. Smittskyddslagen classifies diseases in one of three classes: 1) contagious diseases, 2) diseases posing a danger to public health, and 3) diseases posing a danger to society. This third category contains only three diseases: Smallpox, Severe Acute Respiratory Syndrome (SARS), and Ebola virus infection. HIV infection however, is listed in the second category that calls for, "preventing the spread of the disease through measures aimed at the infected individual" 55 . All of the diseases in the second and third categories must be reported to public health authorities upon diagnosis, and even some of those in the first category of 'contagious diseases'. Along with many of these other diseases, HIV also calls for 'contract tracing' to be performed, a practice that names and locates the individuals who have come into transmissive contact with the diagnosed individual. This practice of contract tracing then informs those individuals now deemed 'at-risk' of the need to get tested. The Swedish system of HIV treatment and its regulated form of disease-control becomes highly valued by agents such as Arvid:

Arvid: The benefits of becoming a recognised HIV positive person in Sweden are rather extensive. You receive free medical treatments and a lot of things like that. (...) Actually, we have fulfilled the 90-90-90 goals of UNAIDS and so we really believe that HIV positive people in Sweden to an extremely high degree follow the treatment protocols and so on. I think the epidemic is different in Sweden because most people are very interested in being diagnosed.

In this account of the Swedish governance of HIV, patients are highly interested in being diagnosed, they follow treatment protocols when receiving a positive result, and Sweden has fulfilled the 90-90-90 goals. Receiving free treatment is presented as a valuable 'good' by Arvid that outweighs any obstacles a patient may encounter in Swedish HIV treatment. The rules and regulations that oblige laboratories and doctors to report positive people to the authorities, combined with the strict treatment protocols for individual patients to follow, are attributed to the success of Swedish HIV care. This success is furthermore linked to the 90-90-90 targets. Everything here seems to be 'go-go-go-ing' along just fine.

In prioritising the numbered targets that can easily be calculated and measured, the last fast-track goal of 'zero discrimination' becomes a silent actor. One thing that is not mea-

\footnotetext{
55 https://www.folkhalsomyndigheten.se/the-public-health-agency-of-sweden/communicable-disease-control/ surveillance-of-communicable-diseases/notifiable-diseases/, accessed 2020.02.20
} 
sured, for example, is the number of people going out of Sweden to test for HIV. While I have heard firsthand stories from patients who have done so, to my informants in public health this action would seem strange and unfitting given the beneficial image presented above. So what could possibly make patients do so? What does it mean to be a 'recognised HIV positive person' or to 'follow a treatment protocol', as Arvid puts it? As the previous chapter tackled the latter of these questions, the former will now be what this chapter sets out to describe. To do so, I will use my own story as an example.

\subsection{Governing HIV through 'knowing your status'?}

December 1st, 2018. This is a day that has been commemorated by the UN Member States as 'World AIDS Day' since 1988. On this day, just as most others, I find myself sorting through my emails. One email in particular catches my attention today - a letter from the International AIDS Society (IAS), an organisation that was founded in same year that World AIDS Day became marked in the UN calendar. This organisation is able to state with confidence that they are, "the world's largest association of HIV professionals"56. IAS notifies me and the rest of its members through this newsletter that a, "special worlds AIDS day editori$a l$ " has been released. Through this newsletter, I become informed about "the importance of serostatus awareness in arresting the spread of HIV". Curious to hear more about this "arresting' strategy, I follow the link and read the statement that opens:

"In the Classical Era in Greece, pilgrims from throughout the Mediterranean region wended their way to the oracle at Delphi in order to learn their fate from the High Priestess, the Pythia. Ironically, engraved above the portal of the temple was the inscription "Know thyself." The underlying message was that individuals had more agency than they realized, and did not need to rely on third parties to ascertain their fate. Similarly, the foundational strategy to address the HIV epidemic is maximizing HIV serostatus awareness." (Mayer et al. 2018)

The message of this story is striking. Transported through a classically romantic style, the ethos of this inscription to 'know thyself' is contextualised in the object of 'arresting the spread of HIV'. The moral of the story frames agency as a property of individuals who, as a fundamental strategy to combat HIV, must attain knowledge of their serostatus ${ }^{57}$. They must sever their attachments to 'third parties' in this quest to know themselves. I strongly disagree on this matter, but it will take some more work to articulate my objection. In any case, this story is not just a mythological tale with a moral point. Further down the page, this story aligns itself with a cascade of references that link it up with other inscriptions (Latour 1986). The authenticity and authority of this story in fact, comes to depend oddly enough on these third party references that come attached to the story. Many of these documents are scientific

\footnotetext{
56 https://www.iasociety.org/, accessed 2020.02.20

57 'Serostatus' refers to the absence or presence of serological markers in the body, usually in blood serum. Serology, as a discipline that specialises in blood serum and other bodily fluids, is specifically concerned with immunological entities such as antibodies and antigens.
} 
articles and technical briefs, papers that often themselves contain traces that may be followed further along. This body of text is strategically organised to address the political agreements that I have been referring to as the fast-track assemblage. In the introduction to this thesis, I showed how these targets are said to have been successfully achieved in the Swedish context. So this story about 'knowing yourself' is also a rhetorical move or tactic in handling what is addressed by the fast-track assemblage as 'the HIV epidemic'. The moral point is not so much to know our 'selves', but rather to know the 'other' - HIV - through 'knowing your status'. After looking through my emails, I take a moment to browse social media and see a tweet from UNAIDS (see figure 8):

\begin{abstract}
UNAIDS @UNAIDS·1h
When you \#KnowYourStatus, you have the power to take control over your health and well-being. Find out all you need to know about HIV testing: ow.ly/hLMi50vPfPI
\end{abstract}

Figure 8: \#KnowYourStatus

Here we see how the strategy of 'knowing your status' becomes once again pivotal to the aim of taking control over your health. With this thesis, I want to ask what it would mean to take care of infectious disease instead. This tweet makes me open another window in my browser and type in the search bar: 'people living with HIV in Sweden'. The first result that is returned to me is a page from UNAIDS. ${ }^{58}$ It opens to the first of two pages labeled 'Data Stories'. While the 'Stories' page contains a series of tales applauding Sweden for its successful accomplishment of the fast-track targets and its efforts to champion HIV initiatives abroad, this first 'Data' page contains the heading: 'Country factsheets, Sweden, 2017'. As I scroll down the page, I see an item that catches my attention: "People living with HIV who know their status - 7500." 59 Why does this enumeration catch my attention? Because I recognise myself in this figure; I am one out of seven-thousand-five-hundred people living with HIV who know their status in Sweden. I am thus the subject that is accounted for within this statement. As we can see from this figure, knowing your status is considered a vital part of the fast-track assemblage that desires to end AIDS and HIV. So much so in fact, that it takes first place in the 90-90-90 targets. Let us have a look at that again: "By 2020, 90\% of all people living with HIV will know their HIV status.” (WHO / UNAIDS 2014) This is an ambitious target to be sure. But in Sweden, this is said to have already been accomplished (Gisslén et al 2017).

So this is where I want to start my personal story. As one of these 7,500 people, I can matter-of-factly say that my HIV status is 'undetectable'. This is how I know my status today. But what does that actually mean? To provide an answer, this chapter will look at an array of devices and techniques that are employed in the diagnosis of HIV in Sweden. I want to look

\footnotetext{
58 http://www.unaids.org/en/regionscountries/countries/sweden, accessed 2020.04.07

${ }^{59} \mathrm{http} / /$ www.unaids.org/en/regionscountries/countries/sweden, accessed 2020.04.07
} 
at what makes it possible to point at this statistic and to truthfully declare - by dint of sobriety and with a touch of humour as well - that this figure is my body excorporated for you, the reader. It is in this sense that my method of 'following the subject' becomes critical for addressing the fast-track assemblage - in this chapter that means the target of 'knowing your status' in particular.

Let me first start with a short diagnostic story. In the following account of rapid-testing, I recall the moment in which my HIV infection officially became known to me at an organisation called Saviours. I then will unpack this description of rapid-testing in order to show how this diagnostic practice comes to render an HIV status as a thing that can be seen and known; as an accountable entity. In contrast with a 'slow' notion of accountability that Vicky Singleton (2012) describes as practices of touch, of looking back, and of becomingwith, I show how this testing practice also performs a 'rapid' kind of becoming-accountable that touches and marks the subject with difference. So let me try to slow down the the practice of rapid-testing just a little to start with:

My Patient Journal (March, 2016): I sat still and held my arm in the same position as it was moments earlier when the needle pricked my finger. The volunteer trainee to my left tried to occupy my thoughts with cheerful conversation, and I tried to play along. The voice to my right let a quiet "oh no..." slip out. My heart stopped. I immediately felt compelled to see what she was looking at. "So what is the place you liked the most?" The voice of the trainee betrayed her concern. I couldn't answer this one. "What happened?" I asked. I didn't have to. "We just have to wait until the time is up to be sure." she replied. "Just try to keep talking to him" she said to the trainee in Swedish. "I think he heard you though". "I know, I could see it already but we have to wait" Should I tell them I understand them? "I love traveling myself..." The trainee continued in English even though her voice was faltering. Bad luck having me on your first day. But she was making such an effort so I had to try too. "Yes...the warm can be nice...so can the cold though...I'm sorry, but I heard you say 'oh no' just now, what does uh..." I moved in my chair and faced the woman conducting the rapid test. "Yes, so it is positive." She enveloped my hand gently with both of hers. "I'm so sorry. But remember that we have to take another test to be sure, and we will make this happen very quickly now. Probably tomorrow. Because there is a chance it is wrong." She didn't sound convinced. "Does that happen often?" "Well, no, but it is possible. For now we will need to ask you some questions, and some of them will not be very comfortable, but when we get this result then we have to get your information. It can be an anonymous test, but only if it is a negative result." I could barely follow the logic. "Can I step outside and have a smoke first?" "Yes of course!" We slowly left the small room and they asked me to wait for a moment in the hall where another volunteer came to escort me outside. I wanted a moment alone but I didn't make a fuss as I guessed they had to make sure I wouldn't disappear before my information was recorded.

So what is going on in this practice? I think it is safe to say "quite a lot". As you 
might imagine after reading this description, this was a very important moment in my life. In chapter 6 I will return to my lived experiences of ongoing treatment and evaluation. Before getting there, I want to first think with this story about the kind of accountability being performed in the Swedish HIV diagnosis enacted by rapid-testing. Slowing down provides me with a way to describe the accountability of this practice. Let me try to unpack the elements at play in this practice and give a better sense of what is going on here.

It is first of all worth noting that tests such as these were a routine part of my life in Denmark before moving to Sweden. I generally aimed for a test every six months and got it done at least once a year. This time things went quite differently. I became cast in a play I did not sign up for and found myself performing an unfamiliar script. This script is played out by a number of human and nonhuman actors working in concert to achieve a result. So 'who' and 'what' are the other actors that are with me here on stage? To start with, there is a person being tested (myself), one that is in charge of doing the test (an authorised tester), another being trained as a tester (the trainee), and a testing device (one of these self-testing devices previously presented as a matter of concern). Each of us have a particular role to play. What becomes a noteworthy difference in the abilities of these actors, is that of being able to know an HIV status through the seeing of it. This ability is not one that the person tested typically has, and in this case, it was not yet given to the volunteer trainee either. This is a skill that is distributed only to 'the authority' in charge - the tester handling the testing device; the testing device visualises a result that this professional is trained to read. These two actors, and all the other actors that enable them to act in this particular setting, come together as an assemblage that collectively render visible the status of 'HIV positive' or 'HIV negative' for the subject being tested. In contrast to this, a different role is distributed to the trainee. Her part is directed at the outset to occupy my attention. This is carried out with cheer at first, with what seems to be hesitation halfway through, and ultimately abandoned by the end. This trainee is participating in an effort to learn just how to conduct this testing practice, and in time she may become an authorised tester and perform a different role. The interruption of the trainee role in the practical script of this rapid-testing is marked by the introduction of an utterance by the authorised tester - the "oh no".

The "oh no" generated a shift of a very peculiar sort. Since the number of people who test positive - something also known as the 'incidence' of HIV - is quite low in Sweden, the practice of diagnostic inscription is usually performed without such an event taking place. Generally, these characters assume their respective positions in the practice of rapid-testing without interfering in each others' role. The tester handles the technical aspects: pricking my finger, taking my blood, and managing the rapid-testing device. The device takes my blood as an input and renders the lines of visibility as an output. One line negative, two lines positive. The trainee handles my attention with conversation and meanwhile observes the interaction taking place. And as the tested subject, I would normally respond to the requests of each party without any hesitation or resistance, generally coming through this practice with a 'clean bill of health', so to speak.

It is with the words "oh no" that I was cast as a different subject. With these words, I 
became no longer the 'responsible gay subject going for a regular test', but immediately became the "irresponsible gay subject of HIV infection and risk'. The "oh no" is generative of this shift and is furthermore enhanced by the staff-escort that keeps an eye on me later on while I smoke a cigarette outside. Looking at my clinical journal many months later, I would furthermore notice how I became observed and reported just after this test as a subject who "knows of several occasions where he has been exposed to risk". Reading this report, I get a strong sense of being judged as irresponsible - staged as to blame for what happened to me. But along with these situations comes a stronger sense of sympathy for me as someone in need of care and antipathy for HIV as a cause for concern and as in need of control. The "oh no" is an event that enacts this relation of sympathy/antipathy (Foucault 2005). Through the singularity of this ${ }^{60}$ event, a multiplicity of entities are simultaneously drawn together and held apart. As I try to confirm the specific and contextual meaning of the particular "oh no" that took place in that first moment, I am told that the proper temporal succession must proceed. The diagnostic inscription must be achieved and the proverbial show must go on.

What followed then was strange. It was not clear if the required time had been reached, or if the dynamics of the situation became necessary to diffuse. In any case, action was then taken by the testing authority. The facts of the matter are now officially given as a 'positive' result, and she takes care to deliver this message through both words and touch. Touching words: 'I' $m$ so sorry'. Her hands folded around mine and the finger that was poked became enveloped by those that did the pricking. This relates the outcome 'it is positive' to me in a personal way, communicating the affect of what has happened. The effect of this test, the 'it' of the 'HIV status' as a positively confirmed reality, is not something outside of myself even though the 'it' she specifically refers to lays beside us on the table. The two lines now visible on the testing device indicate to her that this positivity is located in my person, my body, my flesh; the real enemy is thus not 'I' but rather this 'two'. Her careful touch confirms this. With this caring touch, I am inscribed with the HIV status delivered through this rapidtest; through this situation I become rendered as a person infected with HIV. I am then told of the proceeding step in the protocol we are performing. A confirmation test. But first, some uncomfortable questions. This information is not gathered however, when the device shows a negative result. Positive and negative results are differentially accounted for. After my confirmation test, I will have attained a 'positive' status, a fact that will stay with me for the rest of my life, no matter where I go. In this sense, a 'positive' diagnosis might be thought of as an 'immutable mobile' (Latour 1986) - it holds its shape while it moves with me from place to place. But what then, does this say about rapid-accountability?

In describing this 'rapid-testing' practice, I see different versions of accountability being mobilised simultaneously. The situated activity of rapid HIV testing involves at first the distributed accountability of its members. Each of us have our different roles and abilities throughout the situation. But one of them is translated and dramatically changed by its inclu-

\footnotetext{
${ }^{60} \mathrm{I}$ am rather fond of the term 'haecceity' Deleuze uses to denote a kind of 'thisness' that marks the difference between one event and another. However, perhaps this overcomplicates things. I will try to keep things simple instead.
} 
sion in this encounter. The person tested - myself in this example - becomes accountable through this practice as either (likely) HIV positive or (likely) HIV negative. A further test will ascertain and confirm this likelihood, but for now it is assumed to be the truth about my body. Along with this distribution of accountability comes another change to the accountability of my person. After this event, I will be handed the sheet of paper that I examined in the previous chapter. Through this practice, the accountability to myself and my body becomes changed morally and legally. I become accountable to biomedical authority and become subject to regulatory practices in accordance withe the legal 'policing' of risk in Sweden. Through this diagnostic practice, my body becomes not only bound-up with legal power, but also infused with medical power. Further translations and foldings will occur, but I will discuss those more in the following chapters. What is most important to note here is the generative ability that is demonstrated in this rather smooth practice of rapid-testing. Rapid-testing thus involves both haptic and optic modes of becoming-accountable, but it is only through this diagnostic event that a second more rigid form of power can come to govern my reality as a person living with HIV in ways that may become more or less repressive. In the practice of rapid-testing, 'knowing your status' is thus a process of becoming-accountable through both words and touch, through both sights and sounds.

Apart from the biomedical traditions themselves, science and technology studies (STS) is a field with a longstanding interest in devices of visibility such as these. Michael Lynch (1985), for example, uses the case of electron microscopy to illustrate the methods that render the world scientifically accountable. That is, how electron microscopy becomes a situated practice of neurological knowing and seeing. His analysis highlights three stages in this rendering process that he calls, marking, constituting graphic space, and normalising observations. Each of these activities are organised toward the materialisation of the electron microscopy program in the very object that becomes thereafter knowable. Images of animal tissue show the branching effects in segmented periods of time, but for this to be seen the images must be marked, graphically formatted, and normalised to exclude singularity. What this means is that the rats which were specifically bred for experimentation, fed, killed, cut, and visualised must loose their status as 'specific rats' if the image is to speak with scientific force about the neurological processes of 'animals'61. This leads Lynch to conclude that scientific objects are the artificial product of social activity. In other words, they are abstractions from the material affairs of living things. In his account, scientific practices such as these constitute 'docile objects' through an externalised retina (Lynch 1985:59) that renders them perceptible and analysable. Thinking with Lynch makes me wonder how the rapid-testing device I encountered during my test might be different from or similar to this externalised retina that he accounts for. The notion of a docile object however, comes once again from the work of Foucault. In his earlier work on techniques of perception and vision, Foucault sketched out a biomedical 'gaze' that, in ailing the sick and examining the dead, became a powerful technology that infused the body with disciplinary power.

61 I will describe a similar process or movement that I will call a 'fold' in chapter 5. 
"The medical gaze embraces more than can be said by the word 'gaze' alone. It contains within a single structure different sensorial fields. The sight/touch/hearing trinity defines a perceptual configuration in which the inaccessible illness is tracked down by markers, gauged in depth, drawn to the surface, and projected virtually on the dispersed organs" (Foucault 1973:164)

Through the birth of the clinic (Foucault 1973), represented as a historically and geographically vast array of heterogenous materials, skills, and interests, modern medicine now participated in the objectification of humankind. In the historical account offered by Foucault, modern medicine has come to rely on and perform a specific kind of dualism. For example, after receiving this diagnosis (and the confirmation test a few days later) I can objectively say that I have an HIV positive status. Through another modality, I can also subjectively say of myself that I am a person living with HIV. This is the subject-object dualism. Each modality provides a way of accounting for HIV that becomes available to me after this diagnostic event. But there is still a problem here that I want to navigate through this chapter. Mol and Law (2004) show me how this way of accounting for disease still moves too quickly. As an effect of assuming public-objective knowledge is 'other' to private-subjective knowledge, differences in modes of knowing (Mol \& Law 2004:44) that do not enact such dualisms are left unaccounted for.

In this way of accounting for my diagnostic status, I thus reinforce a problematic binary. HIV becomes either something that is objectively 'out there', something that seems to pre-exist the practice of testing, or something 'in here' beneath my skin - something that becomes staged as an essential part of my being. Material-semiotics offers me a way to get past this subject-object division. Instead of looking at the bodies and diseases we have/are, we might look at the ways we do disease. If you slow down when looking at how things are done in practice, then you start to see that there is not just one reality that can be seen from different perspectives (my feeling, or the objective judgment of the device), but that reality is enacted (Mol 2002) in multiple ways. This chapter will thus problematise the obligation of 'status disclosure' I described in the previous chapter by describing the testing devices of enumeration involved in the ongoing enactment of the manifold subject. I will, in other words, show how the multiplicity of inscriptions emerging from testing devices differentially come to govern what the manifold subject of diagnostic knowing becomes. Through these diagnostic inscriptions, the subject living with HIV becomes governed quite differently than do the subjects of the policing mode of governing I described in chapter 3. This enables me to show nonetheless how 'counting' becomes another obligatory practice in my subsequent and ongoing Swedish HIV treatment. As I will come to show, this counting is done in different ways with different effects. I thus show how counting is a practical and political technique in the ontological enactment and governance of HIV - not only in Sweden, but also elsewhere too. As I will show, different modes of enumeration do not just produce a different set of numbers, but come to order their worlds very differently. Importantly, I will also show how these inscription and enumeration devices can become devices of care for indeterminate subjects. 
This warrants further investigation.

\subsection{The multiplicity of inscription devices; multiple 'undetectables'}

January 20th, 2017. The sun is shining as I head over to a laboratory on the other side of the hospital than the infection clinic. A lot has happened since my rapid-test. In the following days, I underwent a series of confirmation tests and processes of blood-work before starting treatment. I also decided to write about HIV technoscience through my situated experience. Since my professional work has been largely informed by laboratory studies, it seemed like a good idea to follow my blood samples taken from the clinic into laboratories of the same hospital.

This lab is engaged in HIV research and the scientist I have come to meet is specifically involved in a project that looks at the effects of the virus on the human immune system. While giving me a tour of the facility, Edith describes her practice of immuno-virology, discussing what she calls the 'basic science' of HIV research and her specialisation with dendritic cells. She tells me that her work is all about finding ways to 'block' HIV, to stop it from producing infections. ${ }^{62}$ She says that this knowledge is important when producing therapies and hopefully someday a vaccine. While she has no doubt that a vaccine will be produced, she tells me that so far "the virus has been smarter than us".

Coming back to her office, Edith shows me some slides that she uses in her teaching I am in many ways her student too, after all. The first image we have a look at is a visualisation of HIV (see figure 9):

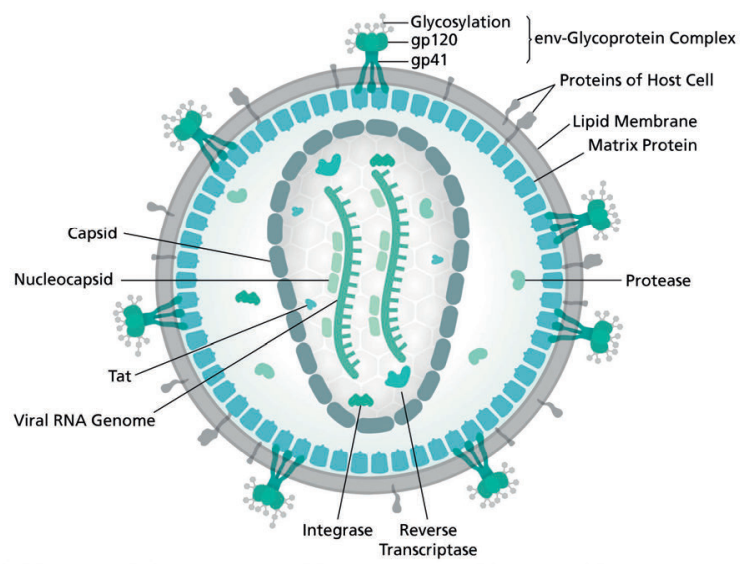

Figure 9: a visualisation of the HIV viron ${ }^{63}$

\footnotetext{
62 See chapter 6 for a continued discussion of this topic.

${ }^{63} \mathrm{https} / /$ en.wikipedia.org/wiki/Structure_and_genome_of_HIV\#/media/File:HI-virion-structure_en.svg, accessed 2019.10.01 Here I chose to replace the original image with a very similar diagram found in the Wikimedia commons.
} 


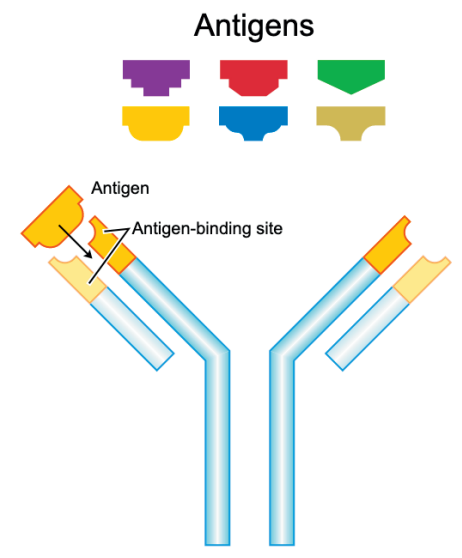

Antibody

Figure 10: a visualisation of an antibody ${ }^{64}$

She points to different parts of this structure while explaining to me the tests and experiments that involve these different components of the virus. This lets her discuss the virological aspects of her work. She then shows me a book that she highly recommends to me, noting one particular figure that is illustrated in this book (figure 10). This is a visualisation of what she calls an antibody, an important component of the immune response to HIV. Through this conversation, I come to see how this practice of immuno-virology focuses on both virologics and immuno-logics simultaneously. Through my participation in this setting, I thus get a sense of how HIV is rendered through a juxtaposition of laboratory sciences. While discussing this work, Edith shows me another slide that she uses in her teaching. It contains a heading - "Controlling HIV is possible!?!" The slide contains three bullet points, each one providing a definition of a type of subject that can control HIV in some way. Along with the text on this slide I am looking at, two images are presented.

The first is a three-dimensional picture of a crowd of blue circles, each containing a simple frowning face. One of these however, is situated in the middle of the crowd and has a yellow smiling face. This picture seems to have been chosen for the slide to illustrate the uniqueness of some subjects that are said to have the ability to become 'undetectable' without medical intervention; this subject comes to be known as the elite controller65 in biomedical practices concerned with HIV.

\footnotetext{
64 https://commons.wikimedia.org/wiki/File:Antibody.svg\#/media/File:Antibody.svg, accessed 2020.03.05 Due to ethical considerations, I have chosen to replace the image I found in the book from Edith with a nearly identical image in the Wikimedia commons.

65 With this encounter surfacing yet again the politics of control and care, I am tempted to rename these 'selfcaring' subjects rather than stick to the established terminology of 'elite controllers'. However, this would interfere with another point I want to make with this thesis: that subjects living with HIV become known as what they are through their dependency on the practices of testing that make them accountable in different ways.
} 
The second image I find interesting on this slide is a two-dimensional illustration of twin figures holding hands and again displaying smiling faces, one containing a red 'plus' and the other a blue 'minus'. This seems to indicate some sense of solidarity between people who are HIV positive and those that are HIV negative. The elite controller subject becomes very interesting for immuno-virology, as they are thought to hold the answer to a cure or vaccine for HIV. However, I want to better understand how they, and the others presented in this slide, come to be known as subjects at all. This chapter will show the methods through which this subject is enacted alongside other undetectable subjects.

If early actor-network theory (ANT) crossed the subject-object distinction once (Latour 1993) by locating knowledge as an emergent effect of practice and post-ANT messed with it a second time by rendering multiple objects in their activity (Mol 2002), I want to wrestle with this boundary a third time by describing manifold subjects as a contingent and situated effect of practical ecology (Stengers 2005). Here, machines and mice may play an equally important ecological role; humans and nonhumans are both involved in the politics of going on together. But as I will come to show through my participation in this ecology of practices, different subjects are enacted in different ways.

I find this slide specifically interesting for two reasons. First, it surfaces the idea of control in an interesting way. Controlling HIV becomes an attainable objective here - apparently for some people even without biomedical intervention. However, I also recognised that I was not one of these people. My tests made me accountable as a far more 'normal' subject to immuno-virology - a mere 'blue' frowning emoticon. Secondly, I found the red/blue colour coding to be a curious detail that would re-present itself again and again throughout my fieldwork. The red/blue colour distinction often comes to code the politics of viro-logics and immuno-logics in a visible way. Blue tends to stand in for the immune system - the forces of bodily defence. Red on the other hand typically colours HIV as the counterforce - a political and violent opposition of colour. In this story Edith tells me, mutation is both responsible for the emergence of HIV ${ }^{66}$ and mutation provides a hope for a future cure. The laboratory envisions a day when this mutation can be harnessed and operationalised as a vaccine that may provide immunity to HIV and AIDS. While this is the overall vision of the immuno-virological programme, the members of the laboratory engage in a variety of testing practices in their everyday work. Over the course of my fieldwork, Edith would come to introduce me to her colleagues working with three distinct HIV tests: ELISA tests, PCR tests, and flow cytometry tests. As an ethnographer, I became interested in observing these tests in practice and describing their particular ways of knowing HIV. As a patient, I was also interested in understanding how my first test results were accomplished and how my ongoing tests were performed.

\footnotetext{
${ }^{66}$ Drawing on SSK, Brian Martin (1996) discuses his own participation in the controversy over polio-vaccines that situates the origin of HIV within vaccine trials. While this theory may be interesting to explore as to the sometimes harmful consequences of science, I find that it produces an unhelpful hope to situate responsibility for HIV in either the 'human' or 'nonhuman' alone. Adopting a more generalised symmetry (Callon 2007) lets me focus on the more interesting aspects of present networks, rather than focusing my energy and analysis on origin stories.
} 
Inquiring about these with my doctor, I came to find that my antibody value was counted at ' 21 ' on my first ELISA test (after being 'rapid-tested' that is) and counted at ' 28 ' on my confirmation test, but that a value called 'p24 antigen' was undetectable during these tests. I would also come to find that my first PCR test detected and counted 53,600 copies of a value called 'HIV-1 RNA'. This fell to an undetectable count after treatment and hopefully will remain undetectable for the rest of my life. Finally, a value called 'cd4' was counted at a level of 800 . This rose to approximately 1000 after treatment and generally fluctuates by a few hundred. This chapter will now show how each of these tests can be analysed as a different 'inscription device':

"An inscription device is a patterned set of arrangements for producing inscriptions or traces out of materials that have been made to take other forms. (...) Then they become manipulable, and they also become mobile. (...) Inscription devices don't just exist in laboratories. They are to be found, in different modalities, in health care, accountancy, politics, or the criminal justice system - you name it, and you are likely to find inscription devices. They can be seen as technics for producing naturecultures." (Law 2004:6-7)

My aim in this chapter is to show how each of these different ways of doing diagnostics through 'counting' inscription devices comes not only to perform a mode of enumeration, but how along with each comes a remarkably different world; a different 'natureculture'. Contrary to the understanding that each of these biomarkers indicate a different aspect of an underlying and unified reality, I want to show how three of the devices that make my HIV inscriptions each do the ordering of HIV in a different way and how they each enact (Mol 2002) a different subject. The next three sections will follow the subject of diagnostic testing as it is differentially enacted in each setting.

\subsubsection{Knowing HIV in ELISA; enacting the subject with antibodies/antigen}

In this section, I will now describe the first mode of knowing HIV as practiced in ELISA testing, a mode of knowing that enacts HIV as other to the self. As I will come to show, a family of laboratory tests that are known as 'enzyme-linked immunosorbent assays' (ELISA) can be understood as immunological devices that inscribe the subject with an accountable antibody value. The latest descendant of this family - a so called '4th generation ELISA' - inscribes the subject with both antibody and antigen values and has become the 'gold standard' for the front line testing of HIV in most situations. I will show how the ELISA mechanism works according to a principle that is embodied in self-testing devices (such as in the rapid-test we saw earlier in this chapter), manual laboratory tests, and automated combination/differentiation tests performed by clinical or laboratory machines. To learn about this practice, I returned once again to Edith.

Edith: Normally when you have an infection or danger in the body, you have a response to defend, which is called the first innate response, like, the one we are born with. It is supposed to be the first thing happening. It's like a bell ringing, now it's danger! Please recruit cells and activate! 
And then you have a bunch of different receptors, factors that you can study, and different techniques.

Through immunological practices, a complex world becomes knowable and observable. My lived body becomes an organised and responsive defence system, issuing warnings when it detects infection. It calls for the recruitment of cells that must become active and engaged in order to counter invaders. As Martin puts it, "The notion that the immune system maintains a clear boundary between self and nonself is often accompanied by a conception of the nonself world as foreign and hostile." (Martin 1994:53) The $4^{\text {th }}$ generation ELISA is used to study a specific kind of 'nonself' invader known as 'p24 antigen':

Edith: If you want to look for what we call a 'productive infection' then we use something that we call a $4^{\text {th }}$ generation ELISA. The HIV has a component called 'p24', it's one of the protein parts of the capsid, which is like the cytoskeleton inside the virus. So this is normally released together with the viruses from the infected cell. And by saving the supernatum, meaning whatever is released and the liquid around, and we can save that for different days. We can go and test how much of this p24 exists in the different samples. And you can see levels. So we measure the p24 by binding antibodies to the antigen.

So perhaps rather than being an invader itself, this 'p24 antigen' comes to be rendered as the skeletal armour of HIV. By analysing the 'armour' of the virus at the site of infection, this mode of knowing can provide an idea of the character and the strength of the attacker. The principled mechanics of ELISA testing can not only be performed manually at the laboratory bench with the use of a ready-made kit over a three day process, but can be incorporated into a variety of automated machines and an array of self-testing devices - including the one that featured in my first story of a rapid-testing practice.

So in this mode of knowing, a distinctive boundary is enacted between different kinds of 'pairs'. I thus argue that the ELISA mode of knowing enacts HIV as a form of dyadic pairing. Edith told me that this ELISA test utilised the most basic operation of the immune system67 - the ability to discriminate 'self' from 'nonself'. What is self comes to recognise what is nonself; human antibodies respond to nonhuman antigen. This p24 antigen - what becomes known as 'nonself' - is said to be a molecular material that envelops the 'HIV RNA' ${ }^{68} \mathrm{HIV}$ is also known and classified as a 'lentivirus' - a slow virus. This is due to the way that HIV progresses into disease, at first proliferating quite intensely only to go dormant after a few weeks and become asymptomatic for 8-10 years. After this hibernation, HIV once again proliferates and attacks cells that express something called 'cd4' on their surface, something I will discuss later in this chapter as well. However, during those first weeks of infection, the virus and its

\footnotetext{
${ }^{67}$ As in the words of Haraway, "the immune system is a plan for meaningful action to construct and maintain the boundaries for what may count as self and other in the crucial realms of the normal and the pathological." (Haraway 1991:275)

68 I will describe this actor in the next section.
} 
antigen armour can be detected in blood samples, after which time only the antibodies will be detectable. Human bodies produce what become known as 'HIV-1 antibodies' - which in turn become known as 'self' - in response to the viral antigen during those first weeks of infection, but laboratories can also order them and keep them stocked in the fridge for use in tests or experiments. So the ELISA test detects both these 'antibodies' made by the human body in its alarm to an intruder, as well as the 'antigen armour' of the virus.

My conversations with another immunologist at this lab named Astrid shed some light on the role of the ELISA test within the more general framework of HIV diagnosis.

Astrid: So the first step is the HIV serology, where you test if you can detect antibodies against HIV in the serum of the patient. And it's also based on an ELISA, but then its just a bit the other way around. You have the antigen bound in the ELISA from the beginning, and then you add the patients' serum. So you have an antigen that detects the patients' antibodies. So it's the same principle, but you can mix and play around with different things that you add. But it's always the same principle.

So the principle of ELISA can also be reversed and work just as well. In both cases, you start the test with something 'known' - the p24 antigen or a specific antibody to HIV-1 or HIV-2 for example. These entities are considered 'well known' by laboratory professionals because they have often been specifically manufactured and standardised to perform this role in a diagnostic test or experiment. Antibody/antigen material can also be cultivated in the immune systems of animals like rabbits and rats. These laboratory materials may be made from nonhuman 'others', but through the ELISA test they will come to perform the role of human 'self'. Then you add the 'unknown' material being tested, a blood or tissue sample for instance. If the tested material contains the matching antigen or antibody, it will bind together with the antibody or antigen in the testing device and produce a chemical reaction. This reaction shows up as articulation of colour or the formation of a line that indicates a "positive/ negative' result, but this reaction may also be digitalised and quantified. Even though the principles are said to stay the same, in practice these tests produce an interesting variability in their results.

Astrid: There are some individuals that tend to get this positive result. They are not positive but they are slightly reactive, and we don't know why, but if you use another 'kit' from another distributer, then they will be negative. But on the other hand, some other people will get the reactive result in that very kit. There is something in the matrices of the kits that causes these strange reactions. But usually you can tell, "this is unspecific", because the level of reactivity is so low. And I suppose if you have strong reactivity, it's more likely that there is a real infection.

Here we see how the strength or intensity of the antibody-antigen bond becomes a critical value to distinguish between a real infection and an error. ${ }^{69}$ Since the intensity of an-

69 The value of 'specificity' mentioned by Astrid is something I will discuss further in chapter 5 . 
tibody reactions are not made visible in self-testing devices that provide a simple positive/ negative result, a proper HIV diagnosis - the confirmation test - must be performed by laboratory professionals who can measure the reaction through more sophisticated means.

One day I got a guided tour of the ELISA testing process and met with Hilda, a clinical microbiologist who worked more closely with diagnosis and screening practices. Hilda and I discuss my project as we walk down a hall to a small room where two large machines occupy most of the room (see figure 11). They look nearly identical. Both have the brand 'ARCHITECTplus' marked on the top left and 'Abbot' on the top right; these are their commercial brands. Both have a black midsection that is marked off into five segments in white. The machine to the left has a piece of paper taped onto it with the name 'Måns' printed in comic sans. The machine to the right is similarly given the name 'Anders'.

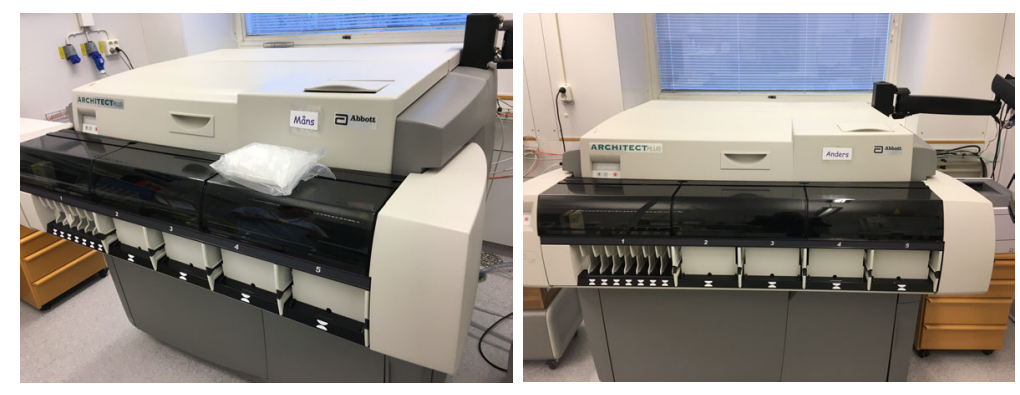

Figure 11: Måns \& Anders (the ELISA machines)

Asking about these labels, I was told that Måns and Anders were named by the students who are trained in these labs. While Hilda said their names simply make the technical work more pleasurable to the student body, I imagine it also helps these students to differentiate which machines gave which results more specifically. Hilda told me how clinical screening for HIV works in this lab. Måns and Anders help to perform a HIV-1/HIV-2 combination antibody and p24 antigen test. Blood samples go into the machines, an automated mechanical arm picks them up and adds a few vital materials. The machine attaches something called a 'fluorophore' that helps to articulate the strength of the antibody-antigen bonds through color so that the human eye or computer can sense and enumerate the result, either as a colour difference in a manual test (figure 12 left) or on a computer screen as digitalised data (figure 12 right). During our conversation, Hilda paused to note that this lab has never come across HIV-2.70

\footnotetext{
$70 \mathrm{http} / / / \mathrm{i}-\mathrm{b} a \mathrm{se}$.info/qa/36, accessed 2020.04.07: "HIV-1 and HIV-2 are two different viruses. HIV-1 is the main family of HIV and accounts for 95\% of all infections worldwide. HIV-2 is mainly seen in a few West African countries (...) On a structural level HIV-1 and HIV-2 have important genetic differences (...) On functional level, there is a difference between the two viruses in terms of how easy it is for the virus to infect someone. HIV-I enters the immune system by attaching onto the CD4+ receptor found on the surface of certain white blood cells. HIV-2 has a harder time gaining such a foothold."
} 

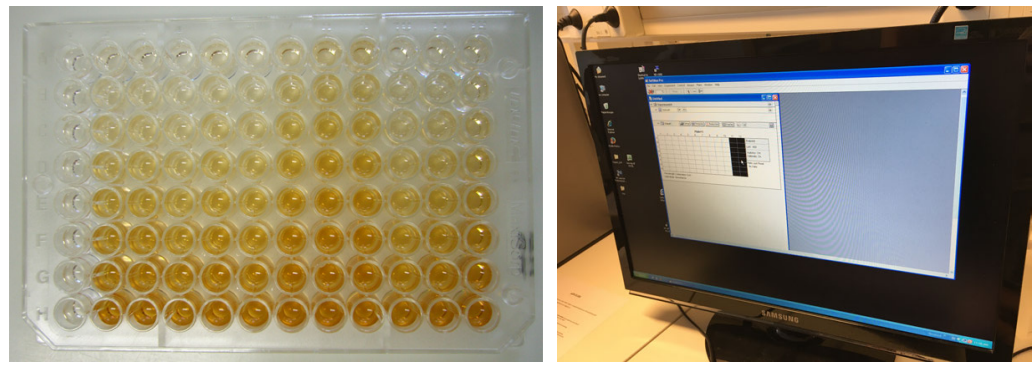

Figure 12: analogue ${ }^{71} \&$ digital ELISA inscription

Hilda: Yeah, here you can see the processing part. What it looks like. When you detect p24, you are looking for the antigen, so the beads are coated with antibodies, and then you have the conjugate and substrate. And on the conjugate you have these special florophores. You will have a florescence that you measure.

Jeffrey: Is there a lot of variation in the florescent signal?

Hilda: Yes. So if you have a pregnant woman, she can react to HIV, but, she doesn't have the disease.

Jeffrey: Ok, so what's it reacting to then?

Hilda: something that's similar, that has a similarity to HIV, but it's not HIV. It can be anything. But we have found that pregnant women react, not always for HIV, but for hepatitis A or B, but then they react very weakly. Normally when you have an infected person, the reaction is much higher.

Here we see how these machines sometimes have trouble with differentiating between the responses of pregnant bodies (a situation in which likewise something 'nonself' is part of the self) and the responses of bodies with HIV, hepatitis C or B, and possibly other conditions. Here, HIV becomes a faceless entity - anything that is not me. So in spite of what the Public Health Agency told me at national level, there seems to be some degree of indeterminacy going on at the local lab level. As Hilda explains to me, different kinds of serological or immunological tests involving antibody-antigen bonds can provide different results. So to make sure the results from the first test are valid, they are run through a second test to determine and confirm the results from the first.

Hilda: pregnant women can show a low reactivity in the Architect, but be negative in conformational testing like the Innolia and HIV RNA. We always recommend a follow up testing. If when screening you get one positive reaction, then you spin the sample and re-test it twice. If these tests show a negative result, both of them, you do no further testing. Then the first test was false. Do you get the sense of it?

If both the first and second tests are reactive, then the result will be recorded as 'posi-

\footnotetext{
71 https://en.wikipedia.org/wiki/ELISA\#/media/File:ELISA.jpg, accessed 2020.04.07
} 
tive'. If neither show a strong reaction, then the result will be reported as 'negative'. But if there is a strong discordancy, then other tests will be called in to judge the indeterminate result. This indeterminacy is a subject I also found helpful to think through with Martin (1994). Her account shows me how the boundary between self and nonself may sometimes be enacted quite rigidly, but other times it may not be: "When the nonself is a disease-causing microbe, the model works quite logically. But when the nonself is a fetus growing inside a woman's body, the model quickly runs into a difficulty." (Martin 1994:59) A testing device based on a strict model of mutual exclusion between self and nonself does not allow more sensitive situations to be understood. ELISA is thus a screening test ${ }^{72}$ that is nevertheless the first that a tested subject will undergo, with the exception of cases where a baby must be tested that has been born to a mother known to have been previously diagnosed with HIV. Since the mother will have shared her antibodies with her baby, possibly without passing along the virus itself, the ELISA test will show a positive result in this situation anyway, even if the baby does not carry a viral infection. In such cases, a direct virological test is needed to establish a diagnosis.

So in the laboratory practice of ELISA testing (a mechanic that is also incorporated into rapid-testing devices), HIV is enacted as something other to the self. This method is referred to as an 'indirect test', because rather than detect the virus itself through virological measures, it looks for immunological reactions to the virus. In ELISA testing, the self is performed as a molecular/cellular response to something it perceives as 'foreign': something 'other' and 'outside' the self. In this enactment, the self is marked by antibodies that the body produces in response to HIV, other diseases such as syphilis, and even the presence of another human, as in the case of pregnancy. While the latest version of the ELISA test is meant to detect a molecule named p24 which forms the 'capsid' of the virus, in practice the test can react to many things that it registers as 'nonself'.

This story highlights the way in which, through the $4^{\text {th }}$ generation ELISA test, I become both an undetectable subject through antigen testing as well a detectable subject through my antibody value, becoming first enumerated with the antibody value of 21 and then confirmed with an antibody value of 28. Martin (1994) helps me to see something important going on in this story. The fast-track strategy of ending AIDS through war comes up here against a more subtle strategy of the immune system: flexible response. Beginning an extensive and immersive ethnographic fieldwork in 1989, Martin (1994) described how the immune system was being rendered and realised in more than one way. Taking AIDS as a moving object with which to explore these renderings, Martin argued that technoscientific modes of knowing and responding to the problem of HIV and AIDS were perhaps becoming less dominant than other more flexible modes. Her account renders a difference between (at least) two ways of imagining and realising the immune system: 1) as a subject at war and 2)

\footnotetext{
72 As a first line of testing, ELISA remains quite cheap compared to other possibilities. The Swedish Public Health Agency told me that an HIV-1/HIV-2 antigen/antibody screening test would cost only 62 SKK, making it quite an affordable technique in HIV diagnostics. Once a positive test result has been accomplished however, this test no longer becomes relevant for the patient undergoing HIV treatment.
} 
as a flexible subject (Martin 1990:412; Martin 1994). In this second reality, the subject is caught up in a responsive 'dance' (Martin 1994:218) with a variety of molecular agents. This dance of agency (Pickering 2012:317) comes to value the body altogether differently than the body at war as well: "What is emphasised is specificity and flexibility, so that any possible foreign molecule or protein can be matched from the body's store of specific/flexible antibodies." (Martin 1992:XX) This mode of enumerating HIV also complicates the idea of a rigid HIV positive/HIV negative binary by showing how negative or undetectable antigen results, as in my case, can still be taken as positive identifications of HIV infection under particular conditions. My ELISA tests did not result in the detection of p24 antigen, but because HIV-1 antibodies were indeed detected, the result became known as 'an infection older than eight weeks' rather than 'no infection'.

ELISA testing thus comes to know and enact HIV as something other to the molecular self. As a mode of governing HIV, it works by discriminating and at times failing to discriminate between self and nonself. A consequence of privileging this mode of knowing as a perspective is the concerning conclusion that AIDS is not the result of a viral infection, but that it is simply the effect of 'lifestyle factors' and ways of living that are assumed to cause harm to the body and its immune defences - a way of theorising AIDS during its emergence that notably was supported by influential scientists. This also highlights the complexities that come along with knowing HIV as other to the self. As a mode of enumerating HIV, ELISA delivers a result in the form of a strong or weak signal that indicates a detection of HIV-1 or HIV-2 antibodies and/or p24 antigen. But what is interesting about the mode of knowing that is performed here is that HIV becomes enacted as a faceless 'other'. In principle, the ELISA process does not recognise a difference between HIV, other diseases, or pregnancy. Knowing and enacting HIV as other to the self does not require any difference between this 'other' and another 'other'. In the diagnostic practices I encountered, however, this does not become a problem..$^{73}$ This mode of knowing is not simply a perspective that is situated in the minds of professionals. It is a mode of knowing that is enacted in practices of diagnostics and embodied in the material techniques of ELISA as a testing device that I have situated through my personal account. This mode of knowing HIV performs a world, but this world is not set apart from other worlds. Instead, it is coordinated (Mol 2002) with others.

\subsubsection{Knowing HIV in PCR; enacting the subject with RNA}

In this section I will now describe a second mode of knowing that enacts HIV as a deep genetic structure that can be read and written through the PCR device. I will come to show how the polymerase chain reaction (PCR) test can be understood as a device that inscribes the subject with an accountable viral value. The recursive amplification of HIV-1

\footnotetext{
${ }^{73}$ Diagnostic professionals working in South Africa however, are impacted by this problem in a much more concerning way. In such situations, algorithms and protocols seem to have become coordination devices (Mol 2002) that help laboratory professionals handle indeterminate results. They also are said to help those tested cope with the indeterminacy of such results. In this case, testing algorithms may even be fairly described as devices of care for indeterminate subjects.
} 
RNA and DNA sequences allows the genetic structure of HIV to not only be 'revealed', but also to be enumerated and manipulated. Through the practice of PCR, I was first enumerated with 53,600 copies of HIV-1 RNA found in my blood. After a few weeks of antiretroviral treatment, this dropped to undetectable levels; HIV became effectively absent in my blood. 74

To learn about virological diagnostics, I first spoke with Edith. While we discuss the day-to-day tasks that are performed in this lab, Edith also contextualises her work by situating it within the virology of HIV. She tells me that the initial outbreak started with monkeys and apes. According to this story, chimpanzees and a type of monkey called a macaque both carry a version of HIV that is called the 'simian immunodeficiency virus' (SIV). In apes and monkeys, this virus does little to no harm, but when it spreads to humans, it becomes more potent. Edith tells me that this zoonosis, this cross-species jump happened in Cameroon, where the local human inhabitants were often eating 'bush-meat' including these monkeys and apes. She compares the similarity of this practice to the way that Swedish people hunt 'wildgame' like elk and moose. She explains that this is where SIV is said to have mutated into HIV. Adding a further layer of accountability, Edith tells me that chimpanzees are responsible for HIV-1 and macaques for HIV-2. While people were probably dying locally, she says that it was not yet considered a major problem globally because it was contained in a small region. When roads began to connect this area to larger cities however, the virus began to spread and mutate rapidly. She tells me that these mutations changed the genetic structure of the virus. This conversation led us to discuss another way of knowing HIV that was different from the ELISA test.

Edith: To measure that you have infection today, the thing that you can find first is the virus, but then you need to test with the so-called PCR. It's a way to detect the virus itself by looking at the virus genome. If you take blood you can see that you have it. And normally there are 7-10 days into the infection where you can see the virus in blood.

So another test that is performed in this lab is called a 'PCR'. The object of this test is the genetic materiality of HIV. Here, HIV is enacted as a retrovirus that starts out as an entity that contains RNA in its core. Through a process called 'translation', the virus integrates itself into a cell and uses the cell as a factory to produce new clones that are ejected out of the cell as new viruses, beginning the process all over. Within this mode of knowing, HIV thus becomes a recursive deconstruction and reconstruction of itself through cellular material. Edith once again explained this for me.

Edith: When you have a gene, it's a sequence. It's like an alphabet. And you know exactly what you are looking for. So you can make the first letters. And by doing the letters at the beginning and the end of the whole text that you care about, which is the HIV in this case, you can 'read' the whole HIV many times. And by reading you produce, like books. And then you can measure, be-

\footnotetext{
${ }^{74}$ In Sweden the limits of contemporary detectability have the defined threshold of 50 copies of HIV-1 or HIV-2 DNA/RNA per $\mathrm{ml}$ of blood. Elsewhere, this threshold varies.
} 
cause one of them is going to be so tiny, so you need to amplify it. So you make copies of the thing you started with by doing that. And then you get a signal in the machine. And you can see, 'ok, this is positive'.

Within this mode of knowing, HIV thus becomes cared for as a textual structure. As we see here again, machines play a key role in the practices of laboratory measurement, and specifically in the PCR process. In this practice, knowing HIV is about reading and writing 'HIV books' made of RNA and DNA; HIV becomes enacted as a deep genetic structure 75 that can be studied and identified. The PCR machine thus makes the genetic code of the virus legible to the laboratory staff. In contrast to the dyadic world of 'self' and 'nonself' that we saw in the previous section however, this mode of knowing is interested in the singularity of the genetic code. Although there may in this world be differences between the genetic structures of 'humans' and 'nonhumans', these are taken to be secondary differences in relation to the primary structure of nucleic acids. In this way, the world of surfaces becomes submerged in a world of depth.

To better understand this machinic process of PCR, Edith arranged for me to come and observe it being performed in the lab by one of her students named Olivia. While the analysis of DNA through PCR has many uses in medicine, forensic practices, and research, when it comes to HIV testing it is the value of HIV RNA that becomes the relevant object to look for. This is because HIV is a retrovirus - it begins as RNA before turning itself into DNA. After a short introduction, we jump into the process (see figure 13) of preparing the samples that are to be tested.
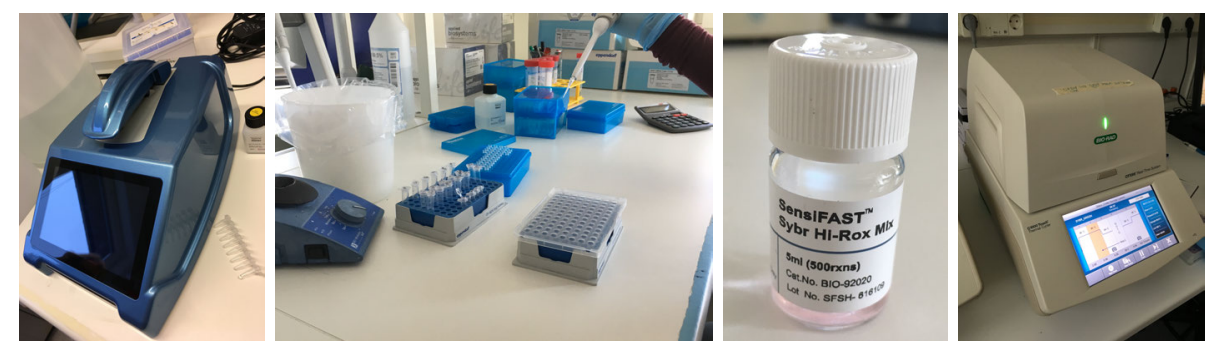

Figure 13: setting up the PCR machine

While doing this work, Olivia explains to me that all of the tubes in the plate need to have the same amount of RNA before starting the test. To 'lyse' a cell means to break it apart and release its RNA, so this process they refer to as 'purification' is first performed on the cells in the sample tubes. Through this process of purification or lysing of cellular material, immunological actors can be deconstructed and reconstructed into virological actors. To make sure there is the same amount of RNA in each tube to start with, the samples are measured in a blue machine (see the first image in figure 13) that looks only slightly smaller than

\footnotetext{
75 See Haraway (1991) for an account of the emergence of this image along with cybernetics.
} 
the PCR machine - a machine she calls 'the nanodrop'. The nanodrop is called in to perform a measurement of the samples and confirm that they are ready for the following step of the process. Next, a small rectangular object called a 'plate' (see the second image in figure 13) is arranged with different materials being added to small tubes for analysis in the PCR machine. The RNA in the sample tubes are then protected with a liquid called 'Syber Green' (see the third image in figure 13) and given to the PCR machine (see the fourth image in figure 13). The machine heats up and cools down the samples, and with the help of an enzyme in the Syber Green that is collected from deep under the ocean near underwater volcanoes, the machine reproduces the sample RNA through a recursive process of what they call 'amplification'. Polymerase, the enzyme upon which the PCR process is named, is a heat resistant enzyme that both protects the RNA throughout the subsequent process in the PCR machine and does the active work of copying the genetic material in each cycle.

The computer screen connected to this device is then used to match the analytic software to the particular arrangement on the prepared plate and the cycle threshold is set to 40 . This number changes slightly from lab to lab, but the general idea is to have enough recursions to allow the enzymes to make enough copies of the genetic material that may be present in the sample. After an hour, the analysis is done. A logarithmic scale has been produced with a number of lines rising sharply and curving toward the top, indicating the RNA that has been amplified. Figure 14 shows an example of these inscriptions produced by the PCR machine. A USB is then used to transfer the data from the PCR machine, which is then taken to another computer where the data can be incorporated into scientific texts or diagnostic reports. With the help of the PCR machine, the blood sample has been displaced and has been translated into an inscription (Latour \& Woolgar 2013).

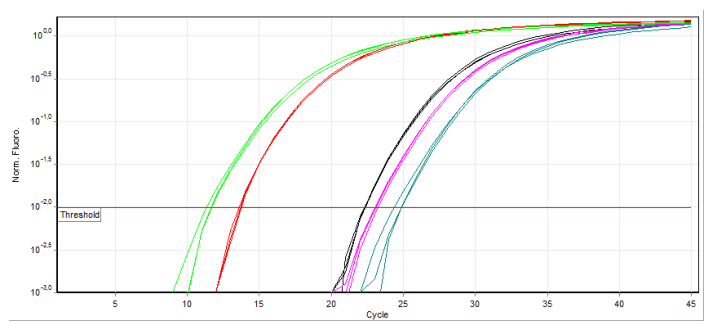

Figure 14: the PCR inscription 76

Through this displacement of my blood, a virological fact can be made present: the fact of my being virologically undetectable. This inscription has furthermore been enumerated as a viral value. While my first PCR test in 2016 found 53,600 copies of HIV-1 RNA, all of my subsequent tests have been enumerated at 0 . Through these inscriptions, I can come to know that a given sample had many viral structures present that could be copied exponential-

\footnotetext{
76 https://en.wikipedia.org/wiki/Real-time_polymerase_chain_reaction\#/media/File:Qpcr-cycling.png, accessed 2020.04 .07
} 
ly or that there were no viral structures present to copy and enumerate. Through this practice, the subject can become translated as virologically detectable or undetectable. The temporal differences between these virological subjects has consequence as well. If the subject is found to have a detectable viral count but subsequent results are found to be undetectable without the subject undergoing anti-retroviral tretment, this would make the tested subject become what is known as an 'elite controller' rather than a 'positive-undetectable'. To be 'positiveundetectable', as I am, means that you have received at least one previous detectable result through a PCR machine, but after starting anti-retroviral treatment are found to be undetectable. So both the 'well-treated' subject and the 'elite controller' subject can become 'undetectable', but through different means.

This PCR test ${ }^{77}$ thus performs a mode of knowing and enacting HIV as a deep genetic structure that can be decoded and recoded. By describing my ongoing enumeration as someone living with HIV, this story shows how HIV is not only translated into a viral fact through a series of material displacements, but also how this way of knowing HIV is contingent upon a retrospective uncertainty. Even the so called 'direct' viral tests show how living with HIV is not simply a case of knowing or not knowing you are positive, but moreover knowing that your current status is a representation of the last blood test that was performed on the small quantity of blood taken from my arm one day. Perhaps it could be otherwise, elsewhere in in the body, perhaps in what are called 'deep viral reserves' that have yet to be understood. Taking medication to remain 'undetectable' thus allows me to handle this indeterminacy. But as with those I discussed in the previous chapter, these diagnostic devices are not only representative of the virus in my body, but performative of my subjectivity as a "safe" and "well-treated" subject. Once again, taking this mode of knowing and enacting HIV as a perspective that can be adopted to the exclusion of others can lead to dire consequences. There are members of both scientific and nonscientific communities who render the virus unharmful by doing so; in the early days, some scientists even claimed to be willing to inject themselves with HIV to 'prove' that it was harmless. Taken alone, knowing that you have or had HIV RNA in your body at one point does not directly translate into knowing that you have a disease. To provide that kind of certainty, a third mode of knowing must be called in. In the hospital lab, even virological diagnostic devices may come to depend on other modes of testing.

\subsubsection{Knowing HIV in flow cytometry; enacting the subject with cd4}

This third and final story will now allow me to illustrate how flow cytometry is a device that inscribes the subject with an accountable $c d 4$ value. I will show how this final mode of knowing enacts HIV as a potential state of conflict. So what is the value of 'cd4'? To answer this question, I visited the haematology lab just across the road from where Edith worked. This is where I met the immunologist I have been referring to as Astrid. Her practical work would teach me a lot about the entities performing the bodily work of immunity.

\footnotetext{
77 From the Swedish Public Health Agency, I was given a cost estimate of 1599 SKK for each HIV-1 RNA quantification performed with PCR. This is a biannual test in my ongoing treatment.
} 
Astrid: so what we do here at this laboratory, we get samples from the department of infectious medicine, from the patients that are HIV positive, and what we analyse here is the number of $c d 4+$ helper T-cells, which is considered an important marker for a good life without infections. It should not go below 200 per microlitre. So that's what we do here. And the cd4 count is analysed with flow cytometry.

The ongoing analysis of my cd4 levels enable me to live a 'good life without infection', while still living with HIV. To help along my imagination, Astrid took it upon herself to draw these immunological entities while she spoke (see figure 15), a drawing that helped to me make sense of immunological actors. Taking advantage of a white board in her office, Astrid explained to me that this thing called the immune system was made out of different entities that performed different functions. In the centre of this image, she drew a circle and labeled it 'T-cells'. These are the primary objects of her analysis and an important actor in the network of immunity. Through our conversation, I would come to learn that T-cells come in various forms, the two most important of these being the 'cd4+ helper cells' and the 'cd8+ killer cells'. I would come to learn that 'cd4' is short for 'cluster differentiation four', a kind of protein that is expressed on the surface of these cells. While the T-cells exhibit 'cd4+' and 'cd8+' expressions, other entities such as the B-cell drawn on the left of the image, come to express themselves differently such as with the 'cd19+' expression shown here.

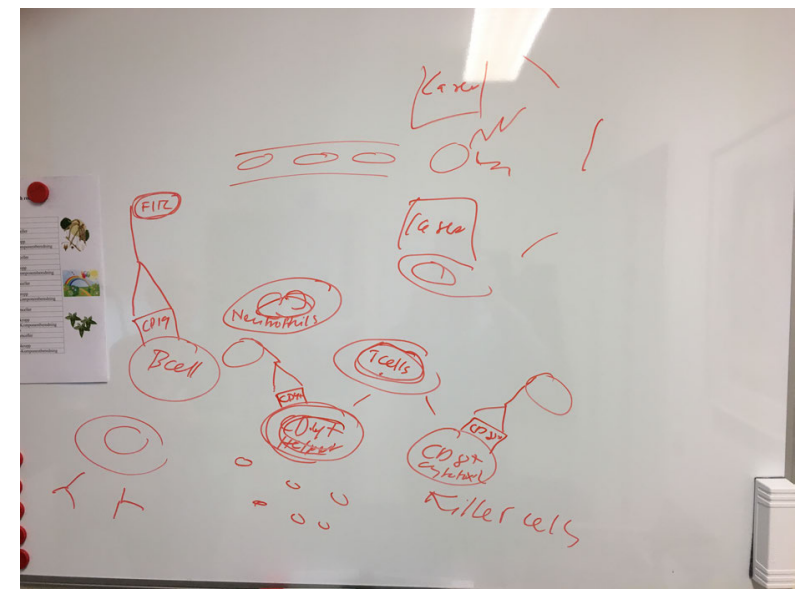

Figure 15: drawing the immune system

Between the T-cells and the B-cell, Astrid drew another circle and labelled it 'neutrophil', an actor which she said dominated the immune system. Their primary job is to eat things like bacteria or antigens, and they do this unspecifically. The 'killer' T-cells, on the other hand, come to have far more specific tastes. As she explained, all of these entities nonetheless belong to a wider class of actors known as 'white blood cells'.

Astrid: These cells are very important for like the immunological tolerance so that you don't de- 
velop autoimmunity, because if there was no tolerance mechanism, then we would all suffer from severe autoimmunity, because these ones must tolerate self but respond very effectively to anything that is nonself. And there are several mechanisms through which they keep the balance.

So here the immune system depends on balancing mechanisms that value tolerance. While the neutrophils and other entities such as macrophages and dendritic cells were described as part of the 'innate' immune system, the cd4+ helper and cd8+ killer cells were part of what she called the 'adaptive' immune system, that is, the system that adapts its strategies and defences as it learns from experience. As Astrid would explain to me, the HIV virus comes to target those particular entities called cd4+ cells. The more the virus replicates, the more cd4+ helper cells are destroyed. This is a problem, because these helper cells come to orchestrate the activity of the immune system; helper cells are involved in molecular choreography. When they disappear, the immune system becomes unable to coordinate its activities, leaving it vulnerable to a host of pathogens and diseases to a point that even a common cold can kill you - me. Without versatility and a flexible response, the organism cannot deal with the changes that it is constantly confronted with during the ecological dance of living. This means that cd4+ helper cells become very important to keep an eye on, especially for those living with HIV. Attached to these different cells, Astrid drew little shapes that look like a 'Y'. These are meant to depict the entity called an 'antibody', such as the ones that featured in the ELISA test. Again, in the process of flow cytometry, the antibodies are tagged with different colours in a process called 'staining'. Along the top of her drawing, Astrid then drew two lines to depict a tube with little circular cells passing through it. By attaching these coloured antibodies to the cells in a blood sample, the flow cytometer can count and distinguish between the kinds of cells as they pass. At the end of the tube, she drew two boxes that she labeled 'laser'.

Astrid: And the antibodies, they are conjugated with a fluorophore, which are molecules that will send out, I think maybe a photon or some kind of light, if they pass a laser beam. So that is what the flow cytometer does. It's like laser beams that will activate these florophores, they are different and they emit light with different wavelengths so we can keep track of the different cellular subsets.

Once again we see how immunology becomes a colourful affair in practice. This time, colour is used to distinguish different kinds of cells rather than the intensity of antigen/antibody bonds, as in the ELISA test. She then took me out of her office and into the laboratory in the adjacent room. Here Astrid introduced me to the two flow cytometers. Like the ELISA machines 'Måns' and 'Anders', these were given names: 'Adam' and 'Elof' (see figure 16 left). I chuckle a little to myself, appreciating the ironic intertextuality of these devices not being named 'Adam' and 'Eve'.

Walking me through this practice, Astrid told me that the samples come into this lab, usually around lunch. These blood samples go through the process of staining or what is also called 'conjugation', which usually takes around thirty minutes. While the blood samples wait 

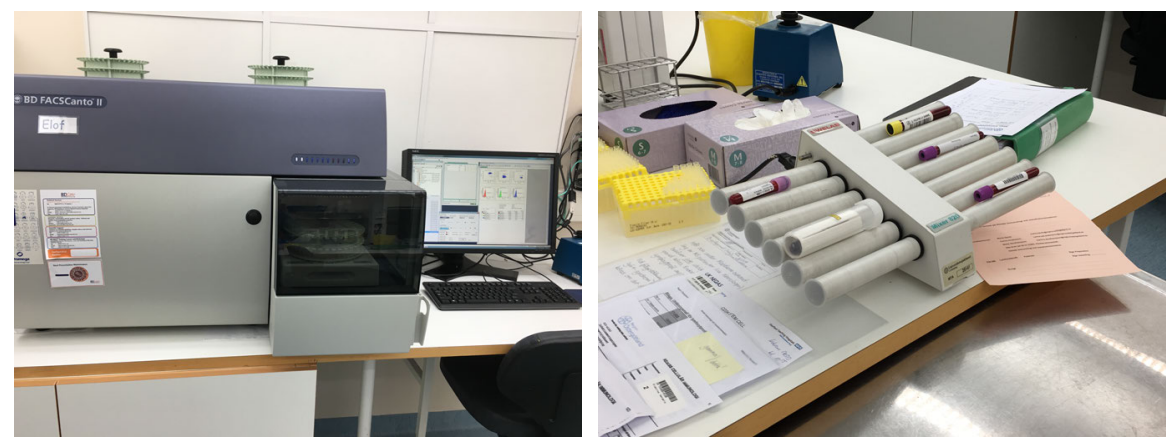

Figure 16: Adam \& Elof (the flow cytometers) \& blood samples rotating

to be conjugated with florophores and put into the flow cytometer, they sit on a strange little machine (see figure 16 right) that rotates, keeping the cells and the plasma from separating, something that they normally do when they are not kept in circulation due to their difference in weight. The samples then go into the flow cytometer and are directed through a very narrow channel. Here, the laser notes the different tags or stains that have previously been added to the cells in the sample. The machine can, in this way, tell whether an item in the blood was marked as 'cd4+' rather than 'cd8+'. By counting and sorting the marked cells, the flow cytometer enumerates the cells that flow through it. The technicians then pick up this data file that the machine has generated to analyse the pattern that has emerged. This flow cytometry inscription takes the form of a scattergram.

Astrid: And then we get like a scattergram where we can see what the cells are. Here, I will show you what it looks like for real. The technicians get these numbers, you see here (points at scattergram) you have the beads, 7291 events within this gate. And then you get the number of beads per microlitre, so you get a percentage. You get the number of cells per microlitre and this number is somewhere here just to calculate how big a portion of the samples that was collected. Because you know, maybe there were 15,000 beads in the tube and, in a volume of 100 micro-litres, we collected 7291 - so a little bit less than half of the total volume. So from that we can calculate how many cd4+ cells the sample contains.

So items called 'beads' are put inside the sample and counted along with it. In flow cytometry, you want to keep track of how many beads you put into the tube as well, as this provides you with a stable variable that you can use to compare with the number of cells you are trying to work out. The beads provide a base figure that can be abstracted from to estimate the class of cells that are deemed interesting to count with flow cytometry. ${ }^{78}$

With a cd4 count of 800 at diagnosis, this mode of enumeration came to know my

\footnotetext{
78 While flow cytometry is an important test for people living with HIV, there are not many of 'us' within this region, and this test is only performed once a year per patient at a cost of 1130 SKK, making it quite expensive compared to the others per test, but less than the overall cost of the PCR performed biannually for each patient.
} 
immune defences as fairly robust, but with a cd4 count that further improves after treatment. However, I myself have never crossed the threshold that lies at $200 \mathrm{~cd} 4$. While a body seem as 'healthy' may exhibit a variation between 500-1500 cd4+ T-helper cells in a microlitre (cells $/ \mu \mathrm{L}$ ) of blood, a flow cytometry result of $200 \mathrm{~cd} 4+$ cells or less would be diagnosed as AIDS, as prescribed by diagnostic guidelines: "There is a markedly increased risk of serious opportunistic infections when the CD4 cell count is <200/ml. (...) The CD4 cell count is used as a measure of the degree of immune deficiency, and is the most important prognostic marker for the risk of opportunistic infections." 79 Crossing this threshold, taken together with a detectable viral load, would then make me known as a subject with AIDS. This makes flow cytometry not only useful for diagnosing AIDS, but also to keep an eye on the immune systems of patients so that they never get to this point.

My analysis furthermore shows how, through this process of inscription, the patient living with HIV comes to embody a specific kind of conflict that, through the practice of flow cytometry, can be located under the skin; HIV now becomes accountable as something that attacks and destroys the molecular agents of the immune system. Through the inscription of cd4 values, HIV is thus enacted as a pathogen that attacks the agents in my body, the most affected of these being the cd4+ T-helper cells. This threshold therefore performs HIV more definitely as the cause of AIDS than in the other modes of knowing. Through the practice of flow cytometry, I become the subject in a potential state of conflict, a state that would only arrive when my levels of cd 4 cross a threshold and come to indicate the condition known as AIDS. The practice of flow cytometry thus enacts AIDS as a threat that lurks, even after the invention of anti-retroviral medications; a constant possibility in the future that must be kept an eye on. As Martin describes it: "No wonder it is disconcerting: the unimaginably small and the unimaginably large coalesced in the same image, agency residing in cells, the person becoming an observer of the agency of others inside him or herself. The "I" who used to wear the body like a closely fitting set of clothes is now miniaturized, and is dwarfed by its body. The "I" is made a passive and powerless witness to the doings of the components of the body. Somewhere in the system lies agency; the "I" can only watch." (Martin 1992:125) Knowing HIV as a state of conflict depends upon knowing the immunological defences and viral attackers as engaged in an ongoing molecular warfare.

\subsection{Conclusion}

In this chapter I have shown how knowing HIV can not only be done through diagnostic enumeration - that is, by counting levels of cd4, copies of HIV-1 RNA, and the value of antibody/antigen pairs in the patient body. I have also argued that different modes of enumerating HIV as an object of knowledge also enact different subjects. I then described and situated three of these enactments: 1) a mode in which HIV becomes other to the self by enacting the subject with antibodies/antigen in ELISA, 2) a mode in which HIV becomes $a$ deep genetic structure by enacting the subject with RNA in PCR, and 3) a mode in which

\footnotetext{
79 https://www.tandfonline.com/doi/abs/10.3109/00365540903214322, accessed 2020.04.07
} 
HIV becomes a state of conflict by enacting the subject with cd4 in flow cytometry. I have thus shown in this chapter how each of these modes of knowing HIV also enact a different subject. Through this story, I have shown how the 'undetectable' subject is multiple: undetectable antigen can be brushed aside when combined with a detectable antibody result, while two subsequent undetectable viral counts can make me a 'well-treated' subject. On the other hand, an undetectable viral load without medication would make me an 'elite controller' subject, a subject that is said to control HIV without taking any drugs. However, an undetectable cd4 count would make me the subject with AIDS, a possibility I hope to never encounter. As such, I argue that the undetectable subject is best thought of as a manifold subject. While my 'patient self' is no doubt fond of the treatment slogan which states that $\mathrm{U}=\mathrm{U}$ or Undetectable $=$ Untransmittable, my 'praxiographer self' finds it to be a critical moment to take stock of who these 'undetectables' variously are and how they are detected (or not) to begin with. As the status of 'undetectable' becomes more and more often ascribed to anti-retroviral drugs, I think it is worth noting that this is not always the case.

Together with Lynch, I see the work these testing devices do as a kind of 'rendering accountable'. But unlike him, I neither think that this necessarily makes objects or subjects 'docile', and neither do I think these modes of knowing and enumerating HIV can be located and situated solely within the reflexive activity of the members in this laboratory practice. Put otherwise, I think the practical activity of laboratory work is performed by a startling variety of 'nonhuman' members, only a few of which I have even attempted to describe and account for. There are enzymes recruited from underwater volcanoes, there are machines that are given names as they are welcomed into student life, and of course, there is the human immunodeficiency virus. But even these entities do not act alone. They too are translated - they are folded - into the practices of the laboratory.

As the next chapter will show, molecular and serological lines become drawn in these laboratories that will again fold into what is called 'molecular surveillance' and used in in public health practices. These diagnostic values also serve to enable and constrain the conditions of treatment as the final empirical chapter will show. The biomedical values that I have described in this chapter are the contingent accomplishments of handling HIV in my own situated case, and describing this work renders me able to account for the manifold possibilities of knowing my condition. In describing these ways of knowing HIV, my aim is not to suggest that these are merely different perspectives one might take on HIV or to suggest that 'anything goes'. Neither is it my point that one of these ways of knowing HIV is more 'right' or more 'real'. Each of them perform reality and truth in a different way. However, through my experiences as a patient living with Swedish HIV, I have shown how they come to coordinate multiple versions of reality. In line with the material-semiotic approach I draw on in my work, this chapter has tried to make sense of the way in which slowing down can be useful in coming to terms with indeterminate subjects, both within the laboratory and outside. By taking this approach, my analysis becomes furthermore rendered capable of responding to the multiplicity of visions that are inscribed in diagnostic practice. The following chapter will now explore this topic of 'visibility' further. 


\section{v // Folding patients into populations}

\subsection{Introduction}

Having now seen how diagnostic practices in the hospital lab inscribe and enact the subject with HIV in three distinct ways, I will now argue that these modes of knowing and doing HIV, of becoming accountable to HIV, each in turn become folded into the object and methods of disease-control. That is, I show how each of these modes of enumerating the subject of HIV become taken up and used in an entirely different space - from diagnostics to surveillance. I argue that these folds bear critical implications for what becomes of the subject in HIV surveillance. By describing the differing effects of these surveillance techniques, this chapter teases out the tensions that arise in the re-inscription of accountability that perform differences in their regard for the subject.

In the STS literature, folded objects have recently gained attention. Described by Law and Singleon as material-semiotic patterns of continuous discontinuity, and by M'Charek as a practical and relational folding between absence and presence, I draw on inspiration from this literature (Law \& Singleton 2005; M'charek 2014). This chapter develops an account of how subjects too are generated through a folding relation between absence and presence in HIV surveillance. The stories I tell will illustrate the processes of categorisation that decompose risk groups into key populations, as this will enable the reader to follow these categories through this chapter and the next to see the consequences of categorisation for people living with HIV.

The re-inscription of accountability in surveillance comes along with specific ways of seeing the subject of HIV; surveillance changes the ways in which the subject of enumeration is known and targeted. As the following stories will show, the folding of diagnostic techniques into surveillance can be seen as a practical activity that makes absent the realities, objects, and subjects upon which the newly populated territory of vision comes to depend. I thus argue that the optic specificity of surveillance devices comes at a cost of haptic sensitivities. Rather than producing an all-seeing vision however, these stories highlight the persistence of problems that emerge for the subject of containment and the way these problems receive attention and regard by the agents of disease control. This chapter argues that not only does surveillance enact an 'overview', but that it sometimes also 'overlooks' it's own hybridity. As an effect, some subjects become folded out of the picture; this chapter aims to ask how and along with what consequences this event may occur.

\subsection{Making absent 'individuals' to present 'key populations'}

October 9th, 2017. My colleague and I have been invited to the European Centre for Disease Prevention and Control to present the results of a social media analysis my colleague has worked on for this agency and to discuss the possibilities of further collaboration. Having been in contact with their HIV surveillance agents through Skype meetings, I have also come along to get a tour of this centre and the work done here. We head up a hill toward the red brick building that stands atop its summit. The structure, complete with a flag and a steeple, 
bears an uncanny resemblance to a fortress. Later, we will be shown what they call the 'outbreak room', a space fitted with high-tech screens that surround a soundproof conference room used when holding meetings about the latest outbreaks of infectious diseases in the EU. Through this encounter, I start to understand why agencies of this type refer to themselves in their documents as 'competent bodies' 80

We head inside the building and are met by a security guard who checks our appointment, our identities, and our bags, bodies, and belongings. While waiting to be met by our contact, I take a look at a series of magazines that are on display by the entrance. They bear the title 'Eurosurveillance - Europe's journal on infectious disease epidemiology, prevention and control' accompanied by the qualifier 'Impact factor 5.7' next to the title. One of them in particular catches my attention - 'Special edition: HIV in MSM, June 2015'. Browsing through the first few pages, I am told that "men who have sex with men (MSM) have been identified as the group most at risk of HIV infection in the European Union"81. Throughout this document, diagrams and tables show me the ways that MSM become subject to surveillance measures.

One article provides me with an evaluation of these measures, and one specific value in particular stands out - HIV incidence. Toward the end of the document on page ninety one, a table organises twenty-four items labeled 'interventions'. Each of these interventions is a technique that is being evaluated for its impact or affect on HIV. These items have all been historically incorporated into public health programs and the practices of gay men. They range from 'condom use', 'male circumcision', and 'serosorting' to 'avoiding nitrite inhalants/ poppers' and the 'reduction of alcohol binge drinking'. All of these interventions are put into question by this table as to their effect on HIV prevention and control. While these are not surveillance measures themselves, they are all strategies that surveillance practices are very interested in understanding and evaluating.

But this table does more than simply provide a list of strategies for mediating HIV risk. The table provides each intervention with what it calls a 'HASTE (Highest Attainable Standard of Evidence) grade' from 1-4, depending on categories such as 'Outcome' and 'Plausibility'. Through this table, some interventions become accountable as more effective than others. In other words, publications such as this one provide a way of qualifying surveillance tools and measures in their effect on practice. From a quick look, it is easy to see that the in-

\footnotetext{
${ }^{80} \mathrm{https} / /$ www.ecdc.europa.eu/en/about-us/who-we-work/disease-and-laboratory-networks/european-networkhivaids-surveillance/about, accessed 2020.04.07: “In the EU/EEA countries, the Member States' competent bodies for surveillance have nominated national contact points for HIVIAIDS surveillance to work with ECDC and the WHO Regional Office for Europe on the reporting of surveillance data to the joint database for HIVIAIDS surveillance in The European Surveillance System (TESSy). For the non-EU/EEA countries, nominations for national HIVIAIDS surveillance focal points are received directly by the WHO Regional Office via the respective ministries of health."
}

${ }^{81} \mathrm{https} / / / \mathrm{www} . e u r o s u r v e i l l a n c e . o r g / d o c s e r v e r / f u l l t e x t / e u r o s u r v e i l l a n c e / 20 / 14 / a r t 21087-e n . p d f ?$ expires=1586265159\&id=id \&accname=guest \&checksum=8ACE2749B8A292E18242836AD637A510, accessed 2020.04 .07 
terventions that are evaluated as having an effect on HIV incidence - such as antiretroviral treatment and PrEP - receive the strongest HASTE rating. Through this evaluation, the value of 'HIV incidence' in surveillance practice becomes apparent.

The field of 'surveillance studies' (Ball, Haggerty \& Lyon 2012) has some interesting things to say about surveillance practices such as these. For example, Lyon calls attention to what he calls 'social sorting' or the categorising of people and populations. In his view, the object of surveillance across its many domains and techniques remains the same: "to capture personal data triggered by human bodies and to use these abstractions to place people in new social classes of income, attributes, habits, preferences, or offences, in order to influence, manage, or control them" (Lyon 2002:3). This begs the question of what it means to 'control' people in this sense. The many new policies, technologies, and initiatives of surveillance that emerged after the 9/11 catastrophe seem to play a critical role for surveillance studies. This event has thus become an iconic opportunity for these scholars to deploy the theoretical repertoire of surveillance studies - often making explicit use of George Orwell's novel dystopia and Jeremy Bentham's Panopticon to illustrate their concerns.

In surveillance studies, Foucault also becomes a notable figure through which to understand the object of surveillance. In Discipline \& Punish (Foucault 1977), he sketched out the figure of the panopticon. Not only was the panopticon the material arrangement of a prison design - a way of organising vision such that every prisoner could be virtually certain they were being watched without actually seeing their watcher - but Foucault furthermore presented this panoptic vision as the diagram of power that was becoming characteristic of post-modernity. The panopticon as a form of power is first and foremost productive of a division between supervised and supervisors, and vision becomes very different for each party as an effect. Haggerty and Ericson (2000) draw on the work of Deleuze and Guattari instead. According to these scholars, we are now seeing the emergence of what they call 'the surveillant assemblage'. For them, the surveillant assemblage produces what they call 'data doubles' (Haggerty \& Ericson 2000:613), copies of individuals that become detached from their embodied person to circulate within spaces and networks of surveillance. In other words, surveillance technology enables the ability to discriminate amongst individuals and populations.

Discrimination here means not only the making of a difference, but also points to a potential disadvantage distributed to subjects marked in different ways. The concern that is shared by these approaches is the study of surveillance - understood as, "the focused, systematic and routine attention to personal details for purposes of influence, management, protection or direction" (Lyon 2007:14). As a prominent scholar in the field of surveillance studies, David Lyon clarifies the term 'surveillance' by relating it to the French verb 'surveiller' or to 'watch over' in English. Here we get a sense of how supervision is an important aspect of this practice. Surveillance might therefore be understood as a way of governing through technologies of vision and oversight. But what exactly is the 'object' of this supervision; who is the subject of surveillance? Who or what is doing the watching and who or what is becoming envisioned through surveillance?

While surveillance studies often identify important aspects of surveillance assem- 
blages, they generally conceive of surveillance as generating an 'all-seeing' vision. Studies of surveillance technologies undertaken by STS show us something quite different. Bruno Latour confronts the trope of 'panoptic' vision with the neologism of 'oligoptica'. The Greek term 'olig' translates into English as 'little', and for Latour this is what oligoptic devices do far from seeing everything, their scope of vision is minimal.

"Oligoptica are just those sites since they do exactly the opposite of panoptica: they see much too little to feed the megalomania of the inspector or the paranoia of the inspected, but what they see, they see it well (...) Whereas oligoptica are constantly revealing the fragility of their connections and their lack of control on what is left in between their networks, panoramas gives the impression of complete control over what is being surveyed, even though they are partially blind and that nothing enters or leaves their walls except interested or baffled spectators." (Latour 2005:181, 188)

For Latour, a map can be seen as an oligoptic device. It highlights particular markers that will help the viewer to navigate the terrain, but at the cost of a great amount of detail that must be excluded so that it may work as an efficient guide. But still I wonder about the notion of oligoptic vision. Are surveillance devices always small and do they always see well? Surely, the extent of the gaze and sharpness of its vision are matters for empirical investigation.

As indicated by its place within the fast-track assemblage and technoscientific evaluations such as the table I describe in my encounter with HIV surveillance, the estimation and lowering of HIV incidence is highly valued in such practices. So how then is this value of 'incidence' calculated? What are the techniques involved in doing so? Discussing these questions with the head of HIV surveillance at the ECDC, I would come to learn that even within the EU, there were a few possible answers. Two surveillance technologies however, took to the stage - the first being referred to as 'RITA' and the second as 'cd4 backcalculation'. Following these technologies through HIV surveillance networks in Sweden, I would later come into contact with Linus, an epidemiologst working with a third surveillance technique: phylogenetic analysis. Linus also made it clear for me how surveillance concerns congeal in the fast-track assemblage. He explained that the two last '90s' - namely, providing treatment to those who are diagnosed and having these patients achieve what is known as 'viral suppression' - are easy to measure in Sweden ${ }^{82}$. This he attributed to what he called 'a very good planned care' of people living with HIV in Sweden. A key feature that he attributed to this good care, was a national HIV database - InfCareHIV.

"The Swedish InfCareHIV cohort is a nationwide observational cohort that monitors HIV management of all HIV-positive people (>99\%) in HIV care in Sweden since 2008, the majority since 2004, and significant number of patients at Karolinska University Hospital and South Hospital,

\footnotetext{
82 While these '90s' are contingent on the diagnostic devices I analysed in the previous chapter, I will slow down and unpack these fast-track targets more in the following chapter as well. For now, I will focus vertically on the third ' 90 ' and horizontally on the infection estimates in various populations and the way which discrimination becomes discounted in favour of these other fast-track targets.
} 
Stockholm, since 1980-thies. The cohort utilizes a software, InfCareHIV, which allows several functions: clinical decision support, national HIV quality assurance registry, long-distance consultation, self-reports of quality of life, and a research database." 83

InfCareHIV is a tool that is used by the clinics everyday for diagnostics, treatment, and management, but since it contains information about all the patients that are presently undergoing HIV care in Sweden, Linus told me that it was a good source for epidemiologists to know how many are diagnosed, how many are on therapy, and how many are virally suppressed.

Linus: And the figures there are excellent, basically everyone is on therapy who is known to have HIV. Almost all of them are also suppressed, so they have a therapy that works.

In accounting for the two latter healthcare targets of the fast-track assemblage, this researcher points out that the care and treatment 84 of those that are diagnosed looks quite good in Sweden. The network of instruments, patients, professionals and techniques of enumeration that we explored in the previous chapter becomes useful to measure the work done in Swedish HIV care against the fast-track assemblage - at least for diagnostic and treatment goals. The national database produces a regional and networked object that 'presents' - that makes present - a great amount of information on Swedish HIV care to agencies working with disease control. In other words, InfCareHIV enables the folding the diagnostic subject into surveillance practice. In the sections that follow, I want to look closer at what happens with these 'presences' as they are folded from one practice and into another. Following Law and Mol (2001), I will thus describe the subject of surveillance as folded in relations of absence-presence.

Investigating the material concerns of a mathematical formula related to aircraft engineering, Law and Mol show how the formula comes to perform, "a flickering between present-presence and absent-presence" (Law \& Mol 2001:617). The messiness of experiments to define thresholds that pilots can endure, for example, are made absent through their presence as elements in the formula. For Law and Mol, these objects take a more or less stable shape through an ongoing enactment of discontinuity (Law \& Mol 2001:618). Law and Singleton (2005) recall this aircraft story to further emphasise the point.

"An object is a presence. It is present, here and now. But whatever the form of its presence, this also implies a set of absences. The present object implies realities that are necessarily absent, that cannot be brought to presence; that are othered. So, to put it slightly differently, an object is a pattern of presences and absences." (Law \& Singleton 2005:342-343)

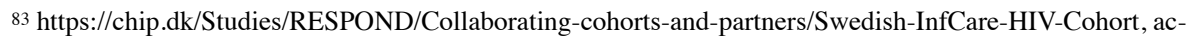
cessed 2020.04.07

${ }^{84}$ I will discuss this topic further in the following chapter.
} 
Amade M'charek (2014) further develops this insight into absent presences with the notion of the folded object. ${ }^{85}$ Thinking through the ways in which 'race' becomes folded into genetics, M'charek shows how this object makes and remakes itself in consequential ways:

"It is vital to attend to the technologies involved in folding, for they do not only allow for naturalization by suggesting an alleged linear development, but also for interferences and surprising relational effects once we take these technologies into account." (M'charek 2014:316)

I find this insight to be a useful way to approach HIV surveillance, so the argument I put forward in this chapter is that this object lesson pertains to subjects as well. When the subject of surveillance is seen as a folding relation between absence and presence, then a new question can be posed: what are the absences and presences upon which surveillance must depend? I will thus show how the subject of HIV surveillance is folded between health-care and disease-control in three distinct ways. Each fold makes different things absent so that others may be made present. Each generates a similar pattern of effects in a different way.

While the notion of 'folding' may work with metaphorical value, I do not take folding to be 'just' a metaphor. Instead, I treat folding as a practice. Folding is a practical activity performed in various material-semiotic settings, and it has specific effects. In this chapter, I will draw together three situations in which I have sketched the practicalities through which the subject of HIV treatment becomes folded into the subject of HIV surveillance - the folding of 'the patient' into 'the population'. By describing these situations and unpacking the details through which these folds are accomplished, I will analyse the consequences of these surveillance technologies in their differential capacity for governing a manifold subject. I will thus show how operations of folding diagnostic values into surveillance practice have a consequential effect as well - they enact the very population in which the incidence rate is then situated. In other words, populations are made real by the folding operations of algorithmic surveillance. Let me flesh this out more empirically.

My talks with these professionals, and my experiences at the 2018 International AIDS conference, made me see how surveillance practices talk a lot about populations. But more specifically, they seemed to be concerned with a variety of 'population' they called 'key' populations. Often, this would even become an acronym in statements made by surveillance professionals, such as “you have to know your KP's well”. While analysing a document from UNAIDS called 'the gap report', I found a series of figures that I found visually affective and that made me better understand this concern with 'KP's. Three of them in particular stood out.

The series of figures is given a title: "12 populations being left behind". I related this at first to the fast-track assemblage and the statements of direction that I analysed in the introduction to this thesis. A list follows the title:

People Living With HIV

${ }^{85}$ M'charek develops her account of the folded object in debt to Serres. 
- $\quad$ Adolescent Girls And Young Women

- Prisoners

- $\quad$ Migrants

- People Who Inject Drugs

- Sex Workers

- Gay Men And Other Men Who Have Sex With Men

- Transgender People

- $\quad$ Children And Pregnant Women Living With HIV

- Displaced Persons

- $\quad$ People With Disabilities

- $\quad$ People Aged 50 Years And Older.

This list is once again marked with the title 'key populations'. On page 122 of this gap report, I found a visualisation of 'People Living With HIV', the first of these twelve key populations (see figure 17).

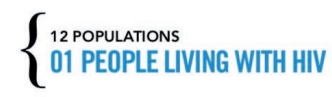

\section{I am a person living with HIV. \\ I face these issues.}

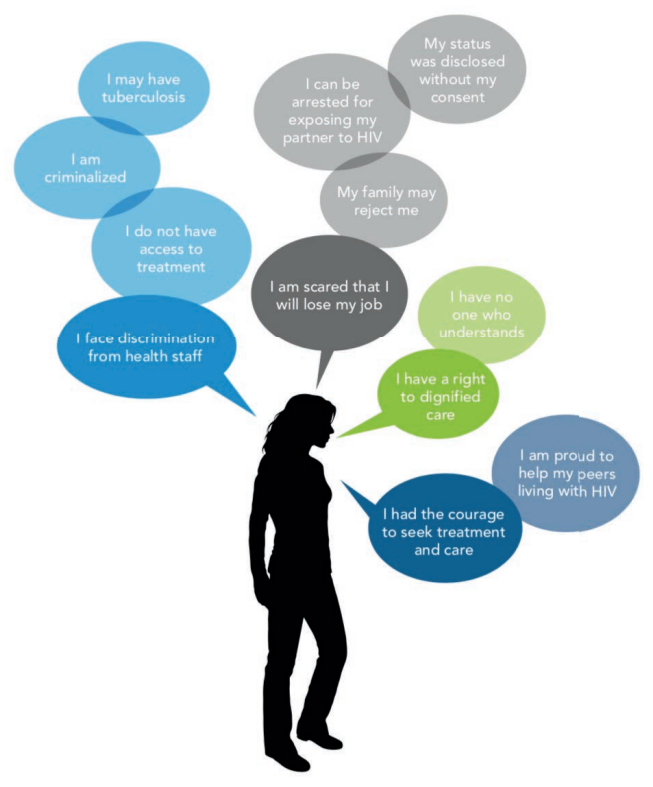

Figure 17: the person living with HIV as an accountable population ${ }^{86}$

\footnotetext{
${ }^{86} \mathrm{http}$ //files.unaids.org/en/media/unaids/contentassets/documents/unaidspublication/2014/UNAIDS_Gap_report_en.pdf, accessed 2020.04.07
} 
As figure 17 shows, the document presents the person living with HIV as an accountable population of interest to surveillance practice. In this way the document identifies and characterises twelve key populations affected by HIV. It presents and differentiates each of their concerns, and it does so in a visual format. Figure 17 is dressed and posed in an androgynous form. Around this figure are twelve speech bubbles, each giving voice to a particular issue this population faces. Through this figure, I become a member of this population, and I share these concerns. Looking at this image, I instantly identify with these issues directly and indirectly. "I can be arrested for exposing my partner to HIV". Sounds familiar. "I am proud to help my peers living with HIV”. I do hope this research can become helpful in some way. Just as the message on the wall in chapter one took on my voice to speak of eradicating HIV, these pages come to assign the population I become a member of. They interpellate me, but this time not as an individual; they interpellate me as belonging to a population. An accountable population or what sometimes informally becomes known as 'a risk group'. As we will come to see later in this chapter, I also identify with more than one of these populations. I will now show how, through the folding operations in HIV surveillance, I become inspected as member of this 'key population' - a subject living with HIV.

\subsubsection{Folding subjects with antibodies into incidence of infection}

This section will describe the way in which the subject enacted with antibodies/antigen becomes folded into a surveillance technology called 'the recent infection testing algorithm' or 'RITA'. To tell this story, I will draw on interviews with epidemiologists making, using, and evaluating these techniques to show how laboratory methods for diagnosis became modified to estimate incidence. In so doing, I will investigate the complications and gains that come along with this movement. This story allows me to show the first aspect of the folded subject: the individual person that must be made absent in order to present a population estimate. So how is incidence measured? How does incidence relate to the subject of HIV surveillance? How is the subject of Swedish HIV surveillance seen and categorised?

One conversation with Linus spoke to many aspects of these questions. Linus told me that there were basically two ways of defining incidence in Sweden, and each came along with its own question. The challenge in a country like Sweden, he told me, was that the number of new cases is low, and the majority of these incidences of HIV are persons who are infected before they ever enter Sweden. These people he characterised as 'immigrants' of different types. Linus told me that around $70 \%$ of the newly diagnosed patients in Sweden were originally infected elsewhere, such as East Africa or South East Asia.

Linus: And that means that there are two components of the incidence. One would be what we normally call incidence, that is, 'how many are being infected today or this year in Sweden?' But that information is too partial to describe the overall situation in Sweden, so the other part would be 'how many infected enter Sweden for the first time and eventually are diagnosed here?' And both of these things relate to the first of the 90-90-90 goals or targets. And then it's much more difficult to estimate the proportion of undiagnosed. And there are many reports on this, and there 
are different ways of trying, but there is no way of ever having a complete record of this. So it has to be estimated because the patients are undiagnosed, so how would you count those persons? The only way is to estimate.

What we see here is that surveillance practices comes to envision the 'diagnosed' and 'undiagnosed' subject differently. The 'undiagnosed' subject is presumed to be a person living with HIV who has not come to know their status through diagnostic testing. The first of the 90-90-90 goals involves first knowing how many people are living with HIV so that the number of those being diagnosed can then be counted and the number of undiagnosed can then be estimated. This is one way in which surveillance sees the subject in practice. But for the practical purposes of surveillance, it matters a lot where and when the infection originally occurred too. In this chapter, I will show how this concern with the spatial and temporal boundaries of infection come to define the topology of Swedish HIV. As I will come to show, understanding the value of 'incidence' is an important aspect of the when. While I will return to Linus' research on the undiagnosed populations living with HIV, I first want to look at one technique that became recommended by agencies such as the World Health Organisation (WHO) and UNAIDS to measure HIV incidence by folding antibody responses from diagnosed patients into more generalised rates of infection.

To understand this technique myself, I first got in touch with two epidemiologists who had worked with the WHO/UNAIDS to evaluate tools used for incidence estimation. These epidemiologists, Patrick and Shane, helped me to understand the benefits of incidence technology and the problems it comes along with. They explained to me that what professionals call 'recent infection testing algorithms' are modified laboratory tests - typically antibody tests like the 'ELISA' we saw in the previous chapter. Through the figure of the recent infection testing algorithm, what they referred to as 'antibody assays' (the ELISA test in the laboratory) now become known as 'incidence assays' and can be used to estimate incidence for a variety of purposes. Figure 18 illustrates the basic rationale behind RITA techniques in the form of a diagram.

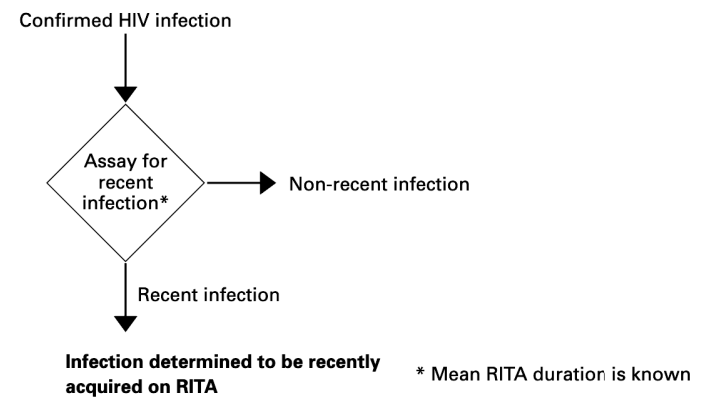

Figure 18: diagram of a recent infection testing algorithm (RITA) $)^{87}$

\footnotetext{
87 https://www.who.int/diagnostics_laboratory/hiv_incidence_may13_final.pdf, accessed 2020.04.07
} 
The visual starting point at the top of this image is labeled 'confirmed HIV infection' and this is meant to represent the input to the algorithm - samples from persons already having been diagnosed with HIV. An arrow points down to a box that contains the label 'assay for recent infection'. This label is given an asterisk that refers to a note explaining that the 'mean RITA duration is known'. This mean RITA duration is a value that is further defined as "the average length of time that people with newly acquired infection in the population are to be classified by the RITA as having recently acquired infection." 88

This implies that a rule called 'mean RITA duration' has been defined locally in a population for this algorithm to work properly, but the diagram erases this complexity for the sake of comprehension. Ironically, I do not in any sense 'know' the mean RITA duration of HIV infection in Sweden, if indeed such a calculation has even been made here. But this matters little for the story I want to tell. What is instead important about this 'RITA' is that in practice this black-boxing89 algorithm performs what I and my colleagues argue is better grasped as a fold..$^{90}$ This particular 'operation of folding' (Lee et al. 2019:1) not only transforms ELISA input into RITA output, but it does so through a modification of the sensitivity to the assay being aligned. I will explain this further in a moment. In the diagram I have presented, the output of this process is then shown by two arrows, one pointing to the right of the page and one pointing downwards. These arrows indicate that the result of RITA will be/is/ was either 'recent' or 'non-recent'.

To me, this diagram was incredibly simple and also very complex. I wanted to better understand the rules and logics that this algorithmic technique embodied, but at the same time the algorithm seemed to be here already. Already on the page or in the list of references somewhere. But there were also practical aspects to this algorithm that I just could not find in these texts. To make matters worse, or at least more difficult, my efforts to engage surveillance practice and learn first-hand how these complexities were handled in Sweden were mostly met with silence and deferral. Someone else down along the chain would help me, but most professionals were just too busy to talk to a 'mere praxiographer'. To find out more about this algorithm contextually and in practice, I talked again to Shane, from whom I received another image to think with.

Shane: In my understanding, an algorithm is like a recipe. They're a set of rules, and if you apply the rules you will certainly get the answer. An algorithm is saying, 'if you take blood, do this, do that, do the other', you will get a number, which can be above or below a threshold. And that is your answer. You put in the ingredients, you get a cake out the end. And if you put in the same in-

\footnotetext{
${ }^{88} \mathrm{https} / / /$ www.who.int/diagnostics_laboratory/hiv_incidence_may13_final.pdf, accessed 2020.04.07

89 "The word black box is used by cyberneticians whenever a piece of machinery or a set of commands is too complex. In its place they draw a little box about which they need to know nothing but its input and output." (Latour 2000:681)

${ }^{90}$ See also Lee et al (2019) for a theoretical exploration of the notion of 'folding' and an empirical account of how algorithms perform what we call operations of folding.
} 
gredients you always get the same cake.

Here, the image of 'the algorithm as a recipe' becomes offered by Shane. The algorithm, like the recipe, is composed of a set of rules made by Shane and other epidemiologists. Do this, do that, do the other. Within the algorithm, a threshold is also set, and this threshold works as a binary knife to cut the result between 'recency' and 'non-recency'. To do this, the assay must undergo what is referred to in this practice as 'detuning' and a value called 'sensitivity' would have to be decreased. According to these professionals, 'sensitivity' is a value that can be used to evaluate how 'good' a given assay or combination of assays can be said to work in providing a diagnosis. For instance, an ELISA test with a high sensitivity will return a higher degree of 'positive' results. Modifying the sensitivity of the assay as it is incorporated into a RITA could allow the individual inconsistencies to be made absent and would allow for the possibility of inspecting the temporality of a population infected. Detuning the diagnostic sensitivity of an ELISA test makes it more useful as a RITA test in surveillance practice.

Through this algorithm, the subject of ELISA testing becomes folded into the recently or nonrecently infected subject in RITA testing. In making absent individual errors, the algorithm is moreover able to make possible a population estimate of incidence. The algorithm requires an input, in this case the antibody/antigen values that were generated through the ELISA diagnostic, in order to produce an output - an estimate of recency/nonrecency for a patient or group of patients, which can then become an infection rate. The antibody/antigen values of patients are thus made absent in oder to present the incidence of a population. Through this operation of folding, a re-inscription (Akrich \& Latour 1992:262) of the subject also takes place. Here, the diagnostic subject with antibodies/antigen becomes re-inscribed, folded into the recently or non recently infected subject of surveillance.

Some of the diagnostic complexities we saw in the previous chapter also come along with these tests in their folding of the subject from diagnostics into surveillance. Shane told me that the problem with incidence assays is that what you are measuring is an antibody response, and this means that you sometimes get 'false positives'. Some bodies react as if they have recently been infected, even though they have been infected for a long time. A 'true positive' result would mean that the person actually had a recent infection and the algorithm detected an antibody response that would be expected of a recent infection. Some bodies don't react at all. Other bodies react 'normally' or as anticipated.

Talking with these developers and evaluators, what came into focus was the way in which bodies did not easily fit through the black box of the algorithm. In practice, there was a wide margin of error for these algorithms. Immune responses to HIV are multiple and this makes serological surveillance and what I will call 'post-serology' complex. Much of the work being done by Shane and Patrick was thus to better understand and handle these complexities within the algorithm. This they said can be done with calculative corrections.

Patrick: You want the positives to be true positives, you want the negatives to be true negatives 
and it can go wrong both ways. You can get a positive who is really negative and a negative who is really positive. Now if we can measure, let's say the sensitivity and specificity are around $75 \%$, then $25 \%$ of the time you're gonna get the wrong answer. $75 \%$ of the time you are gonna get the right answer. But at the population level, you can say 'well, we measured a prevalence of $20 \%$ but we corrected for sensitivity and specificity, and it was $15 \%$ or whatever, so at population you can work it out. We know what the probability of getting a false positive is. Then we can do a correction and say what the true prevalence is.

Shane and Patrick located the mess primarily at the diagnostic level. For their purposes at the surveillance level, any errors in their estimation of incidence or prevalence required merely another step that corrected the probabilities. It merely required a further inspection and re-inscription of the subject. At the diagnostic level things work differently. For patients and professionals doing diagnostic work, the stakes are altogether different. A baby diagnosed as 'positive' will have to be medicated immediately. Sometimes there is no time for a further inspection to find out how 'true' or 'false' that positive is. In what follows, Patrick explains to me how the values of 'sensitivity' - "sorting out the positives" - and 'specificity' "sorting through the negatives" - help these professionals to account for the limits of the algorithm.

Patrick: So the problem is, from the individual point of view you want very high sensitivity and specificity. You do not want to tell someone falsely they are negative or positive or visa versa. So the problem is, the individual need is quite different from the public health need. I mean, all we want to know is, 'is the number of new infections going up or down'. You know, 50.000 last year, 40.000 this year, that looks great. But all we can talk about is the average rate. And we can correct for the sensitivity and specificity, we can see if that corrects errors, we can do everything very nicely, but from the individual point of view that's not a great deal of help.

As I have previous shown, the fast-track assemblage juxtaposes diagnostic and surveillance concerns. In talking with Patrick, it seemed that these concerns were also both at stake in incidence technology more specifically, but in different ways through different situations. Diagnostics has its question: 'was this patient recently infected with HIV or not'? Surveillance has quite another: 'is the incidence of HIV infection going up or down'? Both can be answered by inspecting the answer to this question with a 'recent infection testing algorithm'. Knowing the sensitivity and specificity of a particular assay becomes a valuable way of addressing the limits and errors of these technologies in surveillance practices, but this may not address the concerns of the individual patient. For some patients, the recency of their infection may not matter much anyway. For other patients, it may influence the accountability they hold to others they have had sexual or intravenous encounters with. Importantly, the algorithm here reconstructs the temporality of the infection. It may thus become an important marker for medical professional who wants to know the boundaries of a particular patients' sex life for the management of that patient, without having to trust the verbal account offered by the patient. While an ELISA test may provide the possibility for one estimate of the time 
of infection for a given patient, the detuned sensitivity of a RITA may return an altogether different time of infection. So depending on how the contact tracing ${ }^{91}$ is performed when diagnosing a new patient, this temporal shift may come to matter quite a lot.

Shane and Patrick told me stories of how doctors used to have the time to know their patients intimately. They knew their families and communities well. These days, with the scarcity of time and resources, they told me how doctors were becoming interested in taking advantage of tools like RITA for patient management. Relying on an algorithm may be more convenient for some doctors in ascertaining a time of infection than relying on conversations with a patient. This story thus carries along an idea and problematisation of being free from human error. As they told me, surveillance technology could indeed become problematic when their limits and errors are not taken into account when folding from surveillance back to diagnostics, which is what the doctors were said to be doing. Here the doctor becomes split into (at least) two; from the position of the surveillance practices I encountered here, epidemiologists surveying populations should concern themselves with disease-control through tools such as this RITA, while physicians treating patients should stick with health-care tools and diagnostic tests such as ELISA.

Patrick told me that there had been a widely held view in the HIV field that incidence devices used for staging infections as recent or non recent had a purely surveillance application. Back then, he told me, it was seen as very problematic to interpret them at the individual level. But he also said that this view had strongly shifted. Now there was said to be a lot of interest in using the same technology to generate information about individuals. This, they said, was quite a strong movement at the moment. Shane further explained why this was so. Recent infection testing algorithms become important to measure incidence, as they are cheaper, easier, and quicker than the alternative surveillance method which Shane described as 'getting a thousand people and following them up and keeping track of them'. In some countries such as Sweden, there are tools and databases (such as InfCareHIV) to handle this method of incidence estimation, but elsewhere, techniques such as RITA become much more operable.

Shane: So if you can do a recent infection assay it's incredibly powerful. The problem is, you've got an algorithm, which sometimes produces nice cakes, and sometimes the cakes flop, and you don't know why the cakes are flopping.

In the story Shane told me, the output of the algorithm-as-recipe could be thought of as a 'cake'. But what becomes a matter of concern for surveillance practices, is the fact that many of their 'cakes' seem to turn out rather oddly. In the folding of antibody/antigen inscriptions into this surveillance tools, a tradeoff between the individual value of RITA and the value it holds for estimating population level incidence occurs. In making a good estimation, the tools must make absent the erratic responses of individual bodies so that regularities and irregularities can be made present in populations. But while much work goes into standardising

91 I will return to this practice in chapter 6. 
the 'algorithm' to prevent it from making cakes that flop, what is not taken into account are the differences in flour, water, and humidity while baking, the different intensities of the agents that make the cake rise - or not. In other words, perhaps it is not only about 'the recipe', but also about the multiplicity of 'ingredients'.

This story shows how recent infection testing algorithms can be analysed as an operation of folding individual antibody responses into the temporality of infection, providing the means for estimating population incidence. As an effect, having a 'recent' or 'non-recent' infection are the ways the subject of RITA surveillance comes to be seen. This operation of folding reconfigures diagnostic ways of knowing and seeing people living with HIV. While individual immune responses are made absent in their aggregation, the value of population incidence becomes present as a newfound character of an epidemic.

\subsubsection{Folding subjects with RNA into transmissions of infection}

This section will now look at a second operation of folding the subject: how the natural history and societal treatment of people living with HIV are both made together and simultaneously held apart. This story tells of the myopic visions of powerful technologies. It tells of desires to improve this vision both technically and ethically and to make the care and control of HIV more effective. My analysis of this material will describe the folding of the subject enacted with RNA into transmission histories that may be used in the court of law. This allows me to show how the continuous enactment of the surveillance subject takes place as an effect of discontinuity. So what is the extent and quality of the 'surveilling gaze' and what are the effects that it brings about? As a virologist and molecular epidemiologist, Linus was once again able to speak to this question. Discussing a diagram ${ }^{92}$ that featured in an article he had published on HIV-1 subtype B - the viral strain I live with as a present-absence 93 he explained to me what we were looking at and how it was constructed.

Linus told me that simply put, this was a graph called a 'phylogenetic tree' that displays the evolutionary history of this virus. Things that are close-by in the tree, what he called 'neighbours', were said to be evolutionarily closer to each other than the tips that are further away in the graph. Linus told me that when it comes to evolutionary history and viruses it is also tightly linked to transmission history between the patients that carry these viruses. The 'evolutionary history' and 'transmission history' of HIV are thus related and distinctly accountable within this image. Phylogenetic analysis thus enacts the subject with a 'natural' history.

Linus: So if we look for instance, there is a 'I' at around 5-o'clock in the tree. And there you have like five red coloured tips and branches. So those five are, have genetic distances that are relatively short, at least compared to the distance if you travel from ' 1 ' over to ' 5 '. Because the branch

\footnotetext{
92 https://journals.plos.org/plosone/article?id=10.1371/journal.pone.0033484, accessed 2020.04.07

${ }_{93}$ As we saw in the previous chapters, I am both marked as being 'HIV positive', and yet there has been no detectable virus in my body due to the chemoprophylaxis I started three weeks after my first diagnostic test. Chapter 6 will tell this story.
} 
lengths are proportionate to genetic distance, which are also relatively proportionate to time. So that means that the five that we first looked at, they are some way connected in time and also thereby in transmission history. It doesn't necessarily mean that these five people have infected each other. It could be that they are a part of something bigger.

Linus told me that the length of the branches also said something about the time that these patients and their viruses had been separated from each other evolutionarily speaking, taking note to mention that in this tree, every tip represented the virus from one patient. Importantly, he also notes here that the graph only displays the relatedness of viral strains, but not their directionality. We cannot directly see from this image who infected who. In the way that Linus works this out for me, they are simply part of something 'bigger'.

\begin{abstract}
Linus: So in some way, these five denoted 'I' are a local outbreak, part of a transmission cluster of some type, and the time that they have been separated from each other, these viruses in different types of different individuals, it can be a couple of years, but not sort of decades. A caveat is always that there may be individuals that have not been sampled, so that anything that looks like a direct link may be indirect because there may be intermediates that haven't been sampled. It could be that there are other viruses that should be placed in-between.
\end{abstract}

In spite of these caveats described by Linus, surveillance vision seems to become quite sharp through this technique. Linus himself had published more than one article on this topic. We discussed two particular cases he had studied with phylogenetic methods, one that showed how transmission was compatible with the prosecution of a rape charge in court, and one that later spoke of a shift toward only using these tools to exonerate people accused of transmission. In principle these tools should only be used for the greater 'good', but in practice they can both be used to protect and prosecute. Linus told me that there is a lot of discussion about the advantages and risks when it comes to these types of analysis, especially for a virus like HIV that he said bore so much stigma and consequence, both legally and otherwise, when it comes to someone having transmitted HIV to another person.

Linus: So there is a lot of ethics involved in how you make sure that the information, like the one contained in this tree, is anonymised in the proper way so that you can't really backtrack who is who. But that is also a caveat, because of these ethical and confidentiality issues, phylogenetic trees are not used to their full power when it comes to preventing new infections. If it was completely uncontroversial to understand who infects who, especially right now, then it would be much more straight forward to obtain a sequence from every newly diagnosed patient and try to link his or her virus to other viruses and see for instance, say there is ongoing transmission in cluster '1', and you can do contact tracing, you can try to find patients who are not yet diagnosed, put them on therapy, make them uninfectious, you could prevent that cluster from growing.

So here we see how phylogenetic analysis is said to be somewhat constrained by what Linus refers to as 'ethical' issues. In his view, the full potential of phylogenetic analysis could be unlocked if the ethics surrounding HIV surveillance could become less controversial. This 
would enable a new kind of effectivity for these tools. Linus tells me that in principle, you would be able to determine who is responsible for infecting who. However, what Linus fails to consider is the possibility that these tools are themselves already doing social and political work by engendering some visions at the expense of others. Some perspectives are already more dominant than others, for the better and for the worse.

Linus also told me that the recent infection testing algorithms that I described earlier were less complicated from an ethical point of view, because they are not linking people to the same extent as a phylogenetic analysis does or can do. While in phylogenetic analysis, associations between people are direct and are made present visually, RITA engenders an indirect association between people through the establishment of the temporal boundary of their infection. Linus said that 'false recency' results were more of a problem when it comes to estimating incidence in populations rather than having consequences for the individual, and he told me that in Sweden, RITA is not primarily used for individuals, but rather for populations to understand the increase or decrease of incidence in Sweden. He also said that RITA information was rarely communicated back to patients or even the clinical doctors in Sweden, because it was a "different thing", a different practical assemblage.

While Linus thought the criminalisation of HIV is wrong, he thought that it was very important to do phylogenetic analysis if people were brought into court and to exonerate the patients and absolve the accused party. But then he told me it was two sides of the same coin, because if the analysis shows that the results are compatible with transmission, then that becomes a help for the prosecutor, even if it may not be enough on its own.

Linus: I think the explanation for, and also a big problem in my view, is that HIV is considered very special when it is just like any other infectious disease. There are many other serious infectious diseases, but because there was such an alarm feeling in the society when HIV was discovered, and before there was any therapy, HIV has been viewed as something completely exceptional. But things have changed, so now days HIV is treatable. It is still a serious disease, you need therapy for life, but its not all that different from other serious diseases. The thing that it stands out as being different from other infectious diseases hasn't been washed away in society, in the mind of the public. So that also means that investigations of this type, you have to think more about how you do them.

Linus told me that if I went out and asked people on the street, that most of them would say that they think abandoning HIV criminalisation is crazy and shouldn't be done. He said that this was because they have an opinion based on ignorance, and that this was the main problem for HIV infected people today. Unlike Linus, I do not locate alarm feelings in a bounded entity called 'the society' or 'the public' in opposition to a 'natural history' taken to be an accountable reality beyond critique. These key populations and their transmission histories are only enacted in the relational associations between humans and nonhumans that sustain their possibility. For Linus, the medical aspects of the infection are not all that bad. Patients simply need to take their medicine and take it for life, but as we will see in the following chapter, this is a bit more complicated in Sweden than he suggests. Linus told me that it 
was more the 'social' consequences of the infection that were problematic, and that these consequences were maintained like a vicious circle.

Linus: and if one could break that, then one could also also address things like ongoing transmission and ways of minimising that in a more effective way.

As a patient living with HIV, I both agree and disagree with Linus. I do agree that in some ways the medical aspects of HIV treatment \& surveillance are getting much better at taking more things into account, but I also think that new problems always come along with new techniques, biomedical or otherwise. Problems are immanent to the solutions constructed for them. In this way, I think that Linus overlooks the participant role that surveillance practices play in producing the alarm that has been associated with HIV ever since its emergence. Categories such as 'Gay Related Immune Disorder (GRID)' did not emerge from a society set apart from science. I also hesitate with the characterisation of the public as merely 'ignorant'. I think it is a bit more complicated than that as well. But I also don't want to assume that these technologies are always cause for concern or that they are essentially ignorant. What I rather want to bring out with this story is a better focus on the way that these technologies, while taking part in the association between people affected by HIV, come to distance themselves from 'society' through the construction of 'natural' history. I argue that this produces an irrespective vision; a vision that cannot take into account its own bifurcation. While the 'natural' and the 'social' affects of HIV are clearly constituted together in practices such as phylogenetic analysis and RITA, the hybridity of these techniques are not always taken into account. So sometimes, as the result of folding operations, a blind spot is also produced. Along with this irrespective vision comes the flickering character of the subject between patient and transmitter. Someone to be helped and cared for or someone to be regulated and controlled. I therefore argue that the subject enacted in this practice takes shape as a stable pattern of discontinuity.

In this section I showed how phylogenetic trees can be read as natural histories that reenact the subject we saw enacted in PCR. So here, the subject with genetic code becomes folded into the transmitting subject. Here we also see the way in which the transmitting subject of HIV surveillance emerging from this practice takes its shape as an effect of recursive discontinuity. These visualisations and folding visions have themselves traveled into legal practices where their accountability becomes even more intense. But interestingly enough, it turned out that these professionals who were directly working with phylogenetic analyses simultaneously held these techniques and their 'natural histories' apart from their 'social consequences'. So here we see how HIV surveillance can sometimes enact what I call an irrespective vision - a vision that becomes blind to others while sustaining itself. This vision thus enacts the subject as an accountable agent of transmission. It re-inscribes the subject with HIV-1 RNA as the transmitting subject. 


\subsubsection{Folding subjects with cd4 into undiagnosed infections}

In this story, I will now describe how the subject enacted with cd4 becomes folded into modelling tools in an effort to make present the number of undiagnosed people living with HIV in Sweden. Following a tool from the ECDC that becomes a strong alternative to RITA, this story takes me back and forth between the developers of 'cd4 back-calculation' in the Netherlands and professionals using this technique in Sweden. Describing the ongoing controversy that these tools ignite, I show how the Swedish efforts have used this method to generate evidence that calls into question the earlier claims of accomplishing the 90-90-90 goals. Describing the subject of two additional populations that I become a member of in this practice, my analysis highlights a final folding the subject through cd4-backcalculation. While the addition of multiple perspectives together is thought to provide a better vision of the subject, I argue that it also may perform a bifurcation of 'the natural' and 'the social'. A holistic perspective is thought to include the perspectives that matter, but in practice perspectivism can produce an irrespective vision that fails to take into account its own hybridity. The following section will continue this theme by showing how others subjects of invisibility become handled in HIV surveillance. To follow my argument, let me turn to the case of cd4 back-calculation.

To understand this surveillance technology, I talked to Luuk who had worked together with the ECDC on a method - the aforementioned 'cd4 back-calculation'. This technique would be used to estimate the number of people living with undiagnosed HIV. Back in 2010 when Luuk got started on this project, there were not really many tools that could be used to get an estimate of the number of people living with HIV. Knowledge of the diagnosed population was present and the undiagnosed were simply absent. So to get the number of undiagnosed people living with HIV, Luuk explained that you have to do something more. The methods available were mainly based on what he called 'prevalence surveys'.

Luuk: So you measure in a group the prevalence of HIV, then you get an estimate of the size of the group, you multiply and then you know the number of people who have HIV in the group. But that doesn't work in countries where you have many different sub-groups, like MSM and migrants of different countries, different regions. Prevalence surveys are quite costly, unless you have data from the public health service for instance. So they works well in countries like Africa, or well...countries in Africa. Because then, HIV is a general nice epidemic.

While I don't think that Luuk actually thinks the epidemic in Africa is generally nice, what he is trying to express seems quite important to explore further. What we see here is that in epidemiology, you want the epidemic to be as flat and generic as it can be. This makes it easier to measure, evaluate, and control. An epidemic that rages to and fro across varied peoples and places is an even less nice epidemic. An epidemic populated by diversity, with MSM and migrants in this case, is harder to control. Luuk told me that with a less diverse epidemic, you can just test any group and, provided that group is representative of the total population, you will then see the estimate you are looking for. This gets harder when you have what he called 'risk groups' to account for. 
Luuk: You don't know how many MSM there are in country, that's quite difficult. Maybe MSM is ok to estimate, but you need to have the number of MSM at risk of getting HIV. So MSM can be men who have sex with men, but could also be gay men, but that's not quite the same. MSM who don't have other partners, except their own partners, meaning monogamous, they won't be at risk. So yeah, but if you measure HIV prevalence in monogamous men as well, it's no problem, but its still not easy to work out completely, because you need to match the size of the group estimate with a right prevalence in that same group. So monogamous MSM. And if you measure prevalence in monogamous MSM, you need to have prevalence, you need to have a size estimate of the number of them. That is the tricky part. So you need to make sure that you measure the prevalence in exactly the same group as for which you have an estimate of the size of that group. So that's very difficult in populations here [in Europe], especially when they get very small in numbers. So you need to test a lot of people to find a reliable estimate of prevalence.

As Luuk explains to me the challenges with existing methods that led to his work on 'cd4 back calculation', he also unpacks what he means by 'risk groups'. Sometimes he even seems to do this indirectly, for example by making the switch to monogamous MSM not being at risk rather than directly categorising nonmonogamous or polyamorous MSM as being at risk. As his example also shows, you need to know the group that you want to measure quite well before coming up with an estimate of the incidence or prevalence of HIV in that group. For these reasons, Luuk started working together with the ECDC to look at other methods that were available at that time. Through this cooperation, one of these methods was developed a bit further and became advocated by the ECDC to be used in countries across Europe. Luuk said that while it was still not perfect, this new method of 'cd4 back-calculation' gives at least some more answers than the older methods did. Specifically, it works out an estimate of the undiagnosed population using the cd4 values we saw constituted and enumerated in flow cytometry. Luuk reminded me that people who receive a high cd4 count at their diagnosis, such as myself, will be seen as having been infected more recently. 94

Luuk: so generally people who have a higher cd4 count at the diagnosis will have been infected for a shorter time than people with a lower cd4 count, who will have been infected for a longer time. And if you have multiple years of data and you record the cd4 count at the time of diagnosis and the number of diagnoses in a year, and we also look at whether people have 'AIDS' at the time of HIV diagnosis, so if you have all these data, from ' 86 the beginning of the epidemic, and many countries have such data, then with some mathematical modelling you can estimate the number of people with undiagnosed HIV. So you can actually estimate the number of new infections, the annual number of new infections since the start of the epidemic. And you can estimate how long it takes before people are diagnosed. If you combine those two, you know how many people are not yet diagnosed.

\footnotetext{
${ }^{94}$ This is because the ongoing presence of HIV will typically continue to make cd4 absent in the body until treated.
} 
So this modelling technique of cd4 back-calculation can come to say a lot about HIV. It provides me with a third technique to examine the folding work of surveillance and its ability to estimate a population. This value can be used as a proxy for incidence and to better understand those living with HIV who have not yet been diagnosed. However, along with this fold comes again the problem we saw earlier. Instead of accounting for the vicissitudes of individual bodies, cd4 back-calculation must necessarily rely upon a more universalised notion of the immune response to HIV. In other words, it assumes that HIV lowers the amount of cd4 in the body of the patient at a particular rate. A rate that is based on an average and constitutes a 'normal'. Svea, who works on the clinical side of epidemiology gathering patient data, discussed this issue further.

Svea: So normal cd4 values could be a range from, lets say 600-1200, and if you see a patient that, at their first visit with you has a value of 500, then you have no idea to know, well, was 600 the normal and this patient just recently got infected or was he over 1000 before and maybe has had this infection for some years. So on the individual level we don't know this, but we know that in some areas of the world like in Asia and some countries in Africa, the cd4 level normal is lower. And we also know it gets lower by age. So we've included that in the model, and adjustment for that, but still it is not a very specific test this cd4 back-calculation, but maybe looking overall on the population it is better.

So while the shift from ELISA to RITA comes along with desensitisation, the shift from flow cytometry to cd4-backcalculation comes along with despecification. The principle embodied in cd4 back-calculation differs from that of RITA in this regard. Whereas in RITA you are looking at antibody responses that are expected to climb before falling again, in cd4 back calculation you are looking for the depletion of immune system cells such as cd4. In the first mode of inspection, the 'normal' goes up. In the second, it goes down. Cd4 back-calculation therefore seems to perform what I will call a fold of perspective.

While it knows different subjects, for example what it calls the 'elite controller' subject who can suppress HIV without antiretroviral medication and still retain 'normal' cd4 levels, it also knows how big this population is said to be - approximately one person in every fivehundred. The model can therefore account for this complexity. The subject with cd4 thus folds into this method differently from the way that the subject with antibodies/antigen folds into RITA. Importantly, the perspective I show here is again not located in the mind of an individual such as Luuk or Svea. Rather, surveillance technologies and their folding operations generate differences between envisioned populations.

Luuk: The problem in Sweden is that they're a lot of migrants, and that's a key population, migrants that come to Sweden, and some know that they have HIV, so you need to make an estimate of the undiagnosed population for those people. 

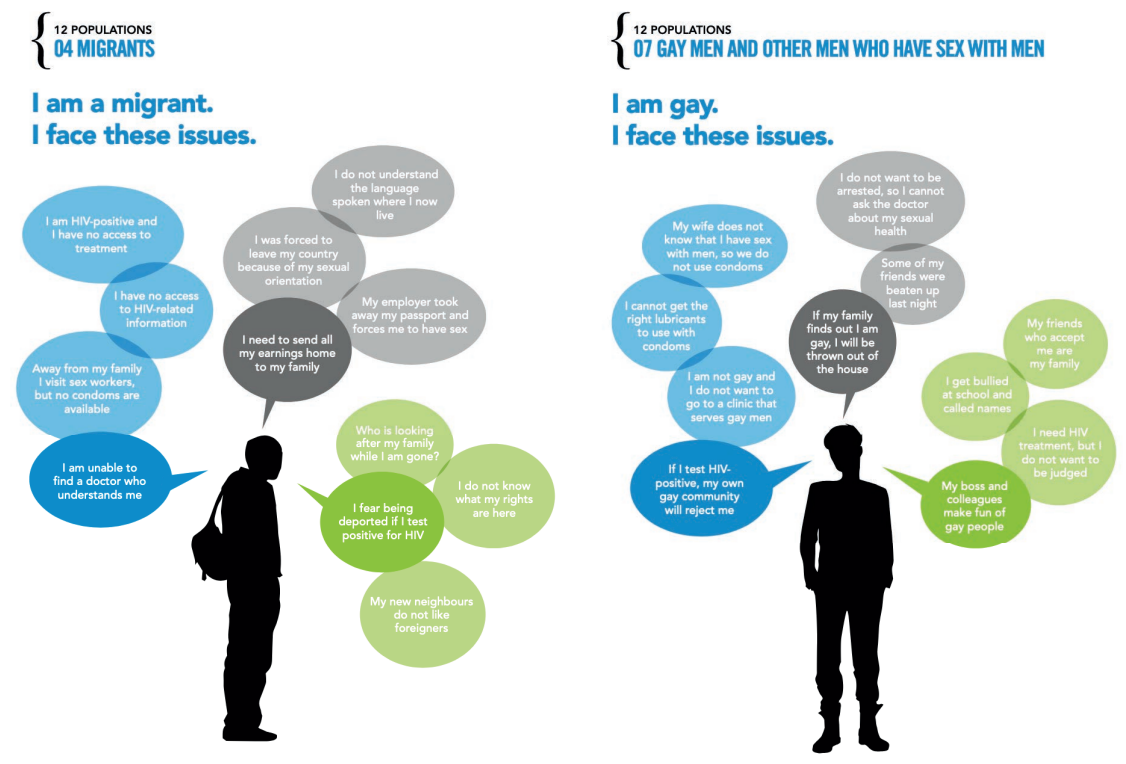

Figure 19: the emergence of the 'migrant' (left) and 'gay men \& other MSM' (right) as accountable populations ${ }^{95}$

Here, the undiagnosed population becomes characterised as 'migrants' - people coming into Sweden from elsewhere. Through this fold of perspective, the undiagnosed population of people living with HIV can be sub-divided into one of the twelve 'key populations', each situated by their own point of view, their different concerns, and their different characters. Luuk even suggests that many of them might even know that they carry HIV. So it seems that in surveillance practice these different key populations are sometimes even ascribed different intentions. Here we come back once again to the UNAIDS gap report. The 'migrant' (figure 19 left) makes for the fourth of the twelve 'key populations' and the 'gay \& other men who have sex with men' (figure 19 right) makes for the seventh population.

Being characterised in military lingo as those 'left behind', each of these populations come to take shape through different methods in surveillance and elsewhere too. As I talk with these professionals, I am told the characteristics of migrants, gay men, and other men who have sex with men - in surveillance terms of course. What I find interesting about these two images, is that I identify with both of them, but in different ways. Through different perspectives, I belong either to one or both of these populations. This doesn't mean I want to 'leave behind' any of the other populations that I do not strongly identify with. It simply means that some of this images hail me and address me in a different way than others. Indeed, the image with the text "I am gay" calls for an identification. Identifying myself as gay, the figure gives voice to some issues that matter to me and some that I find inapplicable to

\footnotetext{
95 http://files.unaids.org/en/media/unaids/contentassets/documents/unaidspublication/2014/UNAIDS_Gap_report_en.pdf, accessed 2020.04.07
} 
myself, much in the same way as the figure of the 'person living with HIV' did earlier in this chapter. However, while I sympathise with the issues voiced by the 'migrant' figure, the concerns illustrated by this population are quite a bit different from that of the 'gay and other MSM' population: "My employer took away my passport and forces me to have sex". This, for example, is not a concern of my own, but I sympathise with those who are in this position.

Still, my transmission did not occur in Sweden and I did 'migrate' to Sweden as far as any statistic or report will be concerned. I also identify as a migrant through my nomadic and international upbringing. So I am a member of this population in some way as well. But of course these formal models will not take into account the differentiation in concerns that I migrated to Sweden with when compared to other people living with HIV that are categorised as belonging to this population. In cases such as cd4 back-calculation, undiagnosed subjects such as these migrants also make evident the limits of the gaze performed by disease-control. Talking with Linus about the technique Luuk had discussed with me, I came to learn more about these limits.

Linus: there are many ways or tools that have been described to try to estimate both incidence and the proportion of undiagnosed. From back calculation tool, which is based primarily on cd4 counts at diagnosis, we know that while the ECDC has made it available, this tool actually performs poorly in a country like Sweden, because it doesn't take into account migration.

So in this section we can once again see how the characterisation of the subject emerges along with another problem for these techniques. Using cd4 back-calculation on the Swedish population, Linus shows how the model fails to take into account migration. How is this handled then? Linus' answer to the shortcomings of cd4 back-calculation is to add more variables. The more variables, the more valuable. Here he proposes a way to handle the problems of the 'cd4' biomarker by adding it together with 'antibody' biomarkers like those used in RITA as well as 'genetic' biomarkers like RNA:

Linus: And then I've done another study where we try to address these shortcomings of more publicly available tools using biomarkers. These three biomarkers, they have their pros and cons, and they're not very exact, but by combining them we get closer to something which is a reasonable estimate since the time of infection.

But what will that do? Linus told me that they had a model that would combine these markers. This model would be trained on patients where the time of infection is well known. In this way they would be able to correct and adapt the model to what he called the 'Swedish epidemic'. In folding together antibodies, RNA, and cd4, the specificities of the Swedish epidemic are expected to take shape. But as a last step, Linus wanted to incorporate the time of entry into Sweden for persons infected outside of Sweden. That would give him the ability to combine the results of the model for both these groups of patients and in doing so, calculate the number of undiagnosed patients in Sweden. 
Linus: So we have the time of these two groups and when we combine them we get the number of undiagnosed patients in Sweden. And we estimate that to be around 800, which would be close to $10 \%$, like over 10\%. So according to this estimate, Sweden hasn't really fully met the first of the 90-90-90 criteria, but the other two are very well met.

Here, the subject of surveillance is folded back upon itself to mark its own limits, while also bringing a new subject into view - the undiagnosed person living with HIV. By adding together different biomarkers, surveillance is able to inspect this 'undiagnosed' subject, and find it surprisingly larger than had been expected. Interestingly enough, adding more variables into the model doesn't necessarily provide a better result when weighed against the fasttrack target for 'lowering incidence'. It shows that there is more to accomplish than was previously assumed. But of course, this is a 'good' thing for surveillance practices that now have even more to contribute. So at times even surveillance practice folds itself in unexpected ways. Instead of confirming that incidence is lowering, this mode of visualising the subject comes along with a more pessimistic estimate of current accomplishments. But in doing so, I argue that it also performs a variety of holism. 96 It performs a world populated by different perspectives, points of view that may be added together in order to attain a 'good' overview.

Svea: We are looking now at other techniques to see if we, by looking at the virus more specifically, and phylogenetic trees also to see how long the patient has actually been infected. And by the techniques we are using, we are hoping to be able to cover the first 8-10 years after infection. And normally someone gets symptomatic on average after 8-10 years, so that would be very good if that method would work. But this cd4, there is a wide range of what is normal in a specific person, so in one person it is very hard to use this cd4 back-calculation, but on a population level it is a bit more precise, but we don't think it is precise enough. So we're trying to include all these different aspects into an overall model that we are working on right now.

When a new problem has emerged, new models can be developed to include more variables in order to better capture and characterise the subject. But as we can now see, this does not always mean progress in a straightforward way. While current methods may only be individually able to provide an estimate of the time of infection for up to 2 years prior to diagnosis, Svea told me that she hoped this newly integrated method will be able to extend that window much further. Perhaps it would even be able to cover the entire possible duration that an individual could have been infected sought out medical treatment by themselves, from 8-10 years. She said that in practice, this tool would be used to get a date on when the person was infected, so that they could find out the number of what she called 'the hidden epidemic'. Here we see once more how subjects and objects are folded together in practice and sometimes folded apart.

Combining clinical data and demographics together with this new model, would enable surveillance to help public health aim their resources toward this undiagnosed population of

96 For the notion of holism I draw on, see Haraway (1991) and Thompson (2002). 
people living with HIV - "Svea: to find and help those patients to identify their infections". While surveillance professionals may think of these subjects as 'patients', they are only patients in potential; until they are found they remain undiagnosed and invisible to health-care practices. New possibilities for envisioning the subject always exist around the corner, but they always come along with new problems as well. In this case, the problem of 'what a normal cd4 level is' will become differentially folded into different regions around the world - at least this is the ambition of this surveillance practice I encountered. This will enable HIV surveillance to identify the 'normal' cd4 levels in various national and geographical regions with the intended aim of providing a more precise estimate of the temporal and spatial dimensions of those infections arriving to Sweden. Through this operation of folding, I become enacted as a member of the population living with HIV, as well as a member of 'migrant' and 'gay \& MSM' populations, albeit no doubt in very different ways. But what becomes absent in this account, and unfortunately the situated particularity of 'the Swedish epidemic', are the many other kinds of people affected by and living with Swedish HIV. Making a generalisation or abstraction that can provide such an 'overview' also comes along with the possibility to 'overlook' subjects that may only be marginally represented: the populations of Adolescent Girls And Young Women, Prisoners, People Who Inject Drugs, Sex Workers, Transgender People, Children And Pregnant Women Living With HIV, Displaced Persons, People With Disabilities, and People Aged 50 Years And Older in this sense might be said to be 'uncharacteristic' of Swedish HIV. Through these operations of folding, the diagnostic subject is not only folding into the surveillance subject, the values of antibodies, RNA, and cd4 are not only folding together, but the subject of surveillance is also folding apart.

\subsection{Conclusion}

In this chapter, I have been describing the subjects of surveillance that emerge in practices of HIV surveillance and disease-control. I started the chapter with a first story that showed how the reality enacted by ELISA gets folded into 'recent infection testing algorithms' (RITA) in the effort to estimate incidence. Rather than having incidence unfold in time however, I showed how RITA methods involve the folding of HIV infection temporality. By making individual errors absent through mathematical correction, population incidence may be brought into presence as a valid estimation. Next, I showed how the genetic reality enacted in the lab becomes folded into transmission history under the phylogenetic gaze to facilitate what professionals call 'molecular surveillance'. Here we saw how possibilities for phylogenetic methods are brought into presence as absences attributed to ethical constraints. 97 This second story showed how 'the natural' and 'the social' become folded apart in surveillance practice as the consequence of an irrespective vision - a method of folding that comes to overlook its own hybridity. Finally, I showed how the cd4 enumeration performed through flow cytometry becomes integral to a method called 'cd4 back calculation'

\footnotetext{
${ }^{97}$ In the following empirical chapter, I will take a closer look at what I and other STS scholars have come to articulate as an ethics of sensitivity and specificity that work with such constraints in a very different way than seen by Linus.
} 
used by public health agencies, a method that involves the folding of HIV infection spatiality. This third story displayed a series of absences and presences that effectively put the Swedish accomplishment of the fast-track into question. By showing how Swedish surveillance networks are developing tools that integrate three different biomarkers and different perspectives together in an effort to better characterise undiagnosed populations living with HIV, both within Sweden and beyond its borders, this story therefore stressed the partiality of visions that are ongoing. In-spite (or perhaps because of) this partiality, these stories showed how HIV surveillance nevertheless produces an overview of the subject.

Providing a summary of different approaches to surveillance, Kroener and Neyland (2012) highlight the differences between surveillance studies focusing on 'risk', Foucauldian surveillance studies, and studies of surveillance in STS. Situating their work within the latter of these approaches, Kroener and Neyland emphasise four sensibilities that come to distinguish studies undertaken by STS: 1) that surveillance technology does not determine outcome, 2) that surveillance is always a complex assemblage of heterogenous actors, 3) that surveillance technologies can be conceived as congealed social and political relations, and 4) that surveillance is ontologically multiple (Kroener \& Neyland 2012:145-146). With this chapter, I have been putting these sensibilities to work in the study of HIV surveillance. Other work in STS has also been helpful in my thinking through of this case.

For example, Akrich and Pasveer (2000) use the case of obstetrics to show how an electronic monitoring device not only coordinates the monitoring of woman, fetus, and uterus, but also of the midwives who come to perform the monitoring differently in French and Dutch practices. Critically, their analysis shows how it is the very monitoring apparatus that distributes professional responsibilities between obstetrician and midwife. Albrechtslund and Lauritsen (2013) furthermore emphasise the fragility and dependency of oligoptica by showing how these surveillance devices are the contingent effect of a heterogeneous network of activity, rather than one dominant actor alone. They call on the case of a technologically sophisticated sports watch to show how the embodied experience of running becomes invisible by its translation into sports data, which may then provide a visual overview of the sport. Turning then to the case of CCTV use by police surveillance in Denmark, they show how this technology prescribes the roles the actors - surveilled and surveilling - must play in order for the technology to be effective..$^{98} \mathrm{Gad}$ and Lauritsen (2009) draw on the work of Haraway and Latour to show how oligoptics produce limited, fractured, and partial visions. Developed through the case of Danish fisheries, their notion of 'situated surveillance' stresses the alignments and negotiations between human and nonhuman actors that must take place in order for surveillance practices to have any effect at all.

These studies all share a concern with 'surveillance' as an object and method of control, but they way this control is understood and handled comes to vary dramatically in relation to the situation of the work. In my work, I have not intended to dismiss control, to render it unimportant or unhelpful. Instead, I have aimed to ask how technologies of folding come to

\footnotetext{
98 In the case of Swedish HIV, surveillance practices come to produce a differentiation between the accountability of different 'doctors' that care for patients and control HIV.
} 
do control in different ways, and how they might come to be done more carefully. Perhaps this even takes my approach beyond a metaphorical 'folding', but I leave for the reader to decide. What seems in any case important, is to stress the consequences of folding: the splitting of the subject. Through the practices of HIV surveillance, the individual becomes split apart from the population, the temporal and spatial dimensions are differentiated, and the moral and material dimensions become held apart. Of course, splitting is itself a consequence of practice, and thus it too can be done in various ways.

In this chapter, I have tried to describe the alignments being inspected and enacted in the surveillance practices that enact me as subject to particular populations. I have shown how they sometimes produce a productive fold of perspective - a shift in the mode of seeing the subject. However, this does not mean that adding perspectives together into a kind of 'holism' is always desirable; sometimes it results in 'overlooking'. In this very chapter we can see how 'patient Jeff' becomes folded out of the story, which is perhaps itself a consequence of 'praxiographer Jeff' finding everyone too busy to include him in their practical activities, leaving him to sort out the intricate practicalities of these tools for himself. But perhaps this was, at the end of the day, a good thing as well. Perhaps it provided me with the motivation I needed to sound the alarm and mobilise my response in as careful a way as I could. Perhaps it allowed me to see things that otherwise would not have been seen. As a practical activity, speculation can also be done in different ways. While the fast-track assemblage endorses and enables practices of desensitising and despecifying, a mode of envisioning the subject that is after all what it is meant to do, I have shown how slowing down can offer an additional way of sensitising (Stengers 2018:81) ourselves and others to the concerns involved in folding (not only) subjects of surveillance. 


\section{vi // Valuing with dependencies}

\subsection{Introduction}

In the three previous chapters, I empirically described the subjects that emerge from biopolitical and technoscientific practices of governing Swedish HIV through various means. Exploring the strategy of slowing down the fast-track assemblage through praxiographic storytelling, I have so far provided the reader with an account of the ways in which the fast-track targets of 'knowing your status', 'achieving viral suppression', and 'lowering incidence' are accomplished, all the while demonstrating how these are contingent achievements that often become contested. The problems that emerged when slowing down and investigating these accomplishments praxiographically allowed me to illustrate complexities that are often smoothed over when fast-tracking. Often finding traditional social science theorising inadequate to capture the detail and texture of these practices I ethnographically encountered in legal (chapter 3), diagnostic (chapter 4), and surveillance (chapter 5) situations, I set about to offer a rearticulation of these forms of governing through a material-semiotic sensibility.

In this next story, I will now fold the insights generated by these previous chapters into an investigation of Swedish HIV treatment as a manifold of dependencies. Having attuned the reader to the matters at stake in these (not only) local practices of governing HIV infection, this chapter focuses on the effects of these various technoscientific and political measures for the subject living with Swedish HIV treatment in everyday life. I first compare and contrast my approach to valuing treatment with recent studies using 'quality of life', a value that is integral to evaluations of the fast-track assemblage and one that is now becoming known as 'the fourth $90^{\prime}{ }^{99}$. This contrast enables me to question the shortcomings of these evaluations and to offer an ethnographic alternative to valuing treatment through QoL. I will show how the values of 'sensitivity' and 'specificity' that are integral to diagnostic \& surveillance practice can also become valuable as a way of charting a different course than critique of biopolitical governance or the severing of attachments to HIV technoscience. I instead will demonstrate how Swedish HIV treatment can be valued as a political ecology of attachments, dependencies, or material-semiotic couplings to be cultivated attentively.

In focusing on the generative effect of this political ecology, I will show how the manifold dependencies of Swedish HIV treatment come to mediate100 a manifold subject. In situating my relations to Swedish HIV treatment as dependencies - by which I mean sets of material-semiotic scripts, codes, and couplings between a manifold of agencies that do not just constrain, but actually enable and enact my 'self' in various ways - this chapter will show how the manifold subject is a contingent effect of valuing dependencies. Critically, the approach I take will start from the assumption that these dependencies are both material-semiotic things that are doing valuing as well as things becoming valued. Queering the values of

\footnotetext{
${ }^{99} \mathrm{https} / /$ bmcmedicine.biomedcentral.com/articles/10.1186/s12916-016-0640-4, accessed 2020.04.07

100 It may be said that the notion of mediation constrains the analysis to following the effect of just one entity as it influences the agency of others, but in my account I intend to explode the concept of mediation in a messier way by taking multiple agencies and actors into account.
} 
'sensitivity' and 'specificity' allows me to practice a kind of self-care by thinking and sorting through my dependency to Swedish HIV treatment and reflecting on the ways it comes to value me. It enables me to become sensitive to the shifts in the manifold subject I differentially become through multiple modes and materials of governance. In other words, I show how the manifold subject of governance that I account for in this thesis depends on an ecology of material-semiotic couplings that make subjectivity possible to begin with. Decomposing my relation to this ecology and sensitively tinkering with these couplings enables me to argue for the empirical value of slowing down with praxiography. This chapter will thus show how the approach I took can be understood as practice of taming dependency and valuing chronic care.

\subsection{The mundane subject}

The sun is finally out and it warms and excites me as I wander through the moss covered woods. This is my version of becoming-mundane, becoming worldly and down-to-earth. I wonder how to start my treatment story, and this feels like as good a place as any. I often come out here to read my theoretical and empirical material. Perhaps my early homeschooling years on the road are responsible for turning my classroom into a campground park and the school bench into any object that could withstand my hoard of siblings and I as we became schooled. Or perhaps my boyfriend is right and I am simply restless due to the Mercurial and Uranian aspects I was endowed with at birth. Whatever the case, these walks in the woods suit me quite well and stimulate my writing. Walking and thinking through the forest and its undergrowth allows me to reflect on my own work and what I am busy doing with this project. So what do I write about? I write about my treatment. I write about the care I take for my body and the ways in which practices of Swedish HIV governance come to enact a manifold of subjects that come to be governed in different ways. I write about processes of translation, multiplication, and folding in these technoscientific practices and in my personal activities. Finally, I write about how this ecology of practices (Stengers 2005) comes to value the subject of Swedish HIV treatment in different ways. And this is precisely what I want to discuss further in this chapter. I want to ask how Swedish HIV treatment values the subject. To investigate this question, I will have to traverse a series of further questions. What is Swedish HIV treatment? What are the accountabilities and values it enacts? What does it depend upon and how do I depend upon it? When and how does it ease, or complicate the effects of HIV in the lives of people treated? How is it made to work and how are its effects evaluated?

Among other sites such as prisons and schools, Foucault described how the hospital became a distinctly concentrated point for the exercise of disciplinary power. Through the practice of examination, a new way of seeing took hold of the patient and the mad and came to know them differently. In the account of Foucault, the disciplines also used the examination to reverse the directionality of visible power. Instead of the 'ascending individualisation' that illuminates the monarch and ignores the subject of pain, disciplinary power worked out a 'descending individualisation' that rendered power anonymous. Critically, this change in the visible direction of power incorporated the techniques of writing, formalising, and an im- 
mense effort to document 'the individual'. Essentially, the disciplines composed the subject to be opened, examined, and optimised. The story I am telling illustrates how this happens. Through the examination of my Swedish HIV treatment, the very subject that I am becomes changed quite substantially. Though explicit care is given to my bodily condition, a great deal of attention is also paid to the way I conduct myself in everyday life.

On the one hand, it seems clear so far that Swedish HIV treatment enacts a kind of normalisation. Foucault in specific pointed out the hospital clinic as a locus of this power that can be seen in the drawing up of tables, the prescription of movements between the subjects and objects of the practice, the imposing of exercises to train the body, and the arrangement and assembling of tactics to make the body accomplished. When I am enacted as having a 'virus under control' 101 or as having achieved the accomplishment of 'viral suppression' in the clinic or elsewhere, I am enacted as the normalised subject. When my doctor tells me that, I will live a normal life in-spite of my diagnosis, what she means is that I will live for nearly the same amount of years as someone without HIV - but only if I stop smoking, she adds. As soon as one norm is established, clinical care shifts to another. Ingunn Moser (2000) helps me better understand how this process of normalising works in practice. Her ethnographic encounters with a man named Olav help her to discuss how it does so in the case of disability, but the very analytical approach that she develops puts norms of 'ability' and 'disability' thoroughly into question. While HIV and disability discourses are no doubt quite different, the example helps me a draw a useful comparison.

Moser shows how normalisation works through a twofold process. First, the subject is measured and found lacking in one way or another. This exclusion constitutes a first norm of 'disability' - and in my case 'pathology'. What this does is then to make possible a second movement that enables inclusion and rehabilitation - a norm of 'ability' or 'vitality' that seemingly can be restored, but that depends on a prior movement while making it also invisible. Thinking through this logic in my own case, I can see that in becoming mediated by the HIV virus, I become unable to sustain my own immune system and become unable to engage in some pleasurable activities without putting others in harms' way. But mediated by Swedish HIV treatment and its evaluation, I can again be included as someone who may become 'normal'. However, what concerns me in the case I describe is the way in which, during the second movement, a version of the 'normal' is enacted that aims at excluding the subject of pleasure. Through my empirical work, I see a tension emerging here that I think important to elaborate.

\subsection{Against stigma: 'quality of life' as the fourth 90}

Swedish HIV treatment is not only the subject of my own research, but it also becomes the object of study for other practices as well. Evaluation practices in the field of biomedicine have become concerned as of late with a new metric, an apparently valuable metric

\footnotetext{
101 Not only is this terminology used in discourses of HIV care, but I am often asked such questions when visiting other parts of the network, for example during STI checkups with other doctors.
} 
that is becoming known as 'quality of life'102. The following quote from a biomedical journal published in 2016 articulates this latest addition to the WHO/UNAIDS and 90-90-90/fasttrack goal.

"Emphasis has shifted from lifespan to healthspan, with improved health-related quality of life $(Q o L)$ being the desired goal. The importance of long-term health and wellbeing with a focus on QoL is becoming a critical priority in the care of PLHIV, a target that is quickly becoming the 'fourth 90'. The fourth 90 aims to expand the continuum-of-treatment paradigm beyond the existing endpoint of viral suppression." 103

As the statement above indicates, this 'fourth 90 ' is positioned as a critical value to move beyond the previous 'three 90s' of the fast-track assemblage. Yet it attempts to make this shift from 'lifespan' to 'healthspan' by extending what it calls the 'continuum-oftreatment'. I want to play a little with this strategy by proposing a slightly different way of attending to the problem of going on with HIV. Rather than only extend treatment, my desire is to experiment with an alternative therapeutic, to create space for different ways of governing and doing intervention.

In 2015, the Swedish Public Health agency published the results of "the first extensive study in Sweden where quality of life has been studied among people living with HIV."104 This inquiry thus undertook a survey of what it calls "self-rated quality of life". In the account of research methods used by this study, we find that it asked its research subjects a series of questions that were presumed to define the qualities of living with HIV in Sweden. Through the self-rated and quantified responses of the research subjects to these questions, this study was able to achieve a sense of what living with HIV in Sweden means. A closer look at these findings show that:

"The participants reported high quality of life in general. Furthermore, most participants were satisfied with their physical health and their emotional wellbeing as well as with their relationship to friends, partners, and families. However, they were less satisfied with their economic situation, and the great majority was dissatisfied with their sex life. (...) Twenty-five percent had stopped having sex with others after being diagnosed, and another $25 \%$ of the respondents had reported that HIV had had a negative impact on their ability to experience pleasure in relation to intercourse."

Apart from economic and sexual situations, people living with Swedish HIV were thus said to enjoy a high quality of life. In the statement below, this even seems to be the case across the board. The study found no differences between geographic and demographic situa-

\footnotetext{
$102 \mathrm{https} / /$ bmcmedicine.biomedcentral.com/articles/10.1186/s12916-016-0640-4, accessed 2020.04.07

103 https://www.id-hub.com/2019/11/08/david-hardy-hiv-treatment-exploring-crucial-role-shared-decision-making/, accessed 2020.04.07
}

104 https://www.rfsl.se/wp-content/uploads/2019/11/Att-leva-med-hiv-i-Sverige.pdf, accessed 2020.04.07 
tions for people living with HIV in Sweden. There are however, some specific troubles that are pointed out by this survey as having a negative impact on quality of life.

"The study showed no correlation between quality of life and gender, age, country of birth, or city of residence. However, the results showed that psychological symptoms, psychiatric side effects from HIV medication, substance abuse, and a higher consumption of alcohol than desired correlated with a lower quality of life."

So symptoms and side effects from prescribed/licit drugs as well as proscribed/illicit drug use are found to be a problem through this research. The study then aims to account for this problem through the introduction of another variable: stigma. This study draws on the work of Erving Goffman (1963) to relate to 'stigma' as a fundamentally social process involving the management of what Goffman refers to as spoiled identity. For Goffman, the stigmatised individual is undesirable, and what he calls 'the normals' (including himself in this category) hope to better the situation of the stigmatised individual through what he calls "a daily round of normalisation" (Goffman 1963:69). Perhaps this approach works for some, but I find it important to ramify and intervene in the normalisation of stigma by taking a more descriptive approach into account as well.

In this Swedish study of HIV treatment, stigma emerges as a negative variable. It also emerges in relation to another variable that comes to be illustrated in a positive light: quality of life. What this yields is an effort to prove that stigma comes to lower the quality of life for people with Swedish HIV. This allows the research to articulate a final implication for people living with Swedish HIV: "Fear of stigmatization because of HIV can lead to people hiding their HIV status from other people." Interestingly, then, when 'quality of life' is studied or read through Swedish HIV treatment, the problems become once again envisioned as a matter of disclosure. The study reframes the problems it finds by staging these as the effect of some deeper and underlying process called 'stigmatisation'. While the study does eventually note that most of the research subjects found it difficult to engage in sexual practices due to the invasive legal requirements present in the Swedish approach, it then quickly shifts the focus away from the Swedish legal framework by ascribing responsibility for these issues to, "the low level of HIV knowledge in society". This analysis ultimately concludes by calling for "evidence-based knowledge" as a solution to the problem. In extending Swedish HIV treatment toward a 'fourth 90 ' by these means, it accounts for these problems by deferring the need for change outside of treatment practices. Through the conclusive findings of this study, then, a bifurcation of 'HIV' from 'society' takes shape. The problems of patients living with Swedish HIV become pinned to society, while HIV knowledge and evidence-based medicine itself, and the public health policies in which these circulate and on which they depend, are left unproblematised - intact, untouched, and unaccountable. In this way, they become staged as innocent solutions instead of being acknowledged in tandem with the trouble. I think we can do better than this. 
Feminist studies of technoscience have taken Foucault's lesson into account, while also problematising the implied 'dehumanisation' or the lack of agency perceived to result from normalisation and patient objectification. Problematising the idea that the objectification of the patient is necessarily oppositional to her subjectivity, Charis Cussins (1998), for instance, describes what she calls the ontological choreography of materials, bodies, techniques, and subjectivities in the treatment practices of infertility. Cussins draws on ethnographic material from engagements with patients and professionals within the zone of treatment to describe how the objectification of infertility can not only be constitutive of the desired self over a long duration, but also how these patients are active participants in their own objectification. An ontologically heterogeneous agency is choreographed in such practices to render the patient compatible with her treatment, but these processes of commensuration are a contingent achievement. It is only when some trails of selfhood become obstructed and the ontological choreography breaks down that modes of objectification can be attributed with dehumanising effects that become 'bad' to the patient. This insight thus leads me to see how the ontological choreography of Swedish HIV treatment might be valued differently. With this chapter, I will further investigate the specificities of this ontological choreography as $a$ manifold process of valuing (with) ${ }^{105}$ dependency. Through the manifold process of becoming dependent on and accountable to Swedish HIV treatment, I become a manifold subject; not only a subject of control, but also a subject of care (Vogel 2016). Unfortunately however, what is deemed 'HIV care' seems to neglect some issues that matter a great deal, issues that I aim to shed more light on in this chapter. While some subjects become valued, others become neglected. I want to find better ways of communicating care (Lindén 2016) and valuing ${ }^{106}$ my dependency on care practices than those I have myself encountered.

By opening up the matters of accountability I have encountered in Swedish HIV governance to further investigation, I believe other entities may come into presence that do things more carefully. For example, the medical ethnographer Casper Bruun Jensen (2007) finds that the notion of 'sorting attachments' allows him to organise and stage his research concerns differently from policy and medical assemblages. His work shows me how these assemblages can also get caught up in each other's concerns.

"The term attachments points to the fact that no such engagement is innocent, since all actors come packaged with sets of cultural, political and economic relationships as well as institutional-

105 The 'with' here can be helpful for some readers, but at the end of the day it may also be redundant. A dependency, in the sense I use it, can indeed be comprehended a 'thing', a noun to work 'with', but it is first and foremost a relation. My work will thus focus on the positive valuing of such relations of dependency, rather than only critiquing their negative or restraining capacity.

106 While I too share the "wish to foster understanding of the composition of multiplicities of values: the establishing of relationships, the drawing of boundaries, commensurations and incommensurations, the ordering of hierarchies, and the production of desirabilities", (Dussauge, Helgesson \& Lee 2015:20), I am less sure that my approach counts as either emic valuography (Dussauge, Helgesson \& Lee 2015:280) in contrast with an etic approach, as these authors consistently argue for. I find it more helpful to think about multiple valuing practices rather than focus on any singular process of valuation in particular. 
ly sanctioned commitments. Sorting attachments, thus, refers to the processes through which researchers, by affinity or implication, become tethered to institutional and political 'machines', which may be quite different from their own but nevertheless shape their research questions, methods and conclusions in multiple ways." (Jensen 2007:239)

For Jensen, the work of sorting involves an effort to situate the attachments that enable, motivate, and shape the research process. He shows that a strong attachment to an object, in his case a medical agenda, may leave little room to assemble the concerns at stake in a new way. This chapter thus articulates an alternative to quality of life by demonstrating a way of valuing dependencies positively rather than negatively through the proxy of 'stigma'. The following section will draw on my story of ongoing treatment in clinical examinations and self-care practices to investigate the attachments at stake in my case of Swedish HIV treatment. Doing so enables me to investigate the normativities and subjectivities that are enacted in my dependency upon the techniques involved in the governing of Swedish HIV.

\subsection{The manifold dependencies of Swedish HIV treatment}

It's a Friday afternoon, so when I get home from my walk, I pack my backpack and will soon head to the station to catch the last-minute train to Copenhagen. I roll up a few changes of clothes, gather together a couple of articles, and find myself a book for the train ride. I don't need much for the weekend, so I pack light. The last things to go in the bag are my toiletries. One item is of vital importance to me, a white plastic jar with pink highlights that bears the title 'Triumeq' and contains 30 large pills, each filled with 50mg of dolutegravir, $600 \mathrm{mg}$ of abacavir, and $300 \mathrm{mg}$ of lamivudine. I chuckle a little as I read these names out loud. They often make me think of sorcery, and I imagine myself casting a protective spell around my body while uttering the word 'abacavir!' However, I am perfectly aware that this protection does not really shimmer around my body, but circulates within my body.

\section{Circulating dependencies}

My dependence on anti-retroviral therapy (ART) is thus the first to take stage. But dependencies such as these are not just restrictive. They are also enabling. This is, of course, merely one brief moment in which I become subject through treatment, but it illustrates well the way I think about my dependency on antiretroviral medication and other devices involved in my accomplishment of what is deemed 'good' treatment adherence. However, in this chapter I want to go one step further. I want to ask how the subject of treatment becomes a manifold subject. I will show how, due to different ways of coupling, of becoming dependent upon material-semiotic practices of governing and becoming governed, the subject that I become is more than one, but also less than many. This will allow me to conclude my thesis with a reflection on the possibilities of shifting between modes of governance. 
In this practice many call 'dosing', I am enacted as the subject of treatment. It would feel clunky bringing around a whole month's supply of my meds ${ }^{107}$, and I don't like the constant rattle of them rolling around in their plastic container. I open the childproof lid, take out four pills, and pop one of them into the tiny pocket on the right side of my pants. I will need to take that one in about an hour, so I might as well keep it accessible. The lavender coloured pills are about two and a half centimetres long each. They are oval shaped, and every one of them contains a number etched into their surface. Half an hour later, I'm sitting on the train with my laptop open. I look at the time. 19:46. I try to be discrete as I take the pill out of my pocket and swallow it down with a sip of my drink. Having done that, I pull out my phone and change my alarm from 20:00 to 19:00. No need for that noisy reminder today.

Changing my dosing time forward or backward by an hour or so is a common practice for me, but I know that if I am four hours late, I should skip my dose for that day rather than risk an overdose, which could be lethal. In delegating this reminder to my phone, I become able to stick to a precise dosing time. The luxury of having an alarm in my phone that I can rely on to this extent allows me to modify my dosing habit and to regulate it. In this sense, and many others as well, I recognise my privileged status. Many people living with HIV do not have this possibility; for them, adherence becomes a whole lot more complicated in practice.

While sitting here on this train 108 , I think about the subsequent physical examinations that took place shortly after receiving a positive HIV test result. The doctor looked for signs of opportunistic infections, checking every bump and bruise on my body while finding out as much as she could about my personal and family medical history. I think about the tests that she had done to check my genetic makeup before figuring out the best ART regimen for me. I remember her telling me about a genetic mutation called HLA-B*5701 that could indicate a higher chance of getting a hypersensitive reaction to one of these drugs and how, in the worst case, this could cause fatality within thirty minutes. She ran that test on my blood samples three times just to take care that it did not. While not entirely eliminating the possibility that this could happen, care such as this gives us both a way of handling indeterminacy. A few weeks later I would start my regimen - the three-in-one drug called Triumeq that I mentioned earlier.

\footnotetext{
107 Which I used to do in the early days out of concern that I could get stuck somewhere without access to them. I remember feeling that my body would explode after missing a dose or two, but knowing full well that this would not be the case.

108 Interestingly, for Latour the differentiation of 'mediators' and 'intermediaries' does not align entirely with his differentiation (or lack thereof) of 'human' and 'nonhuman'. In Latour (1996) we find a story about twins, one that cuts her way through a wild forest populated by spiders and snakes, and another that takes a train to his destination while studying his newspaper. Because the second twin does not have to take into account the journey, the train becomes an intermediary for him. The twin traveling through the forest, on the other hand, feels every bump and bite along the way. She has fought her way through the forest and the temporality of the travels have been inscribed into her body; this twin had to deal with a vast array of mediators in order to arrive at the same destination. The differences in these human-subjects is irredeemably attached to nonhuman-objects.
} 
This medication was new, but my doctor assured me 'it was said to be a good one'. It is composed with three different drugs. Lamivudine, also known as 3TC or Epivir, is a nucleotide reverse transcriptase inhibitor (NRTI). This means that it blocks a specific component of the virus called 'reverse transcriptase' that would enable it to replicate. Abacavir, also called $\mathrm{ABC}$ or Ziagen, works the same way. With both of these drugs enticing the virus to weave them into its DNA, viral synthesis is ultimately obstructed. The third drug I take, Dolutegravir - also known as DTG or Tivicay - works through a different mechanism that makes it part of a class called integrase inhibitors. Used for both HIV treatment and for HIV prevention, Dolutegravir blocks the virus from integrating itself into the host cell. This makes it attractive for those who wish to live without HIV infection, as taking these medications daily has been shown to be highly effective at blocking the virus. So depending on the situation, this drug may help to enact either the subject of prevention or the subject of treatment. It thus becomes a valuable addition to both practices of disease-control and health-care.

After receiving my diagnosis and my first prescription for anti-retroviral drugs, I went back to Copenhagen and stayed with my sister for two weeks with a heightened awareness of every twitch, ache and pain in my body. The image of a side-effect called 'the buffalo hump'109 was a particularly daunting figure during this time, but for the most part I seem to have been lucky enough to avoid any complications ${ }^{110}$. Those first weeks went by very slowly. I remember the follow-up meetings where my doctor showed me the results that indicated that the medicine was working and how she guided me through the details of my condition when it was all still so new for me.

Dr. Elin: the cd4 count, the cd4 cells are lymphocytes with a specific cd4 receptor. And this is why these cells are affected by the virus, and there are even other cells in the body that are affected by the virus, but the cd4 cells are the ones that get the most harm from the virus, and when they go down, then we know that your immune system is affected.

Jeffrey: so is the antigen the same thing as the RNA?

Dr. Elin: it's not the same, it's not the same thing. But all the tests we use are combo-tests - antigen/antibody. And the antigen, that's from the virus, and when you have RNA, you can always de-

\footnotetext{
${ }^{109}$ Early anti-retrovirals often came along with a host of side-effects that generally ended in fatality, such that the question of whether to treat or not treat the infection was a legitimate question to ask oneself. As the drugs got better, this aspect became less concerning, but several side effects were still noted as possibilities during the start of my treatment. Liver and cardiovascular disease were probably the two most concerning to medical professionals, while the buffalo hump - a lump of fat that appears typically on the back of the neck, giving the appearance it is named after - was more concerning to me at the time.
}

110 Many patients undergoing the same anti-retroviral regimen have exhibited symptoms of sleep disorder. Since such troubles have frequently found me, I have found ways to address them through other means and thus have not noticed much of a change in this regard. However, having recently undergone a minor surgery to remove a "squamous cell carcinoma", I am now becoming less sure of the unproblematic framing these drugs often receive. Asking my clinician why I got this form of cancer in spite of my high cd4 count, I was told that I was simply part of the 'risk group' for this cancer. Since my immunological tests return optimistic results, a more pessimistic stance on these drugs seems to be in order. 
tect the antigen. And then when we once had a positive antigen/antibody test, we don't need that anymore, because you're, the antibodies - you will still have them for the rest of your life.

Jeffrey: oh, ok.

I would come to learn a lot about my medical constitution through these events, but as the vignette above shows, in the very beginning I found it strange and complicated information to grapple with. I also asked a lot more questions when I decided to study Swedish HIV treatment with praxiography. In this sense, other patients would perhaps receive less details from their HIV specialist, but it has also been historically common for subjects such as myself to learn as much as possible about the medical and scientific knowledge that we depend upon (Epstein 1996) - and so I did. I would learn that 'the cd4 cells' were an important mark of a healthy immune system, and that when they went down, I was in trouble. I would learn that an indicator called 'the RNA' was how we measured the success of the virus, so keeping this number as close to ' 0 ' or 'undetectable' would come to be a vital goal. In my case, I managed to attain the value of ' 0 ' after about three weeks of medication and I never received another viral mark of detectability since then. I can only imagine the personal and legal strain that would arise from receiving a measure of above zero that would indicate viral detectability - an event that professionals such as my doctor call a 'blip' and one that looms on a dreaded horizon for the patient. While asking as a patient why sporadic blips occur, my doctor would reply with: "we don't know yet, and it is not in every patient we see it". I would later come to realise that such an event would be taken by my doctor to indicate a problem with my dosing habits, thus signalling a need for further care. Once a year had passed however, I could be evaluated as practicing good anti-retroviral adherence and became known as having a so called 'well-treated infection'. So through the valuing of my adherence to anti-retroviral medication, I thus become the well-treated subject. But the well-treated subject I become through clinical practices of examination in this case also depends upon my laboratory enactment as a virologically positive-undetectable subject that no longer poses a risk to the health of others. To achieve this status, more is required than simply taking medication. It requires a physical examination and an inspection of my blood values. The practice of blood collection always takes place after the physical examination is finished.

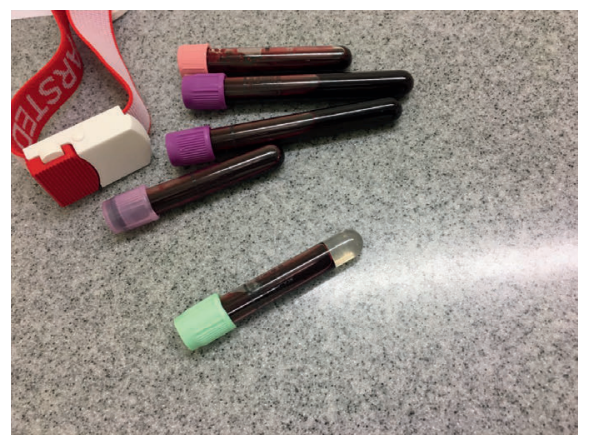

Figure 20: circulating dependencies 
After a few moments in the waiting room following a physical examination, a nurse arrives and we greet each other while heading to a small room that fits just the two of us and a metal chair laced with straps and braces. I am first asked my personal number and I think for a moment before reciting this ten-digit number that consists of my birthday and four extra digits that identify me as a Swedish resident. Here I am enacted as a kind of 'biocitizen subject' that can be identified through a personal number. This small room also contains a chart on the wall with a label - 'Rör ordning' or what translates to 'vial ordering' in English. This little chart provides a reference point for the coloured coordination of the different vials of blood (see figure 22) drawn from my body. With this chart, the nurse will know what coloured vial to choose for the samples that are sent to different laboratories.

As I look at the different colours on the chart, the nurse quickly swabs the inside of my elbow with a disinfectant and asks me if I am ready. I confirm by saying 'yep', and they proceed to insert the needle into my arm. Ouch! Even though I hate this part, I often find myself watching the blood run out of my arm and through the little tube that fills up each vial. The one hand of the nurse skilfully removes each vial when it is full and attaches the next. Their other hand carefully holds the needle in place. The momentary pain I feel in this practice is necessarily a part of my treatment, as it is through the collection and enumeration of my blood that I will come to evaluate the effects of chemoprophylaxis in my body. In this case, self-evaluation is paid for in blood. Let me try to explain this in a bit more detail.

\section{Examining dependencies}

As a patient undergoing Swedish HIV treatment, I can log into an online medical journal online and see some ${ }^{111}$ of the reports that are filed by medical professionals in their treatment of my condition. Taking a look at the first of these, I find the following journal entry by a medical professional.

\section{Medical Journal: Tested positively with rapid test for HIV yesterday via Saviour. Comes in today as emergency. Is shocked, but knows several occasions on which he has been exposed to risk. (translated from Swedish)}

As this note indicates, I am enacted from the start of my treatment as subject to risk. Much has happened since that first examination. Looking more at this online record, I see the name of the medical professional - I will call her Emma - who wrote up this report. I know Emma as the councillor who talked with me after meeting the HIV specialist and receiving my diagnosis. I remember how strange it was that while my doctor told me to keep my diagnosis to myself for awhile and quietly come to terms with it, this councillor advised me to put my status on Grindr, a social media platform that I used at that time. This advice was issued

\footnotetext{
111 There are a vast amount of digital and analogue reports that are assembled for my ongoing testing and treatment, but as a patient, I have access only to the 'front end' reports rather than the 'back end' reports. Direct reports from laboratory professionals, for example, or feedback from public health authorities to my personal doctor remain unaccessible to me, in spite of professionals telling me that such reports and comments do exist.
} 
in relation to my new legal obligation to disclose my status to any sexual partners before engaging in sexual activity, and the councillor had told me that Grindr may be an easier way for me to mediate this disclosure.

I remember how relieved I felt that I had ignored this advice when I heard the news some time later that Grindr had been sharing HIV status data to third parties. Trying to gain access to Grindr records in order to see what specific agencies had been given my Grindr data was impossible for me, even with the help of a legal scholar who had specialised in GDPR policy and wrote some very authoritative letters that I sent to Grindr. In spite of this effort, I was never granted access to my personal data. But what I mean to show with this story is how my translation from the unwell subject into the undetectable subject does not only depend upon the drugs themselves, but upon the ongoing clinical work that makes possible the examination of their effective intervention. So my attachment to Swedish HIV treatment also comes along with a bundle of other dependencies; some of these are obligatory while others are optional.

During my frequent visits to the infection clinic, I sometimes find other tests to ask about for my ethnographic work, usually something I cannot remember from the first round of tests. In such moments, I am enacted as the tested subject.

Dr. Elin: When you first came to us we did, as we always do, tests for different hepatitis $(A, B, C)$ and also for syphilis 112 - that's what we screen for. You didn't have anything.

Next, Dr. Elin or a medical student will ask me to remove my shirt and proceed to check my lungs and blood pressure. I usually sit up on the examination table for this part and I am usually asked small details about my work in order to distract me. With the consent of those present, I have come to place a recording device on the table at the beginning of each examination. As I am asked to breathe in and out while feeling the cold stethoscope slide across my chest and back, I answer questions that the recording often provokes. While my blood pressure is measured with the inflatable device that constricts around my arm, I tell my latest stories about conferences and HIV research. Sometimes it goes the other way around too. I remember Dr. Elin telling me during one examination that a new study was being done in the labs of the same hospital, asking me to participate. The research would contribute to a better knowledge of dendritic cells, one of the immunological entities I described in chapter 4. When Dr. Elin left that examination to find a consent form for me to sign and to check how much blood they needed from me as a research participant, I thought to myself how oddly reflexive this ethnography was turning out to be. I was becoming the research subject of a practice that was the subject of my own practice of research. Here I am enacted as the subject of reflexive examination. This perhaps puts me in a privileged position, as there are many other people living with HIV that do not occupy a similarly symmetrical relation of observation to HIV treatment practices in their role as patients. Having a recording device between me and my medical professionals seems to do quite a lot to our conversations already, so I

112 ELISA tests can provide an 'HIV positive' result when falsely identifying syphilis as HIV. 
wonder what other tactics people use to become less vulnerable without the good excuse of research.

When the physical examination is finished, I get the medical opinion of Dr. Elin. If my blood pressure is high, which it sometimes is, I may be asked if I have been drinking enough water or if I am under any extra stress. Since I smoke more cigarettes than, having asthma, I know I should, we usually proceed to discuss ways that I can quit this habit and improve my lung function. I will tell stories of adventures on my mountain bike in the Swedish forests and these will be applauded. On one occasion, I had been using a vaporiser instead of smoking for a few days and excitedly presented this news to Dr. Elin, only to hear with a concerned tone that I should really aim to quit altogether. I felt a bit like a student receiving a bad grade on an assignment they felt proud of and I am ashamed to say that I went back to smoking cigarettes later on that day. Here we see how the subject of treatment becomes encouraged towards some goals and navigated away from others. We also see once again how the subject of pleasure113 is excluded from Swedish HIV care practices when measured against a health machine.

During my biannual visits to the doctor, I would also come to learn a lot about the biological structure of this disease. HIV-1, of which my subtype is classified as 'epidemic B', is an enveloped retrovirus. That is, it belongs to the 'lentivirus' or 'slow virus' subgroup of the 'retroviridae' family. This lentivirus receives its category as a slow virus due to its potentially long incubation period, generally from 8 to 10 years. After that time, the virus will have depleted the body of cd4 or 'helper cells' to the point that I would become vulnerable to a host of opportunistic infections and AIDS defining illnesses. Structurally speaking, the viron of HIV-1 contains two identical copies of single-stranded RNA. HIV as a retrovirus is curious in this way, as it plays against the central dogma of molecular biology, which states that ' $D N A$ makes RNA and RNA makes protein'114. In the case of HIV the function is a little different; RNA first reverse transcribes itself into DNA before carrying out its process of viral translation. The viron also contains an enveloping layer called a 'capsid' which encloses the RNA along with enzymes such as reverse transcriptase, proteases, ribonuclease and integrase, a layer that is composed of several copies of the viral protein or antigen called p24. Other proteins then envelop this nucleocapsid. We might call this 'the biomedical subject' of Swedish HIV treatment. While I would come to learn about many of these biomedical markers through my personal research, my conversations with my physician would come to focus almost exclusively on two of these values in my own blood - cd4 and RNA (see figure 23).

I think back again on a previous visit to the infection clinic. After a few moments of sitting in the waiting room, Dr. Elin arrived and I greeted her with a handshake. We typically exchange a few congenial comments while proceeding to the examination room. This space is

\footnotetext{
113 I thank a reader who pointed out for me that I used 'pleasure' in relation to smoking, but not to biking. Truthfully, I dislike biking quite a bit and now take pleasure in my exercise by going for long walks instead.

$114 \mathrm{https}: / / w w w . a t d b i o . c o m / c o n t e n t / 14 /$ Transcription-Translation-and-Replication\#figure-central-dogma, accessed 2020.04.07
} 
clinical and uncluttered with some shelves on the one side holding rubber gloves, syringes, and other medical objects. The padded examination table stands on the other side. Between them is a desk with a computer and two chairs. I sit in one of them while Dr. Elin takes her place in front of the computer screen.

Dr. Elin: All your blood values are very nice. No red, no red marks. And about your HIV specific tests, it's... it's here. The values is ' 0 ', and your cd4 count is nice and high - '1141'.

Jeffrey: And when was this?

Dr. Elin: Eh, it was the 30th of May, when you were here last time. So its... it looks very, very good.

Jeffrey: Nice.

Dr. Elin: And you received also your third Twinrix, eh the vaccination against hepatitis A and B?

Jeffrey: Yes, yeah...that was pretty recent.

Dr. Elin: And...yes, it looks...

Jeffrey: All good?

Dr. Elin: It looks all good.

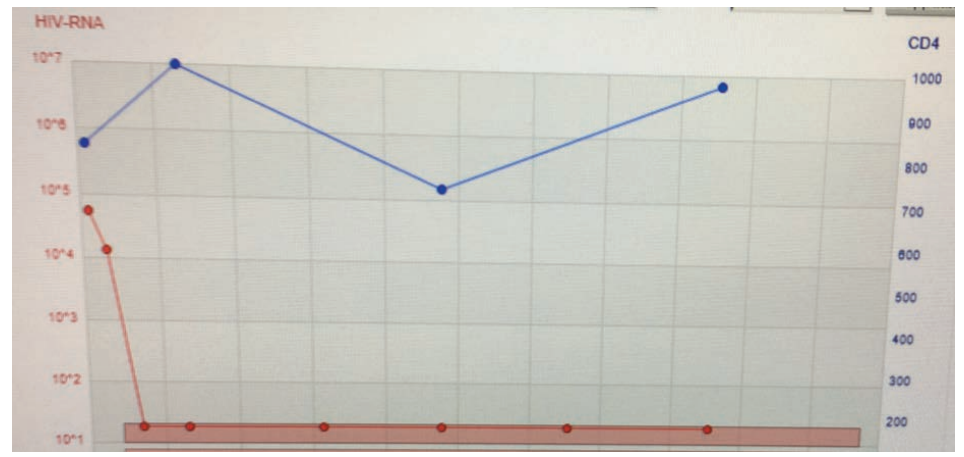

Figure 21: examining dependencies

We look a computer screen (see figure 23) and discuss the results from my previous blood work. These are shown to me on a graph that charts my cd4 and RNA values quantitatively on the $y$-axis and their changes over time on the $\mathrm{x}$-axis. These inscriptions will become the indication criteria of my successful treatment. Through these inscriptions, both HIV and I, as well as the anti-retroviral drugs, become examined and evaluated in relation to each other. Cd4 is indicated by a blue line, and HIV RNA is represented in red, which is why Dr. Elin speaks of 'no red marks' during the examination. The name of the game is to keep my immune system high (blue) and the virus low (red).

This graphical chart of my InfCare health data coded in red and blue have become a kind of dashboard or interface that makes possible the monitoring of my condition. Through 
this practice, I become the examined subject ${ }^{115}$. Both funny and concerning was an issue that arose when a reader of an earlier draft of this chapter asked me if it was possible to take a better screenshot of my data. Interestingly enough, these values are not available to the patient through their online medical journal. Being the unique privilege of the health care system, I have access to these values only during the clinical examination. This makes me subject to treatment incentives and participation.

As you can see, this particular clinical practice focuses on the value of RNA and cd4 to the exclusion of many other issues affecting those of us going-on with HIV. Having the appropriate numbers becomes the express goal of my treatment. I go into the clinic to make sure that my numbers look fine, and I leave upon hearing that they do. In this way, the biomedical subject is enacted in tension with the patient subject. While these numbers are no doubt important, here controlling the viral risk can come to displace the attention given to the 'dis-ease' that many patients experience when undergoing Swedish HIV treatment. In this way, the unwell subject becomes translated into the undetectable subject as well.

The category of 'undetectable' makes for a desirable subject. My well-being depends upon this categorisation of my condition, one that requires my ongoing participation in practices of monitoring and self-evaluation; of self-care done in this way rather than another. As the praxiographer Else Vogel (2017) aptly puts it, this 'self-care' is not to be understood as do-it-yourself-care, but rather as a process of learning to attune and align with what is valued in Swedish HIV treatment - the production of a desirable and long-term-self. In this way, the subject is made to value self-governance by cultivating a sensitivity to the values that govern the self.

\section{Evaluating dependencies}

While these so called 'highly active' antiretroviral treatments (HAART) and pre-exposure prophylactics (PrEP) are relatively new innovations in the biomedical governance of HIV, scholars of both STS and queer studies have already been generating notable accounts of these biotechnologies. With a situated interest in both of these traditions, Race (2009) offers a critical analysis of several devices ranging from pharmaceutical and recreational drugs, diagnostic tests, legal frameworks, and online hookup apps to show how these devices come to mediate the sexual encounters of people affected by HIV. This work shows how a range of techniques - condoms and testing strips for example - each do something quite specific to the practices they become situated within. With an exemplary display of what he terms "responsive attentiveness to the practical dynamics in question" (Race 2009:120), his account enables me to show how not all devices are given the same responsibility in mediating health

\footnotetext{
115 In a similar vein, Gerlitz and Lury, are interested in the abilities of 'enumerated entities in processes of mediation' (Gerlitz \& Lury 2014:177): “how the evaluation of the self by individuals in social media is linked to the capacity of the tools to give value to themselves (...) it makes what is valued the outcome of recursive processes of valuation, the multivalence of which in turn depends on the limits of inclusion and belonging that organise the open-ended participation of those individuals whose activities are the object of valuation." (Gerlitz \& Lury 2014:177)
} 
and disease. For example, while 'diagnostic tests' and 'condoms' have come to be positioned as reliable mediators for the legal status of people living with HIV through the obligations I outlined in chapter 3, 'antiretroviral medications' are only just beginning to achieve this same status as legally responsible devices in Sweden.

Even though my doctor has instilled in me the importance of religiously sticking to my regimen, I often think about stories I have heard from other medical professionals that tell me how these drugs are so effective that it would take a minimum of 7 days and more likely 14 days without these drugs in my body before the HIV would start becoming a detectable presence in my body once again. However, I have no desire to test this in practice. I would much rather adhere to my daily regimen and retain my status of 'undetectable' without any interruptions. My attachment to this status is by now a very strong one. This status not only alleviates much of my embodied concern with HIV, but it also grants me exemption from the legal constraints I became obliged to follow from the start of my Swedish HIV treatment trajectory.

Thinking through the normalising effects of Swedish HIV treatment in my own life, I travel back to the first days after my diagnosis and remember how it was councillor Emma who carried out the practice of what this clinic calls 'contact tracing' after my HIV infection was confirmed. This practice aims to trace the network of people who may have come into contact with my HIV infection and thus put at risk. In Sweden, this is executed by a medical authority. Elsewhere, the patient may be asked to notify their partners of their medical status on their own or with the help of medical professionals. When a person is diagnosed with HIV (among other infectious diseases), the Swedish healthcare system will record, if possible, their complete sexual history and send a letter to these people it deems at risk of transmission. This letter of risk notification to sexual partners does not disclose the name of the patient who reported them, so anonymity is said to be preserved. This strikes me as a strange way to do contact tracing, as I can imagine many homes in which such a letter could cause quite some havoc for the recipient. I wonder why this information is not provided in a more discrete way to those concerned, rather than made available to any friends or family they may share a mailbox with. Perhaps there are better ways of offering care to those who may need it, maybe via the electronic systems used for other interactions with governmental agencies in Sweden. Turning to my online medical journal, I find the first report made by Dr. Elin - my HIV specialist - after establishing my diagnosis. I find the following:

Medical Journal: Rapid-tested pos via Saviour yesterday. Last neg test in August. Has known that he has been exposed to risk. Only had a general conversation as the patient is going to take his first HIV test today. Gets a time on Thursday when the HIV test and confirmation test should be completed. (translated from Swedish)

These medical records confirm the details of the conversations that were deemed relevant for diagnostic work at this infection clinic. In both of these medical reports, I am enacted as the subject at risk. I wonder to myself how my treatment would have been different if I 
had not disclosed the event in which I became infected, or if I had instead declared my memory to be completely blank. Questions were required of me, and I honestly answered them as best I could. It seems that at the start of my treatment, I was deemed a 'risky' subject due to my frankness. In this context, my own account seems to have paved the way for my future monitoring and surveillance. Reading a qualitative study from the Swedish Public Health agency ${ }^{116}$ that evaluated the experiences of people living with Swedish HIV, specifically in relation to legal/medical codes of conduct communicated to them by their HIV specialist, I find that it is quite common for Swedish HIV treatment to keep the patient in the dark about their treatment trajectory. This study starts by mentioning the legal form of Swedish HIV governance: specifically noting two responsibilities given to the patient: the "obligation to inform sexual partners about the infection" and "the obligation to minimize the spread of infection". While these obligations seem quite reasonable articulated in this way, I argued in chapter 3 that such obligations can become a problematic concern for the subject passing through them. This Swedish study came to a similar conclusion.

Characterising the situations described by these patients as "navigating between rules and reality", the study showed that patients are often given these rigid codes of conduct to follow without much guidance or care for how to achieve them. After being virally undetectable for a full year, I was deemed 'well-treated' enough for my doctor to wave my disclosure obligation. As long as their viral count stays undetectable117, people living with Swedish HIV as a present-absence are not legally obliged to inform their sexual partners of their HIV status, but if the virus becomes detectable as a present-presence, this event would automatically revert the legal status of the patient back to one requiring disclosure. However, in both the case of being 'undetectable' as well as being 'detectable', people living with HIV in Sweden are still required by law to adhere to anti-retroviral therapy and to comply with treatment protocol; this protocol is given to the patient by their HIV specialist. In my case, the initial protocol I followed starting treatment required me to disclose my condition to a variety of people, demonstrate good anti-retroviral adherence, and demonstrate full condom compliance. The last of these obligations would be evaluated by regular checkups in the STI clinic of the same hospital.

These obligations however, are now changing - but only for those deemed 'well-treated'. Importantly, the unwell-treated subject enacted by medico-legal practices of policing is in direct conflict with the subject of pleasure performed by many queer practices. Cruising ${ }^{118}$

\footnotetext{
116 https://www.folkhalsomyndigheten.se/publicerat-material/publikationsarkiv/e/erfarenheter-och-upplevelserav-kommunikation-kring-forhallningsregler-och-smittsamhet-bland-personer-som-lever-med-hiv-i-sverige/, accessed 2020.04.07

117 Or what is actually less than 50 copies of HIV per ml blood, the official limits of detectability in Sweden.

118 Typically a practice involving sexual activities that are performed without verbal communication.
} 
and barebacking ${ }^{119}$ become virtually impossible to practice under these legal conditions. But health care professionals do seem to understand this and are happy to help their patients when they can by providing formal 'proof' of the absence of HIV in their patients, which these patients may then provide to their sexual partners, professionals dealing with their blood ${ }^{120}$, or to other medical professionals such as dentists. They are happy to contribute to the enactment of the disclosing subject.

While I have noted the legal changes that are now occurring in chapter 3, I imagine that it will be a good deal of time before these legal changes come to alter this perception of HIV as a subject to be policed. The work of Desireé Ljungcrantz (2017) helps me address this issue further. With an interest in developing artistic practices of care for HIV narration, Ljungcrantz mediated her interviews with a variety of people affected by HIV in Sweden. These she wove into a speculative and fabulously fictitious account, empirically grounded and artfully rich, of how 12 different characters come to relate to and experience HIV in everyday Swedish life.

"One key finding is that, in spite of HIV being repositioned as a chronic illness with favourable medical outcomes, the study shows that the social dimensions of HIV are still severe. This results in the fact that becoming HIV positive might be a painful, processual and relational experience. (Ljungcrantz, 2017:214)

One of the points this lets me articulate with my material, is how the fast-track target of 'ZERO discrimination' is simultaneously sought and obstructed by the very practices that give voice to it in discourse. When 'stigma' is called out as a problem, it typically becomes detached from the tests and trials through which it is produced. Stigma thus becomes a purely 'social' phenomenon, something in the minds and on the lips of people, but something that is set apart from biomedical practice. While Swedish HIV treatment practices often declare themselves to be fighting stigma, it is paradoxically these very practices that enforce the measures that come to have stigmatising effects. With this thesis, I therefore argue that stigma is not merely 'discovered' by Swedish health-care and disease-control practices, but rather that the measures taken in Swedish HIV treatment are themselves performative of stigma.

Upon my last visit to the infection clinic, I was given yet another form by my clinician. She explained that this was not something I should think too deeply about, but that it was a just a little survey that care practices were becoming required to present to their patients; just another item on the checklist, so to speak. This survey presents the patient with a series of 10 questions (figure 24). After answering these questions, I had a little chat with my doctor while explaining my answers. While most of my answers were quite positive, some of them were

\footnotetext{
119 Tim Dean (2009) differentiates between 'raw sex', 'barebacking', and 'bug chasing'. While these categories usefully enact a different sense of intention towards HIV, I will simply use the term 'bareback' to denote all condomless sex.

120 As might be the case in a visit to the tattoo parlour.
} 
less so. Of course, the possibility for these answers to be either positive or negative is itself an effect of this survey method that values my answers with exactly this polarity.

Upon hearing my justifications for the more negative responses, my doctor agreed that things were not always easy for patients. After telling me about the trials tribulations of some HIV positive celebrity who was 'coming out' with his HIV status to the public, she made a final comment: that patients really need to change their way of thinking about this condition. Perhaps unsurprisingly, I objected. I told her that I felt it was Swedish HIV treatment practices that needed to change. She seemed puzzled at first, and we ended up having a small chat about my last visit.

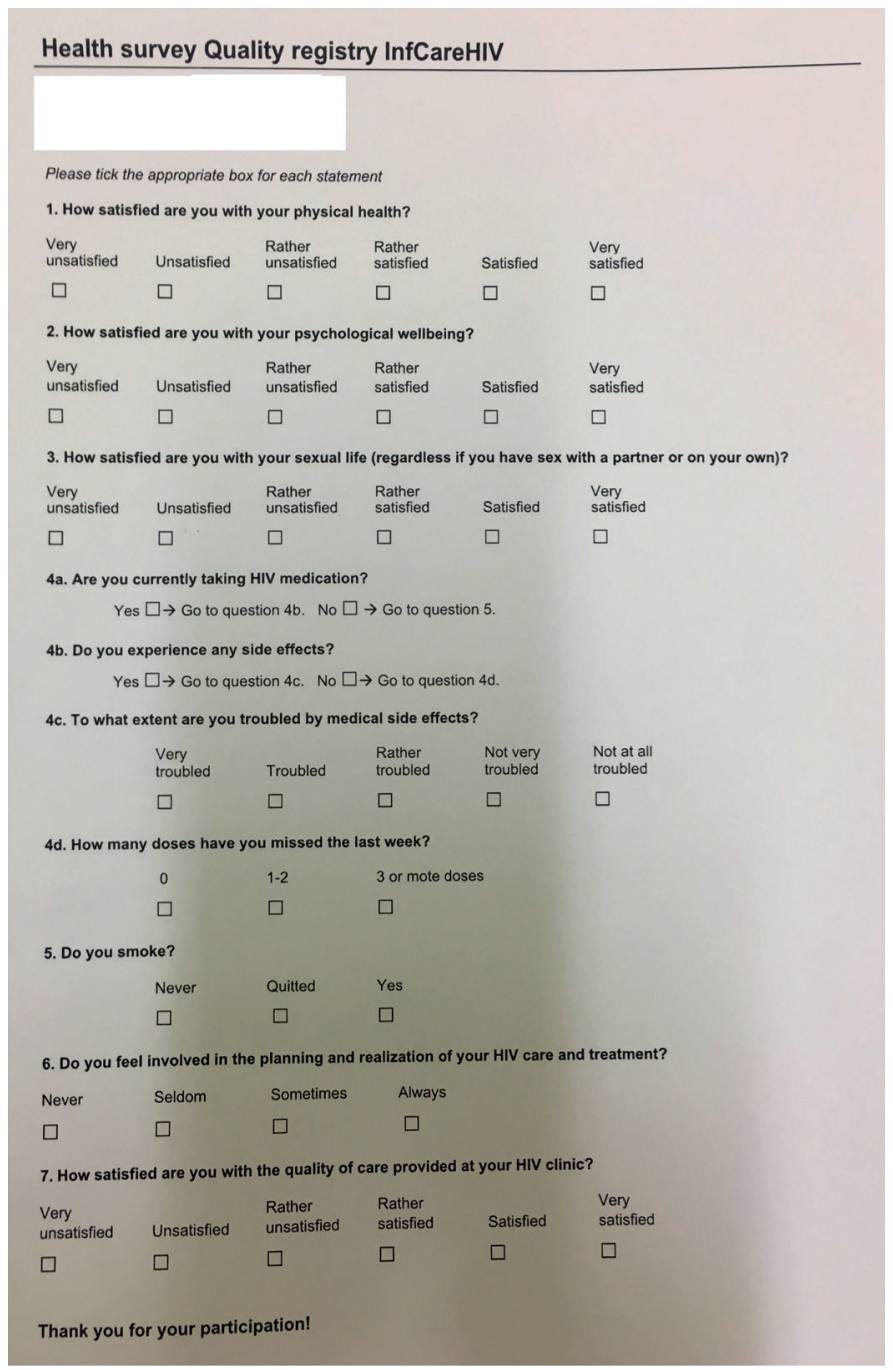

Figure 22: evaluating dependencies 
During that encounter, she had presented me with the updated 'well-treated-patientinformation' document I analysed in chapter 3. Being told that this was a change in the legal obligations I hold, I asked if she had an English copy for me, to which she said no, but that she was happy to explain the changes instead. As I previously described, my disclosure obligation was lifted after having undergone a year of treatment - under the condition that I remain virally undetectable and STI free. This change now notified me that the STI clause was no longer relevant, as my medication was now deemed effective enough that even if I did have another STI, there would be no statistical increase of HIV transmission risk. She turned to me and took care to say " $U=U$. Undetectable equals Untransmittable." I was so surprised and happy to hear that phrase finally come out of her mouth, that I actually clapped my hands and said "Yay, you said it!", to which we all laughed a little awkwardly.

$\mathrm{U}=\mathrm{U}$ is a phrase that has become the primary slogan for treatment activism ${ }^{121}$, and we had talked about it after my conference the previous year with me asking specifically why it was not acknowledged in Swedish practice. However, after this discussion about my changed disclosure obligation, my doctor had left me with a final statement: "but of course, you should still use condoms." Now then, was this instance of 'should' a form of legal or medical advice?

At that time, I took this comment to mean that my disclosure obligation had changed, but that condom compliance was still mandated. While participating in a seminar in which I presented my research and received feedback from colleagues, a colleague working at the public health agency told me that this was no longer the case and that I should revisit the legislation. Thanks to this advice, I found that not only had the disclosure obligation now changed, but that having been deemed a 'well-treated' patient, I could no longer be prosecuted for having sex without a condom. So it seems that this 'should' was more of a medical caution about other STIs than in reference to my legal status. What 'should' I then do with this experience?

I think that this story speaks not only of my personal encounters with my clinician, but also of a final issue that I want to explore further. Not too long ago, I was confronted in the STI clinic before an examination with a form that required me to answer a two page series of questions. Questions such as: "How often do you use a condom when you have sex with a new partner", were followed by boxes where I could provide either the answer of "Always", "Usually", or "Never or occasionally". While the subject here is given a multiple-choice question, there is only one out of three answers that is legally safe to give. A further question presented a similar issue, "Have you recently (last 12 months) had unprotected (no condom) orogenital 122 sex with a new partner?" This question thus also shows how medical research in Sweden still fails to acknowledge preventative anti-retrovirals such as PrEP to be a form of protected sex at all. The question here is thus not about asking the subject which forms of

\footnotetext{
121 https://www.ncbi.nlm.nih.gov/pubmed/30629090, accessed 2020.04.07

122 I found myself wanting to look this term up online when reading it, as it was the first time I had encountered this combination of oral and genital sex as a term in itself.
} 
protected sex they practice, but instead poses a direct equivocality between the the absence of a condom and the absence of protection. Not only does this form require from the patient a count of the partners they had sex with in Sweden and abroad, it also proceeds to ask for the total sum of sexual partners the patient has had "in the past twelve months", as well as the total sum of all sexual partners "so far (life time)". The STI specialist then confirms my answers face-to-face and records my answers into the digital system, or at least tries to. Such answers can then be used to quantify different measures of HIV risk at play in varying cases, conditions, and populations.

Since these systems are connected quite well in Sweden, it seems almost certain to me that the answers from patients to such questions are found useful for research, but in the STI clinic, I was never asked for research consent. The form does not give the patient any idea of what their information will be useful for, or what it may contribute to. It is simply required. While I would probably be fine with answering such questions in a research context, it seems deeply problematic to ask such information from patients before giving them access to the care they need. Here we see that not only is there an ongoing work of normalisation involved in Swedish HIV treatment, but also even a moralisation of the subject. Those engaging in higher quantities and specific forms of sexual activity come to be deemed 'risky' through this practice. Through this normativity of valuing risky forms of sex, some versions are sex are thus deemed 'worse' than others. In working towards the normality of 'viral control' the patient is made to navigate not only HIV care, but care for their sexual health more generally, but under the moral orderings of Swedish HIV treatment, this care comes to exclude a great deal of sexual pleasures from 'healthy' sex lives. In other words, STI testing in this clinic is not staged as part of responsible, careful sexual practices, but as a means to control for irresponsible sexual practices. Instead of moralising the patient for being sexually queer in any way however, the logic of care (Mol 2008) would offer them support and encouragement for attending to the practicalities of their sexual health. I therefore found it ironic and somewhat infuriating to see a rainbow badge pinkwashing the door of this clinic, a badge that certified this clinic as a LGBTQI* friendly space.

\subsection{Conclusion}

The social sciences, natural sciences, and humanities alike have all engaged intensively with the subject of HIV infection and AIDS, in a variety of ways. At the very beginning of the phenomenon, feminist technoscience scholar Paula Treichler (1987) argued for a greater sensitivity to significant meanings given to this disease. Through a critique of 'biomedical' and 'public' discourses, presented in this account as a continuum that reinforce each other rather than being dichotomous, Treichler showed how AIDS became a "deeply problematic signifier" (Treichler 1987:373), and how as a result the lived reality of AIDS exceeded its 'inherent' properties. Struggling to make sense of AIDS, Treichler walked us through the many myths and forms of mania that infected this object from its very inception. This analysis shows how speculation about the origin and nature of HIV and AIDS has frequently brought about homophobia and racism in its wake, through what has been otherwise labelled 
a "contagious relationality" (Sampson 2012). Through what she calls "rewriting the AIDS text', Treichler called attention to the ways in which powerful cultural narratives can be challenged.

In this chapter, I have aimed to develop an ethics of sensitivity and specificity as a mode of governing that might be more able to account for the ways in which Swedish HIV treatment both and constrains and enables the ongoing enactment of particular subjects. With this story, I thus aim to cultivate methods that contribute to the enactment of pleasure and care for subjects in vulnerable positions. I have thus tried to handle Swedish HIV treatment through an ethnographic alternative to a mere critique of controlling governance strategies or by embracing the notion of stigma, a strategy that tends to ignore the practicalities through which effects that may come to be known as stigma are produced. Through my inclusion and re-mediation of sensitivity and specificity, I instead showed how devices of control can be turned back upon themselves in order to better care for manifold subjects.

This thesis thus not only offers an empirical description of the Swedish HIV treatment I underwent, but it aims to do so while creatively working through an affirmative and queer ethic of care. With this work, I have experimented with different ways handling and researching HIV together with the values of sensitivity and specificity that I have met in the field, rather than choosing between the dominant strategies of either control or critique. The following chapter will now summarise my findings. 


\section{vii // Taming and attuning to the manifold subject}

\subsection{Slowing down Swedish HIV treatment}

This research has empirically addressed and answered the research questions I posed in the first chapter and set out to answer. Specifically, I have answered my first question: i) "what bodies, understood in the broadest sense, are given responsibility for HIV in Sweden; to what obligations are subjects living with Swedish HIV held to account" by showing how both individual and collective bodies become responsible through legal, diagnostic, surveillance, and pharmaceutical technologies. However, as I have also shown, they do not all become responsible in the same ways. This thesis has provided an empirically grounded and theoretically rich account of how my own body can be accounted for as a manifold subject that is differentially governed in a variety of practices involved in Swedish HIV treatment. While investigating my second question: ii) "how do diagnostic and surveillance practices know, make visible, speak about, classify, and manage people living with HIV”, I took extra care to sensitise my account to the 'how' of what might be called the matters of accountability that I met in the field. In other words, I showed how differences in governing take place in a wide range of practices through which the subject variously becomes accountable. Finally, my last question: iii) "how does Swedish HIV treatment take shape in the lives of the subjects it affects" enabled me to relate to the ongoing work of handling HIV through my personal and professional work.

Navigating the reader through the literature on HIV in the social sciences and humanities, I have provided a reading of the fast-track as a biopolitical and governing assemblage, an assemblage that makes us who 'we' are - subject to HIV technoscience and its various practices of governing. By describing a moment of interpellation in my participation at the 2018 international AIDS conference, I was able to show how it is a critical moment to account for the subject formation being achieved in this fast-track assemblage. I moreover showed how I went about following the subjects of Swedish HIV technoscience by describing their material-semiotic enactments in various situations. So what does it mean to slow down Swedish HIV treatment at the end of the day?

In chapter 3:Policing the unwell, I discussed the legal framework that formally enacts the subject undergoing Swedish HIV treatment. Here, slowing down let me follow the fasttrack into the local practices that contribute to its accomplishment in Sweden. My argument in this chapter was that not only are formal codes of conduct powerful scripts, but that they make me subject to three specific obligations: disclosure, compliance, and adherence. Situating my description of this medico-legal structure in relation to my personal experiences, I argued that Swedish HIV treatment can be quite aptly grasped as a policing script that is productive of different subjects. In its governance of Swedish HIV, not only does this policing script comes to differentiate the responsibilities of doctors and patients, but it also comes to produce a difference between subjects becoming well-treated and subjects becoming treatedunwell. Slowing down thus enabled me to articulate this rigid mode of ordering accountabili- 
ty, subjects, and objects, while also showing how the policing script of Swedish HIV treatment has come to change quite substantially over the duration of my study.

In chapter 4:Detecting the undetectables, I investigated the fast-track target of 'knowing your HIV status' to better understand the complexities at stake in knowing HIV through laboratory diagnostics. While much has been written in STS about the differences between clinical, laboratory, and epidemiological modes of knowing, I wanted to cope even further with the different micro-politics within laboratory modes of knowing and to flesh out the molecular accountabilities, subjects, and objects they perform. Here slowing down enabled me to describe how knowing HIV is done in three different ways: knowing HIV as other to the self in ELISA testing, knowing HIV as a deep genetic structure in PCR testing, and knowing HIV as a state of conflict in the practice of flow cytometry. By following my blood into these practices and describing the values enacted through these measures, I also showed how different subjects are enacted along with each diagnostic device: the subject with antibodies/ antigen, the subject with viral RNA, and the subject with $c d 4$. Slowing down enabled me to show how these different testing devices all perform a different mode of knowing and enumerating HIV. Finally, I argued that these devices enact a the 'undetectable' subject as a manifold. Each subject is indeed different, but they each also depend upon one other in specific ways. I thus showed how the manifold subject takes shape as the simultaneous effect of differentiation and commensuration. While this chapter focused on the multiplicity of the subject, the following chapter then looked at practices of assembling through what I described as 'folding'.

In chapter 5:Folding patients into the undiagnosed, I followed these values that are generated in the lab into the surveillance practices that take place at local, regional, national, and international levels. Introducing HIV surveillance as a practice that works through a folding relation of absence-presence, I showed how these practices of disease control come to perform a bifurcated vision of individual and collective subjects. By empirically describing the folding of antibody/antigen results from ELISA tests into incidence estimates, of cd4 counts from flow cytometry into undiagnosed populations, and of genetic sequences into outbreaks of infection, I argued that each of these methods come along with a different visibility as well, a different way of seeing the subject. Here slowing down allowed me to show how, in order to make one subject visible, another subject must be made invisible. The folding of the subject performed in HIV surveillance makes the patient-individual absent in order to present a key-population. While showing how three HIV surveillance practices fold the subject differently, I also argued that some of these surveillance practices come to enact an irrespective vision of the subject, a vision that cannot take into account its own detuned sensitivity.

Finally, in chapter 6:Valuing chronic care \& governing with dependency, I showed how a value called quality of life $(Q o L)$ is becoming known as 'the fourth 90'. I then unpacked this emerging research effort that works at optimising the fast-track strategy by illuminating processes of stigmatisation. However, I also showed that when stigma become staged in opposition to QoL, the need for change becomes deferred to a 'social body' that is set apart from 'Swedish HIV treatment'. Here slowing down became an experimental strate- 
gy of sorting attachments and valuing dependency by holding things together. I thus offered my own case of treating HIV as an example through which the manifold subject comes to be enacted through dependency. This praxiography has thus demonstrated how slowing down can become a way of governing HIV otherwise. The way in which it does so can be summarised as follows.

First, slowing down complicates the aims of governing assemblages by refusing to take for granted what these assemblages are and do. It would certainly be the faster and easier way forward to simply assume that the fast-track is merely a kind of motivational or rhetorical object, a kind of publicity stunt put forward by governing bodies to indicate progress, without assuming it to hold much weight in either a positive or negative light. In the case of the fast-track, slowing down provides me with a strategy for conducting an empirical inquiry of this assemblage and its aim of 'ending HIV and AIDS'. Secondly, slowing down makes visible what is excluded or brushed over by faster governing assemblages. It allows me not only to investigate the practicalities upon which the fast-track depends, but also to explore the unexpected consequences emerging from this governing assemblage. As I have shown in my work, the subject enacted in these practices is more than one, and many of these subjects are often overlooked when speeding by. So finally, slowing down and mapping the materialsemiotic practices that are coupled with the fast-track assemblage provides me with a strategy for taking the fast-track seriously. Slowing down has enabled my work to make space for subjects that might normally get squeezed out of the picture. Slowing down allows me to care for the concerns of the manifold subject. In this way, the manifold subject can also be grasped as a cacophony of voices, each speaking in a different tone with different frequencies and messages. Faster approaches might simply consider many of these voices to be noise; they would filter them out in favour of clearer or less messy signals.

Thus, while slowing down does things differently than does the fast-track, it too is a means of governing HIV, but perhaps one that wishes to be governed not quite so much. Slowing down becomes for me a way of carefully taming Swedish HIV through its very own ethos. Translating my encounters with this 'lentivirus' has enabled me to articulate another way of going on with HIV, one that operates through a different logic than outright war. My efforts to tame Swedish HIV have required me to participate and observe from within the practices that enact this entity. Situating my account in professional and personal practices enables me to cultivate a sensibility toward the varying concerns I have met in the field. Slowing down enables me to attune my account to the wild symphony of the manifold subject that I have situated through my experiences.

\subsection{Governing the manifold subject with sensitivity and specificity}

Through empirical fieldwork with this array of Swedish HIV treatment practices, I have argued that subjects depend on practical activities, and since practice here is manifold, so is the subject that is enacted. With my account of observing and participating in HIV governance, I have thus tried to decenter my personal experiences to capture a sense of what it means to become subject to a manifold of practices that govern Swedish HIV. I have also un- 
dertaken to describe the normativity of these practice while situating my own normativity. In closing this thesis, I want to touch on the normative topic once more through my findings.

While I am grateful to be one of the lucky ones to have become a subject deemed well-treated, this does not mean that I must approve of the means taken in the Swedish case of policing subjects that become treated unwell. I found it important to not only affirm the diagnostic subjects upon which becoming well-treated depends, but to also show how the subject becoming known as 'undetectable' was always more than one to begin with. As I told in my stories, the category of 'undetectable' is increasingly being attributed to antiretroviral adherence through the $\mathrm{U}=\mathrm{U}$ movement, but $\mathrm{I}$ found it salient to also highlight the specificities through which multiple subjects can become known as undetectable, some through testing and treatment and others without. In the case of surveillance, I found it crucial to affirm the value of calculating practices and the ways in which they come to fold patients into populations. However, I also found it pertinent to investigate the way in which diagnostic devices become desensitised to become surveillance devices. This enabled me to better understand the generative capacity of surveillance while taking into account the means through which this value is achieved. Finally, I found a way of working together with these practices by taking into account what is valued in HIV governance. Through an ethics of sensitivity and specificity, I have provided an account of my own experiences undergoing Swedish HIV treatment. In this way, I thus became the experimental subject (Papadopoulos 2018:156), experimenting with chronic care in everyday work-life.

Taking inspiration in my conceptual work from the empirical problems I found in the field, I want to conclude this thesis by emphasising my call for an ethics of sensitivity and specificity in the treatment of Swedish HIV. My descriptions are an effort to cultivate a sensitivity and specificity to the matters at stake in different modes of governing infectious diseases and in the careful taming of wild monsters taking many shapes and forms. In other words, I have tried to cultivate a sensibility in my work to the practical realisation of the manifold subject presently governing Swedish HIV.

But other ways of governing are no doubt going on elsewhere, and these no doubt deserve their own specific form of care. In other words, the interventions I have put forward in my arguments pertain to Swedish HIV treatment in particular, here and now. The relation and relevance of the Swedish case to other cases and in other times and places is something that remains to be explored in more depth.

This ethics of sensitivity and specificity I argue for can also be grasped as a nonhuman disposition. I hold that a disposition is a politics, an ethics, and a style of study; that a disposition is not just personal, but political and collective first and foremost. Casper Bruun Jensen helps me to articulate what a nonhuman disposition might entail for HIV governance:

"Non-humanism then promotes the ethical and the evaluative, it asks which kinds of assemblies of relations between people and things we wish to support, what kinds of lives are worth living (where the category of 'life' is not reserved for humans alone). In this sense non-humanism might also be called 'alternate humanism' insofar as it carries for- 
ward the experiential and emancipatory dynamic of humanism beyond its established confines. Non-humanism is a practical matter." (Jensen 2010)

A nonhuman disposition is not only about identifying which modes of governance are 'really' going on in a given situation or event, but rather about finding ways of experimenting with governance, of combining intense governing with mundane governing, of shifting between different modes of governing as each situation presents the demand for. In the cases I have described, sensitising myself to the specificities of the events that I find myself going on with provides me with a mode of accounting for and becoming accountable to not only Swedish HIV, but also in relation to other situations, machines, and organisms more generally as well. Undertaking this research through a nonhuman disposition has helped me to demonstrate the heterogeneity of actors and agencies involved in HIV governance practice. It has furthermore enabled me to tame the subjects I become in these practices through descriptive intervention together with HIV. Of course, intervention should always be done carefully, but this begs the question of how intervening carefully might best be done.

In the previous chapter, I showed how Jensen found a way to sort and care for his attachment to a medical agenda through what he called "an ethics of specificity" (Jensen 2007:249). By engaging with the particular concerns met in practice rather than importing a normative framework for judging and assessing practices preemptively, Jensen shows how varying attachments_come to affect our research in often unanticipated ways. By reflexively analysing the ways in which specific attachments come to act as research participants, a reflexive account of this sort provides a way of accounting for the subject of attachment. This careful work of sorting attachments requires an insistence on the value of specificity for studying and doing intervention ${ }^{123}$.

Jensen's argument draws on and resonates with the sociology of attachment (Gomart \& Hennion 1999; Hennion 2007), a body of work which prompted me not only to argue for an ethics of specificity, but of sensitivity as well. As I showed in this thesis, not all methods and devices allow for the same degree of sensitivity. Experts of disease-control taught me that the desensitising of a diagnostic device can make it become a valuable surveillance tool. Hennion however, takes as his case the practices of what he calls 'amateurs' to think through the sensitive subject. The amateur is described as a figure who performs an art of "reflexive examination" 124 (Hennion 2007:106). Hennion argues against a tendency in social science to explain or describe the practices of their research subjects in ways or terms that the actors do not recognise themselves in. In the pragmatic approach Hennion argues for, becoming-sensitive requires, "direct contact with things, uncertainty of sensations, methods and techniques used to become sensitive to, and to feel the feeling of, the object being sought" (Hennion 2007:98). What then makes the amateur stand apart from the expert, is the insistence that this figure places on becoming affected by the object in question. While the expert 'knows' very

123 See also Zuiderent-Jerak 2015.

124 See also Woolgar 1988, Ashmore 1989, and Lynch 2000. 
much and very well about the state of things (at least within their domain of expertise), the amateur works with and through uncertainty and indeterminacy (Stengers 2011:59) in order to get a better 'feel' for the matters at hand.

For Stengers, taking the risk of indeterminacy requires trust. While at the start of my treatment, especially upon finding out about my legal status, my trust in Swedish HIV treatment was put to the test. However, I am very happy to affirm that many of my fears have remained just that: fears that can eventually be brushed aside. Through the trust that has now been established by working together with these HIV governance practices, I become able to take the risk of accounting for other problems I experience in the Swedish treatment of HIV, and perhaps this work might even become helpful for others who may come to navigate these governance practices. Rather than observing and performing valuation from the outside-in however, I showed how it is also possible to situate 'valuing' more precariously between the domains of the strange and the familiar simultaneously.

Valuing a sensitivity to the subject of Swedish HIV treatment has enabled me to attune my account to subjects that are also becoming silenced and invisible. Valuing a specificity to the subject of governance has enabled me to describe the particularities of the techniques through which these absences and silences are achieved. In this sense, the ethos of sensitivity and specificity that I am arguing for is already a manifold subject. I argue that manifold couplings, always in some way taking shape in relation to each other, come to enact different subjects. I have described the ways in which they have come to do so in my own case in experimentation with the manifold possibilities afforded by my situation. I have shown how situated practices provide their own accountability and provided not only a demonstration of experimental possibilities for intervening in care practices, but of also of accounting for the possibilities of shifting between modes of care in response to changing conditions.

Embracing both the mediating role of the researcher and the amateur role of the activist, I have argued for the value of becoming-sensitive to differences in governance and in becoming-specific about their practicalities. My work has shown how, "'activities provide their own accountability', their own aptitude to present themselves, they give a grasp on their own reporting." (Hennion 2007:108) In my case, this means that instead of importing a normative or ethical framework with which to judge Swedish HIV governance, I have argued for a remediated ethics of sensitivity and specificity.

This thesis therefore also challenged the dominant view of normalisation, but it aimed do so through a different strategy than the adoption of anti-normativity. Slowing down and describing the manifold subject of Swedish HIV treatment enabled me to demonstrate how different modes of governing nevertheless operate through practical dependency. Looking back at the array of devices, materials, techniques, and tactics involved in my own Swedish HIV treatment, I highlighted the material-semiotic dependencies that make me subject to this governing assemblage in particular ways. This enables me to show how dependencies are organised in manifold ways and how they come to organise a manifold subject. By focusing my analysis on just a few of the subjects I become through my dependency on Swedish HIV 
treatment, I argued that the normativity of the subject comes to shift along with the mode of ordering through which the subject is enacted. In other words, I situated and analysed the normativities at stake in multiple modes of governing the manifold subject. 


\section{Acknowledgements}

My gratitude goes out to all of those humans and nonhumans that helped me in my undertaking of this research. In particular, I want to thank the ValueS collective at the department of Technology and Social Change (TEMAT) for providing me with a space with which to develop my ideas under careful critique and along with supportive suggestions: to Steve Woolgar, Claes-Fredrik Helgesson, Teun Zuiderant-Jerak, Sonja Jerak-Zuiderent, Lisa Lindén, Oscar Javier Maldonado, Ivanche Dimitrievski, Lotta Björklund, Réka Andersson, Nimmo Elmi, Else Vogel, David Moats, Francesco Colona, Fredy Mora, Sara Bea, Emma Dahlin, and Cesar Camilo Castillo Estupiñan - thank you! I also want to thank those who acted as my opponents and readers for my 30\%, 60\%, and 90\% seminar-reviews: Corinna Kruse, Francis Lee, Marsha Rosengarten, Else Vogel, Jenny Gleisner, Ericka Johnson, Mark Elam, Desireé Ljungcrantz - your feedback and suggestions have been critical to the development of my professional work.

This development would not have taken place in the way it has without the contribution of those I met during my exchange with the Amsterdam Institute for Social Science Research (AISSR). My eternal gratitude goes to Annemarie Mol in particular for hosting me during my stay and for introducing me to what I experienced as an inspiring, challenging, and nourishing environment. A special thanks also goes to those I worked together with on what we then called the 'waste water treatment' project - Justine Laurent, Tait Mandler, Carolina Dominguez Guzman, Fenna Smits, and Rebeca Ibanez - learning together with you on this case was truly a pleasure for which I am grateful. I also extend my appreciation to Anja Hiddinga, Mattijs Van de Port, Anita Hardon, Jeannette Pols, Marianne de Laet, Kristine Krause, Ulrike Scholtes, Filippo Bertoni, Letizia Bloom, Shahana Siddiqui, Kevin Singh, Lisette Jong, Sarita Fae, Anastasia Golovneva, Carolina Frossard, Tanja Ahlin, Ildikó Zonga Plájás, Willemijn Krebbekx, Petter Törnberg, Davide Beraldo, Simon Cohn, Annekatrin Skeide, and Annelieke Driessen who engaged with my work through comments, meetings, and through our chats over lunch. I also thank the Writing Care collective for allowing me to participate and contribute to the seminar on more than one occasion.

To the many others I have the pleasure of referring to as colleagues, to the visiting scholars from abroad and to the established locals who exchanged comments, emails, and tips with me - Kristin Zeiler, Kajsa Ellegård, Hannah Grankvist, Alexandra Kapeller, Alma Persson, Kristina Trygg, Anette Wickström, Corinna Kruse, Maria Eidenskog, Linus Ekman Burgman, Fredrik Envall, Wiktoria Glad, Madelene Gramfält, Simon Haikola, Anders Hansson, Dick Magnusson, Amelia Mutter, Johan Niskanen, Darcy Parks, Björn Wallsten, Bistra Vasileva, Harald Rohracher, Jonas Anshelm, Lisa Guntram, Daniel Andersson, Boel Berner, Nancy Brett, Catelijne Coopmans, Jelmer Brüggemann, Yelyzaveta Hrechaniuk, Sarah Mitchell, Daniel Gustafsson, Alex Orrmalm Makii, Emilia Strid, Anna Sparrman, Martin Hultman, Elin Björk, Ekaterina Tarasova, Eva Danielsson, Josefin Frilund, Piotrek Maron, Anne Hagen Berg, Hedvig Gröndal, Marianne Elisabeth Lien, Brian Rappert, Alan Irwin, Mike Lynch, Don Ihde, Thomas Hylland Eriksen, Geoffrey C. Bowker, Lucy Suchman, Amade M'charek, Steven Epstein, Kane Race - thank you for taking the time. To any others whose names may not have made it to this list, I am truly sorry for my horrible memory. My encounter with you has nonetheless written itself into this project in ways I cannot ever hope to put words on. Per Gyberg and Else Vogel, I cannot hope to repay the debt I owe you for the supervision, guidance, support, patience, care, and motivation you gave me. I am forever grateful. Last but not least, Estéfano Romani my love, thanks for putting up with me while I finished this up. 


\section{Bibliography}

Akrich, M. (1992). The description of technical objects. In Shaping technology/building society: Studies in sociotechnical change, edited by WE Bijker and J. Law, 205-224. Cambridge, MA: MIT Press.

Akrich, M., \& Latour, B. (1992). A summary of a convenient vocabulary for the semiotics of human and nonhuman assemblies.

Akrich, M., \& Pasveer, B. (2000). Multiplying obstetrics: techniques of surveillance and forms of coordination. Theoretical medicine and bioethics, 21(1), 63-83.

Albrechtslund, A., \& Lauritsen, P. (2013). Spaces of everyday surveillance: Unfolding an analytical concept of participation. Geoforum, 49, 310-316.

Ashmore, M. (1989). The reflexive thesis: Wrighting sociology of scientific knowledge. University of Chicago Press.

Berner, B. (2011). The making of a risk object: AIDS, gay citizenship and the meaning of blood donation in Sweden in the early 1980s. Sociology of health \& illness, 33(3), 384-398.

Bredström, A. (2008). Safe sex, unsafe identities: Intersections of'race', gender and sexuality in Swedish HIV/AIDS policy (Doctoral dissertation, Linköping University Electronic Press).

Bredström, A. (2009). Sweden: HIV/AIDS policy and the'crisis' of multiculturalism. Race \& ' Class, 50(4), 57-74.

Bruun Jensen, C. (2007). Sorting attachments: Usefulness of STS in healthcare practice and policy. Science as Culture, 16(3), 237-251.

Callon, M. (2007). Some elements of a sociology of translation. The Politics of Interventions, $57-78$.

Cussins, C. (1998). Ontological choreography: Agency for women patients in an infertility clinic. Differences in medicine: Unraveling practices, techniques, and bodies, 166-201.

de La Bellacasa, M. P. (2011). Matters of care in technoscience: Assembling neglected things. Social studies of science, 41(1), 85-106.

De Laet, M., \& Mol, A. (2000). The Zimbabwe bush pump: Mechanics of a fluid technology. Social studies of science, 30(2), 225-263.

Dean, T. (2015). Mediated intimacies: Raw sex, Truvada, and the biopolitics of chemoprophylaxis. Sexualities, 18(1-2), 224-246.

Dean, T. J. (2009). Unlimited intimacy: Reflections on the subculture of barebacking. University of Chicago Press.

Deleuze, G. (1992). Postscript on the Societies of Control. October, 59, 3-7.

Deleuze, G. (2007). Two regimes of madness: Texts and interviews 1975--1995.

Deleuze, G., \& Guattari, F. (1977). Anti-Oedipus: Capitalism and Schizophrenia, translated by Robert Hurley, Mark Seem and Helen R. Lane. New York: Viking.

Deleuze, G., \& Guattari, F. (1987). A Thousand Plateaus: Capitalism and Schizophrenia. 1980. Trans. Brian Massumi. Minneapolis: U of Minnesota P. 
Despret, V. (2013). From secret agents to interagency. History and Theory, 52(4), 29-44.

Dussauge, I., Helgesson, C. F., \& Lee, F. (Eds.). (2015). Value practices in the life sciences and medicine. Oxford University Press, USA.

Epstein, S. (1996). Impure science: AIDS, activism, and the politics of knowledge (Vol. 7). Univ of California Press.

Epstein, S. (1998). Gay politics, ethnic identity: The limits of social constructionism. Social perspectives in lesbian and gay studies: A reader, 134-159.

Foucault, M. (1973). The birth of the clinic. London: Tavistock.

Foucault, M. (1977). Discipline and punish: The birth of the prison, trans. Alan Sheridan.

Foucault, M. (1982). The subject and power. Critical inquiry, 8(4), 777-795.

Foucault, M. (1985). The use of pleasure: The history of sexuality, Vol. 2. New York: Vintage.

Foucault, M. (1986). The care of the self: The history of sexuality, Vol. 3. New York: Pantheon.

Foucault, M. (1998). The will to knowledge: The history of sexuality vol. I.

Foucault, M. (2005). The order of things. Routledge.

Foucault, M. (2012). The birth of the clinic. Routledge.

Foucault, M., Davidson, A. I., \& Burchell, G. (2008). The birth of biopolitics: lectures at the Collège de France, 1978-1979. Springer.

Gad, C., \& Bruun Jensen, C. (2010). On the consequences of post-ANT. Science, Technology, \& Human Values, 35(1), 55-80.

Gad, C., \& Bruun Jensen, C. (2010). On the consequences of post-ANT. Science, Technology, \& Human Values, 35(1), 55-80.

Gad, C., \& Lauritsen, P. (2009). Situated Surveillance: an ethnographic study of fisheries inspection in Denmark. Surveillance \& Society, 7(1), 49-57.

Galis, V., \& Lee, F. (2014). A sociology of treason: The construction of weakness. Science, Technology, \& Human Values, 39(1), 154-179.

Gerlitz, C., \& Lury, C. (2014). Social media and self-evaluating assemblages: On numbers, orderings and values. Distinktion: Scandinavian Journal of Social Theory, 15(2), 174-188.

Goffman, E. (2009). Stigma: Notes on the management of spoiled identity. Simon and Schuster.

Gomart, E., \& Hennion, A. (1999). A sociology of attachment: music amateurs, drug users. The Sociological Review, 47(1_suppl), 220-247.

Haggerty, K. D., \& Ericson, R. V. (2000). The surveillant assemblage. The British journal of sociology, 51(4), 605-622.

Haraway, D. (1988). Situated knowledges: The science question in feminism and the privilege of partial perspective. Feminist studies, 14(3), 575-599.

Haraway, D. (1991). Cyborgs, simians, and women: The reinvention of nature.

Haraway, D. J. (2016). Staying with the trouble: Making kin in the Chthulucene. Duke University Press.

Helgesson, C. F., \& Muniesa, F. (2013). For what it's worth: An introduction to valuation 
studies. Valuation Studies, 1(1), 1-10.

Hennion, A. (2007). Those things that hold us together: Taste and sociology. Cultural sociology, 1(1), 97-114.

Johnson, E., Sjögren, E., \& Åsberg, C. (2016). Glocal Pharma (Open Access): International Brands and the Imagination of Local Masculinity. Routledge.

Kroener, I., \& Neyland, D. (2012). New technologies, security and surveillance. Routledge handbook of surveillance studies, 141.

Latour, B. (1984). The powers of association. The Sociological Review, 32(1_suppl), 264-280.

Latour, B. (1986). Visualization and cognition. Knowledge and society, 6(6), 1-40.

Latour, B. (1987). Science in action: How to follow scientists and engineers through society. Harvard university press.

Latour, B. (1993). The pasteurization of France. Harvard University Press.

Latour, B. (1994). On technical mediation.

Latour, B. (1996). Trains of thought the fifth dimension of time and its fabrication. Swiss Monographs in Psychology, 4, 173.

Latour, B. (2000). Opening Pandoras Black Box. Technology, Organizations and Innovation: Theories, concepts and paradigms, 2, 679 .

Latour, B. (2004). Why has critique run out of steam? From matters of fact to matters of concern. Critical inquiry, 30(2), 225-248.

Latour, B. (2005). Reassembling the social. Política y Sociedad, 43(3), 127-130.

Latour, B. (2012). We have never been modern. Harvard university press.

Latour, B., \& Woolgar, S. (2013). Laboratory life: The construction of scientific facts. Princeton University Press.

Law, J. (1992). Notes on the theory of the actor-network: Ordering, strategy, and heterogeneity. Systems practice, 5(4), 379-393.

Law, J. (1994). Organizing modernity (pp. 100-104). Oxford: Blackwell.

Law, J. (1999). After ANT: complexity, naming and topology. The Sociological Review, 47(S1), 1-14.

Law, J. (2000). On the subject of the object: Narrative, technology, and interpellation. Configurations, 8(1), 1-29.

Law, J. (2004). After method: Mess in social science research. Routledge.

Law, J. (2016). 1 STS as Method. The handbook of science and technology studies, 31.

Law, J., \& Mol, A. (1995). Notes on materiality and sociality. The sociological review, 43(2), 274-294.

Law, J., \& Mol, A. (2001). Situating technoscience: an inquiry into spatialities. Environment and planning D: society and space, 19(5), 609-621.

Law, J., \& Moser, I. (1999). Managing, subjectivities and desires. Concepts and Transformation, 4(3), 249-279.

Law, J., \& Singleton, V. (2005). Object lessons. Organization, 12(3), 331-355.

Lee, F., Bier, J., Christensen, J., Engelmann, L., Helgesson, C. F., \& Williams, R. (2019). Algorithms as folding: Reframing the analytical focus. Big Data \& Society, 6(2), 


\section{9.}

Lindén, L. (2016). Communicating care: The contradictions of HPV vaccination campaigns (Doctoral dissertation, Arkiv förlag \& tidskrift).

Ljungcrantz, D. (2017). Skrubbsår: Berättelser om ur hiv föreställs och erfars i samtida Sverige (Doctoral dissertation, Makadam förlag).

Lynch, M. (1985). Discipline and the material form of images: An analysis of scientific visibility. Social studies of science, 15(1), 37-66.

Lynch, M. (2000). Against reflexivity as an academic virtue and source of privileged knowledge. Theory, Culture \& Society, 17(3), 26-54.

Lyon, D. (2002). Surveillance Studies: Understanding visibility, mobility and the phenetic fix. Surveillance \& Society, 1(1), 1-7.

Lyon, D. (2007). Surveillance studies: An overview. Polity.

Lyon, D., Haggerty, K. D., \& Ball, K. (2012). Introducing surveillance studies. In Routledge handbook of surveillance studies (pp. 33-44). Routledge.

M'charek, A. (2014). Race, time and folded objects: the HeLa error. Theory, Culture \& Society, 31(6), 29-56.

Martin, B. (2003). Investigating the origin of AIDS: some ethical dimensions. Journal of medical ethics, 29(4), 253-256.

Martin, E. (1990). Toward an anthropology of immunology: The body as nation state. Medical Anthropology Quarterly, 4(4), 410-426.

Martin, E. (1992). The end of the body?. American ethnologist, 19(1), 121-140.

Martin, E. (1994). Flexible bodies: Tracking immunity in American culture from the days of polio to the age of AIDS. Beacon Press.

Marx, K. (1844). Estranged labour.

Mol, A. (1999). Ontological politics. A word and some questions. The sociological review, 47(1_suppl), 74-89.

Mol, A. (2002). The body multiple: Ontology in medical practice. Duke University Press.

Mol, A. (2008). The logic of care: Health and the problem of patient choice. Routledge.

Mol, A., \& Law, J. (1994). Regions, networks and fluids: anaemia and social topology. Social studies of science, 24(4), 641-671.

Mol, A., \& Law, J. (2004). Embodied action, enacted bodies: The example of hypoglycaemia. Body \& society, 10(2-3), 43-62.

Moser, I. (2000). Against normalisation: subverting norms of ability and disability. Science as culture, 9(2), 201-240.

Moyer, E., \& Hardon, A. (2014). A disease unlike any other? Why HIV remains exceptional in the age of treatment. Medical Anthropology, 33(4), 263-269.

Moyer, E., \& Hardon, A. (2014). A disease unlike any other? Why HIV remains exceptional in the age of treatment. Medical Anthropology, 33(4), 263-269.

Mykhalovskiy, E. (1996). Reconsidering table talk: Critical thoughts on the relationship between sociology, autobiography and self-indulgence. Qualitative sociology, 19(1), 131-151.

Mykhalovskiy, E., \& Namaste, V. (Eds.). (2019). Thinking Differently about HIV/AIDS: 
Contributions from Critical Social Science. UBC Press.

Papadopoulos, D. (2018). Experimental practice: Technoscience, alterontologies, and more-

than-social movements. Duke University Press.

Paparini, S., \& Rhodes, T. (2016). The biopolitics of engagement and the HIV cascade of care: a synthesis of the literature on patient citizenship and antiretroviral therapy. Critical public health, 26(5), 501-517.

Pickering, A. (2012). The robustness of science and the dance of agency. In Characterizing the Robustness of Science (pp. 317-327). Springer, Dordrecht.

Pols, J. (2005). Enacting appreciations: Beyond the patient perspective. Health Care Analysis, 13(3), 203-221.

Preciado, P. B. (2013). Testo junkie: Sex, drugs, and biopolitics in the pharmacopornographic era. The Feminist Press at CUNY.

Pryke, M., Rose, G., \& Whatmore, S. (Eds.). (2003). Using social theory: thinking through research. Sage.

Race, K. (2009). Pleasure consuming medicine: The queer politics of drugs. Duke University Press.

Race, K. (2017). The gay science: Intimate experiments with the problem of HIV. Routledge.

Rhodes, S. D., Tanner, A. E., Mann-Jackson, L., Alonzo, J., Horridge, D. N., Van Dam, C. N., ... \& Nall, J. (2018). Community-engaged research as an approach to expedite advances in HIV prevention, care, and treatment: A call to action. AIDS Education and Prevention, 30(3), 243-253.

Sampson, T. D. (2012). Virality: Contagion theory in the age of networks. U of Minnesota Press.

Schubert, K. (2019). The Democratic Biopolitics of PrEP. In Biopolitiken-Regierungen des Lebens heute (pp. 121-153). Springer VS, Wiesbaden.

Serres, M. (2013). The parasite (Vol. 1). U of Minnesota Press.

Singleton, V. (2005). The promise of public health: Vulnerable policy and lazy citizens.

Environment and planning D: Society and Space, 23(5), 771-786.

Singleton, V. (2012). When contexts meet: Feminism and accountability in UK cattle farming. Science, technology, \& human values, 37(4), 404-433.

Sontag, S. (2001). Illness as metaphor and AIDS and its metaphors. Macmillan.

Stengers, I. (2005). The cosmopolitical proposal. Making things public: Atmospheres of democracy, 994, 994.

Stengers, I. (2011). Thinking with Whitehead: A free and wild creation of concepts.

Stengers, I. (2018). Another science is possible: A manifesto for slow science. John Wiley \& Sons.

Svanström, Y. (2000). Policing public women: The regulation of prostitution in Stockholm 1812-1880 (Doctoral dissertation, Atlas).

Thompson, C. (2002). When elephants stand for competing philosophies of nature: Amboseli National Parc, Kenya. J. Law et A. Mol (Eds.), Complexities, 166-190. 
Thorsén, D. (2013). Den svenska aidsepidemin: ankomst, bemötande, innebörd (Doctoral dissertation, Acta Universitatis Upsaliensis).

Treichler, P. A. (1987). AIDS, gender, and biomedical discourse: current contests for meaning.

Tzu, S. (2008). The art of war. In Strategic Studies (pp. 63-91). Routledge.

van Loon, E., Zuiderent-Jerak, T., \& Bal, R. (2014). Diagnostic work through evidence-based guidelines: avoiding gaps between development and implementation of a guideline for problem behaviour in elderly care. Science as Culture, 23(2), 153-176.

Verran, H. (2001). Science and an African logic. University of Chicago Press.

Vogel, E. (2016). Subjects of care: Living with overweight in the Netherlands. Universiteit van Amsterdam.

Vogel, E. (2017). Hungers that need feeding: On the normativity of mindful nourishment. Anthropology \& medicine, 24(2), 159-173.

Woolgar, S. (1986). On the alleged distinction between discourse and praxis. Social Studies of Science, 16(2), 309-317.

Woolgar, S. E. (1988). Knowledge and reflexivity: New frontiers in the sociology of knowledge. In With one exception, the chapters in this volume originated as papers presented at a series of meetings known as' Discourse Analysis' workshops. The meetings were held at various institutions: University of York (15-16 Apr 1983 and 78 Apr 1986); Oxford Polytechnic (7-8 Sep 1983); Brunel University (31 Mar-1 Apr 1984); University of Surrey (13-14 Sep 1984); University of St. Andrews (20-22 Sep 1985); and University of Bradford (22-3 Apr 1987).. Sage Publications, Inc.

Woolgar, S., \& Neyland, D. (2013). Mundane governance: Ontology and accountability. OUP Oxford.

Zuiderent-Jerak, T. (2015). Situated intervention: Sociological experiments in health care. MIT Press. 


\section{Appendix}

00

01 Patient information, rights and rules of conduct. County Medical

02

03

\section{HIV}

officers' infection prevention sheet.

\section{Why have you been given this information?}

You have been, or are suspected of having been, infected with HIV. This sheet provides information about HIV, how it can be treated and what you need to do.

\section{What is HIV?}

HIV is a virus that affects your immune system. There is now medication that, if taken correctly, reduces the amount of the virus present in the body and potentially enables a person with HIV to live a long and healthy life. If the medication is taken correctly, the risk of infecting someone else with HIV is very low. There is no cure for the HIV infection; even with stable treatment, the virus is still present in the body. If an infected person does not receive treatment, their body's immune defence is weakened after a while and uncommon infections or cancer can develop. This latter stage is called AIDS. Most people with HIV today will never develop AIDS.

\section{How is HIV spread?}

Most people with HIV have acquired it as a result of unprotected sex, either vaginal sex or anal sex, and sometimes oral sex. Blood containing HIV is very infectious, and HIV can be transmitted from one person to another during a blood transfusion or a needle stick or if they use the same syringes or other injecting equipment. There is also a risk of infection if blood containing HIV comes into contact with mucous membranes in the eyes, nose or mouth or with a wound. Effective HIV treatment drastically reduces the risk of contagion, but does not completely eliminate the risk of infection. HIV can be transmitted from mother to child during pregnancy, birth and breastfeeding. If a mother is known to have HIV, it is possible almost completely to eliminate the risk to the child through medication and by not breastfeeding.

\section{When is HIV not transmitted?}


HIV is not passed on by hugging, kissing or cuddling. Tears, urine, faeces, vomit and catarrh containing no blood are not infectious either. Blood coming into contact with undamaged skin does not present a risk of infection.

\section{Rights}

According to the Swedish Communicable Diseases Act(Smittskyddslagen), testing for, clinic visits for and treatment of HIV are free. You are also entitled to the psychosocial support you may need in order to deal with the disease. Your doctor should advise you on how to avoid putting others at risk of infection. You should not be treated less favourably because you are living with HIV. HIV is covered by the Swedish Discrimination Act (Diskrimineringslagen) under the issue of discrimination on the grounds of disability.

\section{Professional activities}

HIV infection will not normally result in restrictions to your studies or professional activities.

\section{Pregnancy and breastfeeding}

You can get help to enable you/your partner to conceive with a minimal risk of infection to your partner or your child. Women with HIV must not breastfeed.

\section{Children with HIV}

The parent/carer and child will receive information on protecting against infection via the doctor providing treatment, and this information will gradually be adapted as the child gets older. Children living with HIV have the same entitlement to childcare and schooling as other children, but may have special needs which have to be taken into account. The doctor providing the treatment or the County Medical Officer can provide the preschool with information if parents/carers grant consent to this. When the child starts school, the school healthcare service will be informed.

\section{Condoms for vaginal sex, anal sex and oral sex}

Condoms provide good protection against HIV and other sexually transmitted diseases and must always be worn throughout the entire sex session. It is probable that female condoms also work, but this method has not been evaluated scientifically. In the case of stable 
treatment, condoms must still be worn during anal and/or vaginal sex so as to reduce the risk of passing on HIV as much as possible.

\section{Preventive drug therapy}

If there is a chance that you have infected someone through sexual contact as a result of a condom not providing protection, through contact with your blood or in some other manner, it is possible to give preventative drug therapy, known as post-exposure prophylaxis $(\mathrm{PEP})$. This must begin as quickly as possible. Contact the doctor providing treatment or an infection clinic/24-hour service as soon as possible.

\section{Contact tracing}

It is very important to identify people with HIV so that they can get treatment and prevent the infection being passed on to others. If you have HIV, you must, therefore, name the person or people who may have infected you or whom you may have infected. These may be people with whom you have had sex or other sexual contact, people with whom you have shared syringes, and in some cases family members. Contact tracing is performed by the doctor providing treatment, a counsellor or a nurse at the clinic. Anything you tell the contact tracing officer is confidential. The people you name will not be told who you are. They will only be told that they must get tested.

\section{Blood must always be handled as infectious}

Anyone who may come into contact with your blood while changing would dressings or the like must wear gloves

Bloody material must be well wrapped before being discarded. Clothes can be machine-washed.

If anyone gets your blood in their eyes, nose or mouth, flush immediately with water. You must inform the person that your blood is infected with HIV and that they must get in touch with your doctor or with an infection clinic/24-hour service as soon as possible.

\section{Rules of conduct which you should follow so as not to infect anyone else}

HIV is a public health hazard according to the Swedish Communicable Diseases Act. You are, therefore, obliged to protect other people from the risk of infection. If a risk of infection arises, you must disclose your illness to the other person. Below is a list of the 
rules of conduct for preventing infection based on the areas covered

118 by the law. Most of these rules apply to anyone with HIV, while

119 others are specific to your situation and may also change over time.

120 It is the doctor treating you who decides which of the following

121 rules of conduct should apply in your particular case.

123 Restrictions may apply in respect of your work or participation in

124 other activities where there is a risk of infection.

125 You must not donate blood, organs or tissue for transplantation.

126 If you use syringes/needles/other injecting equipment for medical

127 purposes, you must not let other people use them.

128 If you use syringes/needles to inject drugs or the like, you must not

129 let other people use them. You must not share mixing cups either. All

130 injecting equipment must be stored and discarded so that it does not

131 place others at risk of infection.

132 You must disclose that your blood is infectious when you seek dental

133 or medical care where personnel may come into contact with your

134 blood, for example while taking samples or performing surgery/

135 procedures.

136 If you want a tattoo, to have your ears pierced or have any other

137 treatment involving the use of sharp tools and where bleeding may

138 occur, e.g. Body piercing, you must disclose that your blood is

139 infectious before the procedure is carried out.

140 You must inform your sexual partner that you are infected with HIV

141 before sexual contact which presents a risk of transmission of HIV.

142 There is a risk of such infection during all types of oral, vaginal

143 and anal sex. As condoms can break, you must disclose your HIV status

144 even if you are planning to use condoms. You must use condoms during

145 sex where the penis is inserted in the vagina, the rectum or the

146 mouth. During other sexual contact, a female condom must be used. If

147 you are on stable treatment, condoms must still be used during

148 vaginal and/or anal sex.

149 You must not share personal care items such as razors or toothbrushes

150 with other people.

151 You must attend the repeat visits which your doctor considers

152 necessary.

153

154 If you have been given a rule of conduct which you think is wrong, 155 you can contact the County Medical officer in your county. 


\section{FACULTY OF ARTS AND SCIENCES}

Linköping studies in arts and sciences,

No. 788

ISSN 0282-9800

Linköping University

SE-581 83 Linköping, Sweden

www.liu.se 